\title{
III.2 Anlauf zur europäischen Integration 1950-1954
}

\section{III.2.1 Mübsamer Start: Der Schuman-Plan 1950/51}

Mißlungener Auftakt: Der Streit über den westdeutschen Beitritt zum Europarat $1949 / 50$

Waren die ohnehin kaum übermäßig forcierten Anstrengungen der Bonner und der Pariser Regierung um eine Aufhebung der Teilung Deutschlands aufgrund unüberbrückbarer Differenzen zwischen Ost und West über den einzuschlagenden Weg und das konkrete Ziel zu Beginn der fünfziger Jahre zum Scheitern verurteilt, so gestalteten sich ihre Bemühungen um die europäische Integration zumindest partiell erfolgreich. Mit der "Wende"1 der Jahre 1947/48 im Verhältnis zum östlichen Nachbarn hatte der Faktor Europa für Frankreichs Deutschlandpolitik besondere Bedeutung gewonnen. Kontrolle durch Integration lautete die Zauberformel, die das Sicherheitsproblem lösen sollte. Eine Einigung der europäischen Demokratien schien freilich auch aufgrund des wachsenden Einflusses der USA auf dem Kontinent und der zunehmenden Spannungen mit der Sowjetunion im Zeichen des Kalten Krieges dringend geboten. Da sich der Wunschpartner Großbritannien einem engen Zusammenschluß mit den kontinentalen Demokratien verweigerte ${ }^{2}$, war die Beteiligung der soeben aus der Taufe gehobenen Bonner Republik unumgänglich, denn der europäische Chor benötigte die deutsche Stimme, um sich Gehör zu verschaffen.

Als förderlich für die Durchsetzung dieses Gedankens wirkte gewiß die Tatsache, daß Bundeskanzler Adenauer mit dem Petersberger Abkommen im November 1949 einen ersten außenpolitischen Erfolg erzielen und damit seinen Anspruch auf Souveränität und Gleichberechtigung unterstreichen konnte. Anstatt sich der anglo-amerikanischen Deutschlandpolitik weiter in den Weg zu stellen, glaubte die französische Regierung nun, Deutschland durch den freiwilligen Verzicht auf einen gewissen Teil ihrer eigenen Souveränität und durch die Assoziierung der beiderseitigen Interessen binden zu können. An eine wirklich gleichberechtigte Partnerschaft war dabei allenfalls im Rahmen der europäischen Institutionen gedacht. Außerhalb dieses Terrains pochte Frankreich auf seine Vorrangstellung als Besatzungsmacht mit weltweiten politischen Ambitionen.

Wie Schuman am 18.12. 1949 auf einer öffentlichen Versammlung in Brüssel unterstrich, ging es ihm vor allem darum, die Fehler der Vergangenheit nicht zu wiederholen. Sicherheit, so lautete seine Devise, könne Frankreich gegenüber dem Nachbarn vor allem durch dessen Beteiligung am europäischen Friedenswerk erzielen. „Europa ist auf dem Weg zum Zusammenschluß. Wenn Europa nicht von uns mit Einschluß Deutschlands geschaffen wird, dann wird ein neues Europa gegen uns geschaffen, und in diesem Falle wird Deutschland nicht auf der Seite derjenigen stehen, die in Ohnmacht versinken." 3

1 Auerbach, Wende.

2 Vgl. Kap. II.

3 Ansprache Schumans, 18.12. 1949, in: AdG 1948/49, S. 2171G; s.a. Poidevin, Robert Schuman, S. $214 \mathrm{f}$. 
Wie schwer Paris die Umsetzung der als notwendig und richtig erkannten deutschlandpolitischen Kursänderung fiel, verdeutlichen die Hürden, die es dem Beitritt der Bundesrepublik zum Europarat in den Weg stellte ${ }^{4}$. Diese älteste und zugleich größte europäische Institution war als "Sprachrohr des demokratischen Europa"5 am 5. 5. mit der Verabschiedung einer Satzung von zehn Staaten in London aus der Taufe gehoben worden ${ }^{6}$. Schon einige Tage zuvor hatten die Westmächte entschieden, Westdeutschland nach der Bildung einer Regierung in die europäischen Institutionen aufzunehmen. Was den Europarat betraf, konnte die im September auf die internationale Bühne tretende junge Republik gemäß seinen Statuten nur in der Beratenden Versammlung, nicht aber im Ministerrat vertreten sein7. Da die Mitgliedschaft von Frankreich wärmstens befürwortet wurde, schien ihr nichts im Wege zu stehen.

Tatsächlich aber liefen die Beitrittsverhandlungen alles andere als reibungslos. Denn sie gerieten schon bald in den Sog eines der schwierigsten deutsch-französischen Streitobjekte - der Saarfrage. Schon im März hatte sich der Quai d'Orsay dazu entschlossen, für eine Saarvertretung im Europarat zu plädieren, wie sie der Hohe Kommissar in Saarbrücken Gilbert Grandval seit August 1948 forderte, um eine völkerrechtliche Anerkennung des Saarlandes als selbständigen Staat zu erreichen'. Eine entsprechende Démarche im Straßburger Ministerausschuß vom Juni 1949 blieb jedoch ohne Antwort ${ }^{10}$. Schuman erneuerte daher einen Monat später in einer Note an die Gründerstaaten des Europarates das Gesuch und verlangte, der Beitritt müsse vor der Aufnahme der Bundesrepublik erfolgen, weil das Saarland verfassungsmäßig dem erst im Entstehen begriffenen westdeutschen Staat voraus sei. Die erhofften positiven Stellungnahmen der Westmächte und der Mitglieder des Europarates blieben abermals aus ${ }^{11}$. Da man mit seinen Vorstellungen nicht durchdrang, versteifte sich Paris in der Folgezeit darauf, daß die Zulassungen Saarbrückens und Bonns wenn schon nicht zeitlich abgestuft so doch zumindest gleichzeitig zu erfolgen hätten ${ }^{12}$. Würden nur Bonn die Tore geöffnet, meinte Schuman Ende August in einer Pressekonferenz, bliebe die Saar als einziges Land Westeuropas ausgeschlossen ${ }^{13}$. Kurz darauf erklärte er sich mit einem gleichzeitigen Beitritt beider Kandidaten einverstanden und einigte sich mit Acheson und Bevin darauf, das Thema vorerst ruhen zu lassen ${ }^{14}$. Dementsprechend faßte die

4 Zum folgenden vor allem: Enders, Konflikt; Guldin, Bundesrepublik Deutschland, S. 150-164.

5 Lappenküper, Sprachrohr.

6 S. Satzung des Europarates, 5. 5. 1949, in: BGBl 1950, S. 263-273; zur Gründung vgl. Loth, Weg, S. 69-76.

7 Zum Geflecht der Organe des Europarates vgl. Lappenküper, Rolle.

${ }^{8}$ S. Schuman an François-Poncet, Nr. 1, August 1949, Entwurf (nicht abgesandt), in: BDFD I, S. 57.

9 Vgl. Poidevin, Robert Schuman, S. 225 f.; ders., Faktor Europa, S. 415.

10 Vgl. ebd., S. 417 f.; ders., Robert Schuman, S. $226 f$.

"I Vl. Enders, Konflikt, S. 25-27; Kerkhoff, Großbritannien, S. 88 f.

$12 \mathrm{Zu}$ dem von der französischen Regierung aufgestellten Junktim zwischen dem Beitritt der Saar und der Bundesrepublik zum Europarat vgl. Bruce an Acheson, Tel. 3212, 3. 8. 1949, Secret, in: FRUS 1949, Bd. 3, S. 480-482; ders. an dens., Tel. 4505, 29.10. 1949, Secret, Priority, in: ebd., S. $491 \mathrm{f}$.

13 Vgl. Enders, Konflikt, S. 27 f.

14 S. Unterredung zwischen Acheson, Bevin und Schuman vom 15. 9. 1949, Top secret, im Auszug in: DzD, 2. Reihe, Bd. 2, S. 461 f.; AMAE, Europe 1944-1960, Généralités, Bd. 132, Bl. 1-5, Bonnet an MAE, Tel. 3432/42, 20.9. 1949, Réservé; Guldin, Bundesrepublik Deutschland, S. 150 f. 
Beratende Versammlung während ihrer konstituierenden Sitzungsperiode in diesen Wochen keinen förmlichen Beschluß, obwohl das Problem in den Debatten immer wieder eine Rolle spielte ${ }^{15}$. Ende Oktober setzte sich in Washington die Auffassung durch, man könne das Thema nur vertagen oder auf die Pariser Vorstellungen eingehen ${ }^{16}$. Wenig später stimmte London einer gleichzeitigen Aufnahme zu, sofern der Einladung an die Saar eine Klausel beigegeben würde, derzufolge der Beitritt keine Anerkennung seiner Unabhängigkeit impliziere17.

In der Bundesrepublik stießen die Forderungen Frankreichs auf entschiedene Kritik und belasteten den innenpolitischen Konsens über die Frage der Westbindung schwer. Die Koalition betrachtete die Teilnahme an der europäischen Integration als zentralen Bestandteil ihrer Außenpolitik, bot die Mitwirkung doch die Chance, Anerkennung und Gleichberechtigung zu erhalten und zugleich den eigenen außenpolitischen Handlungsspielraum zu erweitern. Die Opposition stimmte in der Frage der Westorientierung und der Bereitschaft zu einer vertraglichen Bindung an überstaatliche europäische Institutionen im Prinzip mit ihr überein, setzte aber hinsichtlich der Prioritäten und der Instrumentalisierung der Westbindung für die Durchsetzung nationaler Ziele deutlich andere Schwerpunkte ${ }^{18}$. In diesem Sinne verknüpfte Schumacher sein „generelle[s] Ja“ zur Aufnahme in den Europarat mit zwei „konkreten Vorbehalte[n]“. Zum einen forderte er die volle Gleichberechtigung für Deutschland, und zum anderen lehnte er dezidiert die Mitgliedschaft der Saar ab ${ }^{19}$. Schon im Juli hatte er auf einer Wahlveranstaltung in Hannover klargestellt, daß die Saar „Bestandteil Deutschlands“ sei und die Zulassung eines „selbständigen Saarland $[s]$ “ in den Europarat den Verzicht der Westdeutschen nach sich ziehen müsse20.

Seine Auffassung über die staatsrechtliche Position der Saar entsprach zwar der überwiegenden Meinung in den übrigen Parteien, seine Argumentation zum Europaratbeitritt wurde aber sogar von innerparteilichen Kritikern wie Wilhelm Kaisen gerügt ${ }^{21}$, von den innenpolitischen Gegnern gar als "Generalabsage an Europa" gebrandmarkt ${ }^{22}$. Für Adenauer stand die Aufnahme der Bundesrepublik außer Frage, obwohl ihm die Organisation an der Ill „von Anfang an fehlerhaft konstruiert" anmutete ${ }^{23}$. Der Zutritt zu diesem Forum des demokratischen Europa bot die Möglichkeit, Vertrauen und Prestige zu gewinnen. Diesem potentiell zu ziehenden Nutzen ordnete der Kanzler die Kosten, den Beitritt der Saar, eindeutig unter. Um seinen Handlungsspielraum nicht einzuengen, hielt er sich mit öffentlichen Erklärungen auffallend zurück. Der Wahlkampf zum ersten Bundes-

$15 \mathrm{Vgl}$. EA 1949, S. 2571 f.; Enders, Konflikt, S. 22-24.

16 S. McCloy an Acheson, Tel. 3448, 26. 10. 1949, Secret, in: FRUS 1949, Bd. 3, S. 488 f.; Acheson an McCloy, Tel. 2373, 28. 10. 1949, Secret, Priority, in: ebd., S. 489 f.; Bruce an Acheson, Tel. 4505, 29. 10. 1949, Secret, Priority, in: ebd., S. 491 f.; Kerkhoff, Großbritannien, S. 93.

$17 \mathrm{Vgl}$. Acheson an Douglas, Tel. 3917, 31. 10. 1949, Top secret, US urgent, in: FRUS 1949, Bd.3, S. 492-494; Kerkhoff, Großbritannien, S. $91 \mathrm{f}$.

$18 \mathrm{Vgl}$. Hrbek, SPD, S. 86-101; Paterson, SPD, S. 33-48.

19 Hrbek, SPD, S. 86 u. 87.

20 Erklärung Schumachers in Hannover, 15. 7. 1949, zitiert nach: Enders, Konflikt, S. 28; s.a. Erklärung des Außenpolitischen Ausschusses der SPD, 5. 9. 1949, in: Paterson, SPD, S. 35.

$21 \mathrm{Vgl}$. Merseburger, Kurt Schumacher, S. 469.

22 Ebd., S. 465.

23 Aufzeichnung Adenauers, o.D., in: AAPD 1949/50, S. 105. 
tag und die Jungfernsitzung des Parlaments hatten ihm vor Augen geführt, wie schwer das von Paris aufgestellte Junktim in Bonn durchzusetzen sein würde. Außerdem konnte nicht mit Bestimmtheit davon ausgegangen werden, ob Ministerrat und Beratende Versammlung einer Einladung an die Bundesrepublik mit Mehrheit zustimmten. Eine Ablehnung konnte sich der Kanzler aber kaum lei$\operatorname{sten}^{24}$.

Bei dieser Konstellation kam der Frage der Aufnahmeprozedur eine eminente politische Bedeutung zu. Nach Artikel 4 der Satzung des Europarats hatte der Ministerrat eine Einladung auszusprechen, wobei von diesem Verfahren mitunter abgewichen und ein Antrag des Beitrittswilligen akzeptiert worden war ${ }^{25}$. Vom Vizepräsidenten der Beratenden Versammlung, Lord Layton, erfuhr der Kanzler im September, die Bundesrepublik könne zunächst nur als Assoziiertes Mitglied aufgenommen werden, d.h. keinen Vertreter in den Ministerausschuß entsenden ${ }^{26}$. Adenauer war gewillt, den Beitritt 2. Klasse ebenso zu akzeptieren wie die von Frankreich forcierte Aufnahme der Saar. Der Öffentlichkeit gegenüber verkaufte er seine Position mit dem Argument, es komme vor allem darauf an, gleichberechtigt in der Beratenden Versammlung tätig sein zu können, läge in ihr doch das „Schwergewicht eines echten europäischen Föderalismus“ ${ }^{27}$. Am 20. 10. erkundigte er sich bei Layton und beim Präsidenten der belgischen Abgeordnetenkammer, van Cauwelaert, wie sicher die Annahme eines Antrags sei ${ }^{28}$. Layton antwortete ihm darauf, daß die Behandlung des Gesuchs von der Haltung Frankreichs abhänge. Falle sie positiv aus, sei eine besondere Bereitschaftserklärung von deutscher Seite vor der für Anfang November vorgesehenen Sitzung des Ministerrates nicht erforderlich. Erst wenn die Minister dem Kanzler grünes Licht für die Billigung signalisierten, sei der Antrag umgehend zu stellen ${ }^{29}$. Nachdem er über den amtierenden Vorsitzenden des Ministerrates, den belgischen Ministerpräsidenten van Zeeland, die Haltung des Ministerrates und Frankreichs hatte sondieren lassen, befürwortete Adenauer mit der positiven Antwort im Rücken ${ }^{30}$ am 28. 10. im Kabinett den Beitritt und führte einen Beschluß herbei, der eine „abwartende Haltung "festlegte ${ }^{31}$. Diese Position war aber kaum noch aufrechtzuerhalten, als die saarländische Regierung kurz darauf offiziell um Eintritt in den Europarat bat ${ }^{32}$. In seinem berühmten Interview mit der „Zeit“ erklärte Adenauer am 3. 11. das Junktim Schumans für wenig weise. Ebenso unklug erschien ihm aber die Position Schumachers, und er gab unumwunden zu, daß ein Sitz im Palais de

${ }_{24}$ S. Regierungserklärung Adenauers, 20.9. 1949, u. Bundestagsdebatte, 21. 9. 1949, in: BT, Sten. Ber., Bd. 1, S. 29 f. u. 40-42; Enders, Konflikt, S. $28 \mathrm{f}$.

25 Vgl. ebd., S. 30.

26 S. PA, Abt. 2, Bd. 581, Bl. 16, Layton an Adenauer, 21. 10. 1949.

27 Interview Adenauers mit "Die Zeit“, 3.11. 1949, in: BDFD I, S. 58-63, hier S. 62.

28 S. ders. an van Cauwelaert, Tel. , enthalten in: PA, Abt. 2, Bd. 581, Bl. 64 f., Vermerk G 22/50 (Diktat Adenauers), 18. 3. 1950; Enders, Konflikt, S. 30.

29 S. Layton an Adenauer, Tel. , enthalten in: PA, Abt. 2, Bd. 581, Bl. 64 f., Vermerk G 22/50 (Diktat Adenauers), 18. 3. 1950; Adenauer an Lina Morino, 2.11. 1949, in: Adenauer, Briefe 1949-1951, S. 134.

30 S. PA, Abt. 2, Bd. 581, Bl. 1f., van Cauwelaert an Adenauer, 27. 10. 1949; ebd., Bl. 3, Adenauer an van Cauwelaert, 2. 11. 1949.

31 Kabinettssitzung, 28. 10. 1949, in: Kabinettsprotokolle, Bd. 1, S. 161.

32 S. Hoffmann an Schuman, 31. 10. 1949, in: Hoffmann, Ziel, S. $167 \mathrm{f}$. 
l'Europe für ihn im Konzept der Westintegration einen höheren Stellenwert besaß als die Einlösung nationaler Rechtsansprüche ${ }^{33}$.

Auf seiner Sitzung vom 4. 11. stimmte der Ministerausschuß den Aufnahmebegehren gemäß einer abgeschwächten Fassung des britischen Vorschlags $\mathrm{zu}^{34}$, konnte sich aber aufgrund von rechtlichen und politischen Bedenken nicht zu einer förmlichen Einladung durchringen, da er die Ergebnisse der kurz darauf stattfindenden Pariser Außenministerkonferenz der drei Westmächte und die Tagung der Ständigen Kommission der Beratenden Versammlung in Straßburg abwarten wollte ${ }^{35}$. Auf beiden Ebenen stand man der Frage des Beitritts von Bundesrepublik und Saar aber positiv gegenüber ${ }^{36}$. Acheson stellte seine Bedenken gegen die saarländische Mitgliedschaft zugunsten einer einheitlichen Position der Westmächte zurück, verlangte jedoch, daß sie vom Vorbehalt eines Friedensvertrags abhängig gemacht werden sollte. Von der Bonner Regierung erwartete er mit seinen beiden Kollegen einen Antrag an den Ministerausschuß und eine Einverständniserklärung mit den Statuten der Straßburger Organisation. Insgesamt machten sie ihre Zustimmung vom Ausgang der Debatten in Bundestag und Nationalversammlung über das Petersberger Abkommen abhängig ${ }^{37}$.

Als die Hohen Kommissare dem Bundeskanzler das Procedere vorstellten, zeigte der sich sichtlich zufrieden. Um die durch die in Aussicht stehende Aufnahme der Saar aufgeheizte innenpolitische Stimmung nicht weiter zu schüren, hielt er es für ratsam, das Thema in seiner Regierungserklärung auszuklammern. François-Poncet hingegen empfahl ihm mit Blick auf die kommende Aussprache in der Assemblée Nationale, nicht erst auf eine Einladung zu warten, sondern gemäß dem saarländischen Vorbild selbst aktiv zu werden. Adenauer fand das nicht sehr klug und erhielt den Zuspruch von Robertson, der dazu riet, die Debatten der Volksvertreter abzuwarten ${ }^{38}$. Dementsprechend wich der Kanzler einer Diskussion über die Beitrittsfrage im Plenum des Bundestags am 24. 11. aus ${ }^{39}$. Auch Schuman behandelte das Problem in den Sitzungen der Nationalversammlung vom 22. bis 26. 11. wie ein rohes Ei, verwies auf die Straßburger Zuständigkeit, schloß seine Ausführung aber mit den Worten, daß eine deutsche Verweigerung die gesamte französische Europapolitik untergraben würde ${ }^{40}$.

Die endgültige Entscheidung mußte nun auf der für den 30.3. 1950 terminierten nächsten Tagung des Ministerkomitees ${ }^{41}$ fallen. Das „nicht unerheblich ver-

33 S. Interview Adenauers mit „Die Zeit“, 3. 11. 1949, in: BDFD I, S. $61 \mathrm{f}$.

34 Vgl. Kerkhoff, Großbritannien, S. $93 \mathrm{f}$.

Vgl. Enders, Konflikt, S. 31.

36 S. Bliss an Webb, A 2077, 10. 11. 1949, Top secret, im Auszug in: FRUS 1949, Bd. 3, S. 496f.; AdG 1949, S. 2124G u. 2128A; Guldin, Bundesrepublik Deutschland, S. 152.

37 S. Unterredung zwischen Acheson, Bevin und Schuman vom 9.11. 1949, in: Lademacher/Mühlhausen (Hg.), Petersberger Abkommen, S. 375 f.; Resolution der drei Minister über den Beitritt der Saar zum Europarat, in: ebd., S. 392, Anm. 15; Direktive ders, an die AHK, mitgeteilt in: Acheson an Webb, Tel. 4724, 11. 11. 1949, Secret, in: FRUS 1949, Bd. 3, S. 306-308; Kerkhoff, Großbritannien, S. 95.

38 S. Unterredung zwischen Adenauer und der AHK vom 15. 11. 1949, in: AAPD, Adenauer und die Hohen Kommissare 1949-1951, S. 9-17.

39 S. Regierungserklärung Adenauers, 24. 11. 1949, in: BT, Sten. Ber., Bd. 1, S. 472-476.

40 S. Erklärungen Schumans, 24. u. 25. 11. 1949, in: Annales de l'Assemblée Nationale, Débats 1949, Bd. 8, S. 6230-6235, 6334-6338 u. 6350f.

41 Zur Sitzung vom 30. 3. 1950 vgl. AdG 1950, S. 2314L. 
schlechterte Verhältnis“ 42 der Bundesregierung zu den Besatzungsmächten im allgemeinen und der Streit zwischen Bonn und Paris über die am 3. 3. verabschiedeten französisch-saarländischen Saarkonventionen ${ }^{43}$ im besonderen ließen die Beitrittsfrage aber in eine "Sackgasse" geraten ${ }^{44}$. Adenauer befand sich nun in der mißlichen Lage, eine positive Entscheidung erst nach einem entsprechenden Votum des Bundestages aussprechen zu können, wobei die nötige Mehrheit mehr und mehr schwand. Immer lauter erscholl der Vorwurf, die Mitgliedschaft verfestige die deutsche Teilung und drohe die völkerrechtliche Abtrennung des Saargebietes zu präjudizieren.

Mitte März ergriff die französische Hohe Kommission die Initiative und überreichte der Bundesregierung eine „Aktennotiz über das Verfahren zur Aufnahme Deutschlands in den Europarat". Darin forderte sie sie unter Hinweis auf den Beschluß der Pariser Außenministerkonferenz vom November auf, dem Ministerausschuß ein Beitrittsgesuch zu unterbreiten. Wie bereits in der Sitzung auf dem Petersberg vom 15. 11. ließ François-Poncet keinen Zweifel an der positiven Antwort, machte aber zugleich klar, daß im Fall etwaiger Hindernisse die Schuldigen weder bei den Westmächten noch im Europarat zu suchen seien ${ }^{45}$. Adenauers Einstellung zum Procedere hatte sich jedoch inzwischen erheblich verändert. Ungeachtet seiner positiven Haltung zum Beitritt selbst lehnte er das gewünschte formelle Gesuch nunmehr aus Rücksicht auf die innenpolitischen Widerstände ab. Mittlerweile paßte es ihm nicht mehr, wie Bonn und Saarbrücken auf die gleiche Stufe gestellt wurden. Auch mochte er sich nicht einem in den Statuten des Europarates nicht vorgesehenen Verfahren unterwerfen, zumal die Bundesregierung seines Erachtens bereits im Petersberger Abkommen ihre Bereitschaft zum Beitritt bekundet und damit die erforderliche Bereitschaftserklärung abgegeben hatte. Da ihm der Beschluß der drei Außenminister nicht bekannt gemacht worden war, galt für ihn jetzt die Devise: „Es ist demnach die Einladung durch den Ministerausschuß abzuwarten." 46

Parallel dazu trat Adenauer aus der tiefen Sorge vor einer „ungeheure[n] Katastrophe“ mit einem sensationellen Angebot „die Flucht nach vorn“ an. Die wirtschaftliche Einheit Europas wirkte unsicher, das Verhältnis zwischen den Supermächten verschärfte sich, der Europarat war ,in den Anfängen stecken geblieben“, das Verhältnis zwischen Bonn und Paris hatte sich „zusehends verschlech-

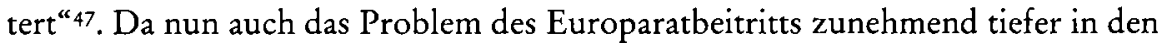
Strudel der bilateralen Auseinandersetzung geriet, versuchte der Kanzler, über die

42 PA, Abt. 2, Bd. 1299, Blankenhorn an Adenauer, Aufzeichnung, 22. 2. 1950, Geheim.

43 Vgl. Kap. IH.3.1.

44 Enders, Konflikt, S. 40.

45 "Aktennotiz über das Verfahren zur Aufnahme Deutschlands in den Europarat", in: EA 1950, S. 3130; das französischsprachige Original in: PA, Abt. 2, Bd. 581, Bl. $42 \mathrm{f}$., Memento sur la procedure d'accession de l'Allemagne au Conseil de l'Europe, 14. 3. 1950. François-Poncet übergab das Schriftstück am 15. 3. 1950 an Dittmann (ebd., Bl. 44, Dittmann an Adenauer, Aufzeichnung G 19/ 50, 15. 3. 1950).

46 Ebd., Bl. 34 f., Aufzeichnung dess., G 18/50, 12. 3. 1950; s.a. ebd., Bl. 47-49, Mohr an Adenauer, Stellungnahme, 16. 3. 1950; ebd., Bl. 67-70, Dittmann an dens., Aufzeichnung G 24/50, 20. 3. 1950; ebd., Bd. 528, Bl. 21-23, Aufzeichnung 4030/2209/50, 15. 3. 1950.

47 Aufzeichnung Adenauers, o.D., in: AAPD 1949/50, S. 104 u. 105. 
Presse mit „ziemlich unausgegorenen europapolitischen Vorstellungen“48 gegenzulenken. Die Reaktionen auf seinen am 7.3. dem amerikanischen Journalisten Kingsbury-Smith vorgestellten Plan einer deutsch-französischen Union ${ }^{49}$ fielen allerdings ziemlich kühl aus, was Adenauer darauf zurückführte, „daß der Vorschlag zu einer allerdings kühnen Neukonstruktion außenpolitischer Verhältnisse von einem besiegten Land ausgegangen ist" ${ }^{50}$. Schumacher stellte umgehend klar, daß er für eine derartige „Außenpolitik der plötzlichen Noteinfälle“ nicht zu haben sei ${ }^{51}$. Nicht ein bilaterales Tête-à-tête, sondern die europäische Integration sei das Gebot der Stunde, hieß es vielstimmig in den Gazetten ${ }^{52}$. Nur eine Minderheit der Kommentatoren wagte es, die Frage aufzuwerfen, ob die „entente directe “ für die Durchsetzung der eigenen Interessen nicht doch vorteilhafter sei als eine „entente plurale“53. Eine einzige „äßßerst beachtliche Stimme“54 äußerte sich in Frankreich positiv: de Gaulle. Am 16. 3. erklärte der General gegenüber Journalisten in pathetischem Stil, dank gemeinsamer Anstrengungen hätten Gallier, Germanen und Römer Attila auf den katalaunischen Feldern geschlagen. Eine deutsch-französische Union würde das Werk Karls des Großen fortsetzen ${ }^{55}$. De Gaulles Eloge auf den Kanzler und seine Andeutung, die bilaterale Union auch auf die französischen afrikanischen Besitzungen auszuweiten, erschien so manchem Landsmann als Versuch, jene deutschen Geister zu verführen, „mêmes démocratiques, qui se souviennent encore des principes nazis sur la ,Géopolitik'“ ${ }_{56}$. Stellvertretend für viele französische Politiker kritisierte der Vorsitzende des Außenpolitischen Ausschusses in der Assemblée Nationale, Bonnefous, Europa könne nicht über eine bilaterale Union, sondern nur über den Europarat gebaut werden $^{57}$. François-Poncet hielt des Kanzlers Angebot für politisch wertlos und sah darin vor allem „une manoeuvre politique destinée à compenser l'effet des diatribes de la veille“. Wie konnte ein so erfahrenen Politiker wie Adenauer bloß so naiv sein, meinte er ${ }^{58}$ und bezweifelte nun auch, daß der Kanzler bereits ein Staatsmann sei ${ }^{59}$.

Adenauer ließ sich davon nicht entmutigen und plante ein neues Interview. Der Unionsgedanke, so riet ihm daraufhin der stellvertretende Leiter des Bundespresseamtes Heinrich Böx, könne der Öffentlichkeit nur dann "schmackhaft" ge-

48 Schwarz, Adenauer und Europa, S. 490.

49 Vgl. Kap. III.3.1.

so Aufzeichnung Adenauers, o.D., in: AAPD 1949/50, S. 104-107, hier S. 104.

51 AsD, NL Schumacher, Bd. 50, Pressekonferenz Schumachers, 24. 3. 1950.

52 S. "L'Information“, 10.3. 1950, im Auszug auch in: BDFD III, S. 88 f.; Artikel Henrichs, in: „Frankfurter Rundschau“, 22. 3. 1950, im Auszug auch in: ebd., S. 89-91.

53 Artikel Moussets, in: „L'Epoque“, 24. 3. 1950, auch in: ebd., S. 91 f., hier S. 92.

54 Aufzeichnung Adenauers, o.D., in: AAPD 1949/50, S. 104.

s5 S. Pressekonferenz de Gaulles, 16.3. 1950, in: de Gaulle, Discours, Bd. 2, S. 344-358; AdG, S. $2302 \mathrm{~F}$.

56 S. AMAE, Europe 1944-1960, Allemagne, Bd. 337, Bl. 191-196, Aufzeichnung der Unterabt. Zentraleuropa im MAE, ca. 25. 3. 1950 (Konzept PK); eine identische Fassung (ebd., Bd. 374, Bl. 119224) trägt das Datum 23. 5. 1950; zu den weithin reservierten Reaktionen am Rhein auf dieses Interview s. ebd., Bd. 373, Bl. 224, François-Poncet an MAE, Tel. 1142/45, 18. 3. 1950.

$57 \mathrm{Vgl}$. AdG 1950, S. 2291D.

58 AMAE, Europe 1944-1960, Allemagne, Bd. 373, Bl. 199, François-Poncet an MAE, Tel. 923, 9. 3. 1950.

59 S. ders. an Schuman, Nr. 343/CM, 17. 3. 1950, in: François-Poncet, Rapports mensuels, Bd. 1, S. 263. Zur Numerierung s. AMAE, Europe 1944-1960, Allemagne, Bd. 125, Bl. 96. 
macht werden, wenn man ihn mit dem Hinweis verknüpfe, daß Europa ein „selbständiges Gewicht" darstellen und eine Eskalation des Ost-West-Gegensatzes verhindern könne. Die Union binde Deutschland an den Westen und hebe damit die Gefahr einer Ausrichtung nach Osten auf. Für Frankreich bedeute sie Vorverlegung der Rheinlinie an die Elbe und damit die Beseitigung aller Sicherheitsbesorgnisse. Natürlich sei der Nachweis zu erbringen, daß die Zweierallianz keiner Blockbildung Vorschub leiste. Zur Verwirklichung der Union dachte Böx konkret an eine Zollunion und Wirtschaftseinheit mit einem Wirtschaftsparlament sowie einem darüber stehenden Ministerrat als Vertretung der Regierungen. In Erwartung einer „Reihe psychologischer Bedenken“ der Franzosen gab sich Böx allerdings keiner Illusionen über die Realisierungschancen hin. Die „schärfste Gegenaktion" erwartete er indes nicht von französischer, sondern von britischer Seite, so $\mathrm{daß}$ es seiner Meinung vor allem darauf ankam, die amerikanische Öffentlichkeit für den Plan zu gewinnen 60 .

Auch der Kanzler dachte an eine Zoll- und Wirtschaftsunion mit einer vom Bundestag und der Assemblée Nationale gewählten gemeinsamen Volksvertretung und "gemeinsame[n] Regierungsorgane[n]" nach dem Vorbild der Deutschen Zollunion und des Deutschen Zollparlaments von 1834. Um dem Konstrukt den Anstrich bilateraler Exklusivität zu nehmen, präsentierte er es als anderen Staaten offene Keimzelle einer „wirklichen europäischen Union“, die Europa als „neuen politischen Faktor " entstehen ließ $\mathrm{e}^{61}$. Dementsprechend sprach Adenauer am 21.3. bei einer neuerlichen Unterredung mit KingsburySmith „von einem allmählichen Verschmelzen der beiden Länder in bezug auf Zölle und Wirtschaft“, wobei er als „Werkzeug“ der Union ein gemeinsames Wirtschaftsparlament und ein ihm zugeordnetes Organ von Regierungsvertretern einzusetzen gedachte ${ }^{62}$.

Im Hotel Dreesen hielt man die aus den Interviews sprechenden Gefühle und Besorgnisse für echt, witterte aber verborgene „intentions de manoeuvre " wie den Wunsch nach mehr Souveränität. Als Schwachpunkt der Gedankenführung machte François-Poncet Adenauers Bemerkungen über England aus, dem der Kanzler eine nicht weiter definierte Rolle in der Zweier-Union angeboten hatte. Das aber reichte dem Hohen Kommissar nicht aus. Denn Frankreich konnte sich seiner Meinung nach nicht einer Nation nähern, die es seit Beginn des Jahrhunderts zweimal überfallen habe, und gleichzeitig erprobte Freundschaften vernachlässigen ${ }^{63}$. Auch im Quai d'Orsay überwog der Argwohn. Verbarg sich hinter den Plänen des Kanzlers nicht die Absicht deutscher Wirtschaftskreise, Frankreich eine Union aufzuzwingen, die sich infolge des ökonomischen Ungleichgewichts zugunsten Deutschlands entwickeln und schließlich zu dessen wirtschaftlicher

60 PA, Abt. 2, Bd. 573, Bl. 10-13, Böx an Adenauer, Aufzeichnung, 18. 3. 1950.

61 Aufzeichnung Adenauers, o.D., in: AAPD 1949/50, S. 106 u. 107.

62 PA, Abt. 2, Bd. 581, Bl. 103-109, Interview dess. mit Kingsbury-Smith vom 21.3. 1950, Mitteilung des Presse- und Informationsamtes der Bundesregierung (PIB) Nr. 347/50; eine Kopie findet sich auch in den Akten des Quai d'Orsay (AMAE, Europe 1944-1960, Allemagne, Bd. 337, Bl. 169175); s.a. Adenauer, Erinnerungen 1945-1953, S. 311-316; Legoll, Konrad Adenauer, S. 232-234.

63 AMAE, Europe 1944-1960, Allemagne, Bd. 373, Bl. 243 f., François-Poncet an MAE, Tel. 1193/ 96, 21. 3. 1950, Urgent. 
und politischer Dominanz führen würde64? Offenbar zielte Adenauer mit seiner Neuauflage auf eine Korrektur des ersten Interviews, in dem er die Union von der Rückkehr der Saar abhängig gemacht hatte. Den Beweis eines konstruktiven Vorschlags sah zumindest Generalsekretär Parodi nicht erbracht. Selbst wenn es Adenauer ernst meinte, gab es für ihn keinen Grund, dem Kanzler zu folgen. Ein „tête-à-tête franco-allemand“ wirkte auf ihn in der Stunde des sich allmählich organisierenden Europa völlig deplaziert. Die bilateralen Probleme glaubte er ohnehin im größeren Rahmen besser beheben zu können. Und außerdem hielt er es wie François-Poncet für selbstverständlich, daß Frankreich engere Beziehungen in der Zehnergemeinschaft - wenn überhaupt - zunächst mit Großbritannien oder Italien aufnähme. Die Entente mit Deutschland, das war für ihn allenfalls ein Langzeitprojekt, "que l'on ne peut mener avec précipitation" 65 . Angesichts dieser von Mißtrauen erfüllten Erwägungen war es kaum verwunderlich, daß die offizielle französische Reaktion auf Adenauers Vorstoß negativ ausfiel. Nach einer Sitzung des Conseil des Ministres meinte Staatsminister Teitgen gegenüber Journalisten, eine dauerhafte Normalisierung der deutsch-französischen Beziehungen müsse in die gemeinschaftliche Organisation Europas eingebunden werden. Denn sie liefere beiden Ländern auf wirtschaftlichem Gebiet jenen Rahmen, der ein befriedigendes Gleichgewicht zwischen ihren Ressourcen und ihren Bedürfnissen schaffe ${ }^{66}$.

Daß Adenauer sich nur einen Tag nach seinem bemerkenswerten Interview schon wieder als entschiedener Vertreter deutscher Interessenpolitik präsentierte, konnte die Glaubwürdigkeit seiner Avancen nicht eben steigern. Sein hartnäckiges Feilschen um die Modalitäten für den deutschen Beitritt zum Europarat zeigte nicht den überzeugten Europäer, sondern den „gerissenen Advokaten“, für den die Aufrechterhaltung der deutschen Rechtsposition und die eigene innenpolitische Machtbasis „oberstes Gebot" waren67. In einer hitzigen Sitzung mit den Hohen Kommissaren vom 22. 3. sperrte sich der Kanzler gegen das vom französischen Vertreter vorgesehene Verfahren, zunächst einen Antrag zu stellen und dann die Einladung abzuwarten. In Übereinstimmung mit seinen Kollegen beharrte François-Poncet aber auf einem derartigen Gesuch, da die Bundesregierung noch immer keine definitive Zusage abgegeben hatte und Adenauer selbst zugab, augenblicklich im Bundestag wohl keine Mehrheit für den Beitritt finden zu können. Letztlich ging der eskalierende Streit über den eigentlichen Anlaß weit hinaus: Als Sprachrohr der Besatzungsmächte verlangte die Hohe Kommission vom unbotmäßigen Kanzler ein Nachgeben, um ihm die Hierarchie vor Augen zu führen. Adenauer hingegen forderte sie bockbeinig aus innenpolitischen Gründen zu einer „Geste“ auf, die die Aussicht auf eine Zustimmung des Bundestages verbessern sollte. Da die Beitrittsfrage durch das Saarproblem belastet wurde, attackierte er namentlich François-Poncet und unterstellte Frankreich, die deutsche Auf-

64 S. ebd., Bd. 337, Bl. 191-196, Aufzeichnung der Unterabt. Zentraleuropa im MAE, ca. 25. 3. 1950 (Konzept PK); eine identische Fassung (ebd., Bd. 374, Bl. 119-224) trägt das Datum 23. 5. 1950.

65 Ebd., Bd. 373, Bl. 276-277, Parodi an London etc., Tel. 2462/69 etc., 23. 3. 1950.

66 S. ebd., Bl. 268, Zirkulartel. Beaumont, 64-I.P., 22. 3. 1950; eine deutsche Übersetzung der Erklärung Teitgens in: AdG 1950, S. 2308E.

67 Schwarz, Adenauer, Bd. 1, S. 705. 
nahme in den Europarat nicht zu wünschen. Schumans Vertreter am Rhein beschwerte sich prompt pikiert darüber, vom Kanzler ständig „eins auf die Finger“ zu bekommen. Nachdem die Wogen wieder geglättet waren, sagte Adenauer eine Kontaktaufnahme mit den Fraktionsvorsitzenden des Deutschen Bundestages zu, um die Chance einer parlamentarischen Zustimmung zum Beitritt zu sondieren ${ }^{68}$.

Nach den entsprechenden Beratungen ${ }^{69}$ präzisierte der Kanzler den Hohen Kommissaren gegenüber am Tage darauf schriftlich den Standpunkt der Regierung. Ein Parlamentsbeschluß könne nur dann in Aussicht gestellt werden, falls sie zuvor die schriftliche Zusage erhielte, daß die Westmächte den Beitritt wünschten, die Aufnahme der Saar nur vorbehaltlich der Regelung der Saarfrage durch einen Friedensvertrag gelte, die Bundesrepublik baldmöglichst ordentliches Mitglied des Europarates werde und bis dahin einen Beobachter in die Sitzungen des Ministerausschusses entsenden könne ${ }^{70}$. Ein derart umfangreicher Forderungskatalog ging den Verbündeten aber zu weit. Sie akzeptierten die ersten beiden Punkte, lehnten den letzten aber $a b^{71}$, obwohl Schuman ihm in einem Gespräch mit dem Vorsitzenden der CDU/CSU-Bundestagsfraktion von Brentano persönlich zustimmte ${ }^{72}$. Von einem Gesuch Bonns zwecks Bitte um Aufnahme war nun aber nicht mehr die Rede. Ende März sprach der Ministerausschuß die offizielle Einladung aus, die die Hohe Kommission umgehend der Bundesregierung zuleitete ${ }^{73}$. Nun lag es an Adenauer, das Einverständnis des Bundestags einzuholen.

Schumacher lehnte den Beitritt unter den gegebenen Umständen aber weiterhin kategorisch $a b^{74}$. Trotz drängender Stimmen aus dem Europarat und französischer Warnungen, sich nicht des Vorwurfs der „Geschäftemacherei oder gar der Erpressung“ auszusetzen ${ }^{75}$, fühlte sich der Kanzler stark genug, um auf Zeit zu spielen. Mit bemerkenswerter Kaltschnäuzigkeit verband er das Problem Anfang April plötzlich mit der Remilitarisierungsfrage und forderte ungeniert eine Sicherheitsgarantie für Westdeutschland, mehr Informationen über die Verteidigung und eine stärkere Mitsprache in den europäischen Angelegenheiten ${ }^{76}$. Hellsichtige Diplomaten wie McCloy hatten sicherlich recht, wenn sie Adenauers vermeintliche Skrupel zur Westbindung als Instrument begriffen, vorzeigbare Kon-

68 Unterredung zwischen Adenauer und der AHK vom 22.3. 1950, in: AAPD, Adenauer und die Hohen Kommissare 1949-1951, S. 147-174, hier S. 166 u. 167; s.a. Adenauer, Erinnerungen 19451953, S. 317-324; Kabinettssitzung, 24. 3. 1950, in: Kabinettsprotokolle, Bd. 2, S. 285 f.; Guldin, Bundesrepublik Deutschland, S. 158-160.

69 S. Adenauer an Schumacher, 27. 3. 1950, Persönlich, Vertraulich, in: Adenauer, Briefe 1949-1951, S. 186 f.; Adenauer, Erinnerungen 1945-1953, S. 324.

7o S. die gleichlautenden Schreiben Adenauers an die Hohen Kommissare, 23. 3. 1950, in: Adenauer, Briefe 1949-1951, S. $183 \mathrm{f}$.

71 S. die gleichlautenden Antwortschreiben der Hohen Kommissare an Adenauer, 23. 3. 1950, und ihr Memorandum vom 28. 3. 1950, in: EA 1950, S. 3130 f.; s.a. Bérard, Ambassadeur, Bd. 2, S. 296 f., Tb. 27. u. 28. 3. 1950.

72 S. PA, Abt. 2, Bd. 581, Bl. 128f., von Brentano an Adenauer, 28. 3. 1950; Bérard, Ambassadeur, Bd. 2, S. 297, Tb. 28. 3. 1950.

73 S. Generalsekretär des Europarates Paris an Adenauer, D 233/8, 31. 3. 1950, in: EA 1950, S. 3132; Robertson an Adenauer, AGSEC (50) 608, 1. 4. 1950, in: ebd.

74 Vgl. Enders, Konflikt, S. 42; Guldin, Bundesrepublik Deutschland, S. 163.

75 Aufzeichnung Blankenhorn Geh.43/50, 11. 4. 1950, Geheim, in: AAPD 1949/50, S. 125; s.a. BA, NL Blankenhorn, Bd. 3, Bl. 144 f., Tb. 11. 4. 1950.

76 Ebd., Bl. 144, Tb. 10.4. 1950. 
zessionen der Westmächte zu erreichen77. Am 6. 5. forderte er Robertson unter Hinweis auf die vorgebliche Verzögerungstaktik der SPD dazu auf, seine Position durch „greifbare Ergebnisse“ der nahen Londoner Außenministerkonferenz zu erleichtern ${ }^{78}$.

Nach Wochen des Hinhaltens entschloß sich Adenauer gleichzeitig, den Bonner Entscheidungsprozeß per Kabinettsbeschluß zu forcieren. Allem Anschein nach wollte er in einer „bewußte[n] Inszenierung“79 die Diskussion mit seinen Ministern durch Entgegenkommen der Alliierten erleichtern und im Gegenzug einen positiven Bescheid unmittelbar vor der Konferenz in London dazu benutzen, um von den westlichen Kollegen Zugeständnisse als Gegenleistung für die von ihm eingegangenen Risiken einzufordern. Im Widerspruch zu seinen Äußerungen vom April zeigte er sich in einer zur Veröffentlichung bestimmten Denkschrift vom 7. 5. überzeugt, daß die Aufnahme ins Palais de l'Europe die Wiedervereinigung nicht hemme, sondern fördere. Denn die Einheit werde nur dann kommen, wenn die Bundesrepublik „innerhalb der europäischen Föderation wirtschaftlich und politisch an Gewicht gewinnt" 80 . Als er sich mit diesen Argumenten zwei Tage später im Kabinett zu Wort meldete, löste er einen erregten Disput aus. Namentlich die für Inneres und Gesamtdeutsches zuständigen Minister Heinemann und Kaiser erhoben schwere Bedenken, da sie befürchteten, daß die Westbindung die Spaltung Deutschlands verewige. Letztlich setzte sich der Kanzler aber gegenüber seinen Kritikern durch ${ }^{81}$.

Am 15. 6. billigte auch der Deutsche Bundestag den Beitritt mit 220 gegen 152 Stimmen bei 9 Enthaltungen ${ }^{82}$. Nicht einmal allen Unionsabgeordneten war wohl bei der Abstimmung, hätten sie doch mit Blick auf das geteilte Deutschland von der Regierung mehr "Reserve“ gewünscht ${ }^{83}$. Die Sozialdemokraten stimmten trotz innerfraktioneller Meinungsverschiedenheiten ${ }^{84}$ geschlossen gegen die Gesetzesvorlage. Gemäß dem Motto, man könne versuchen, einen Zug im Bahnhof aufzuhalten, wenn er aber abfahre, müsse man aufspringen ${ }^{85}$, fanden sie sich danach aber rasch mit den Gegebenheiten ab. Ende Juni beschloß die SPD nach kontroverser Diskussion auf Vorschlag des Parteivorsitzenden, der Regierung das Feld in Straßburg nicht allein zu überlassen ${ }^{86}$. Dementsprechend entsandte sie ab August sieben Vertreter in die 18-köpfige Delegation der Bundesrepublik. Nolens volens traf man dort auch auf drei Abgeordneten von der Saar, wo der Landtag dem Beitritt am 2. 5. einstimmig zugestimmt hatte ${ }^{87}$.

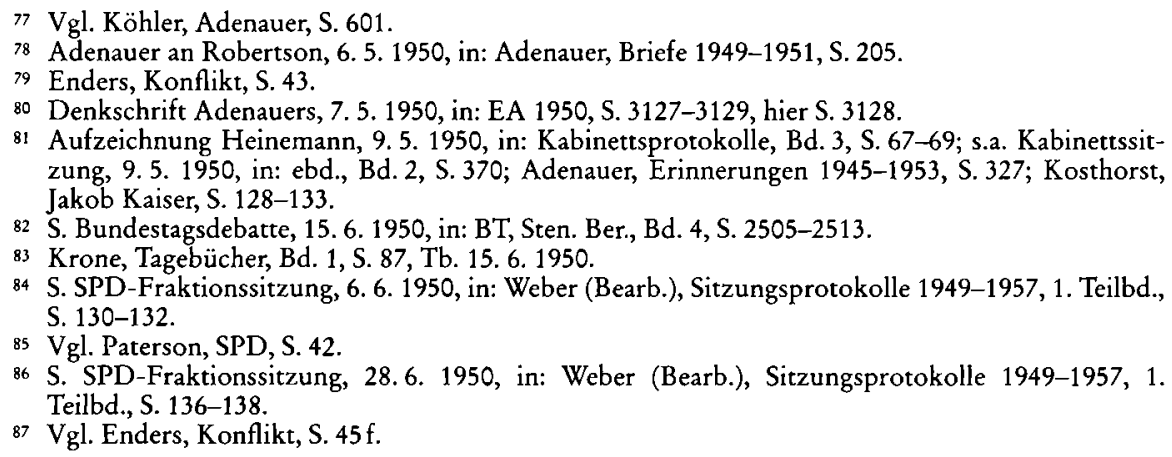

84 S. SPD-Fraktionssitzung, 6. 6. 1950, in: Weber (Bearb.), Sitzungsprotokolle 1949-1957, 1. Teilbd., S. $130-132$.

85 Vgl. Paterson, SPD, S. 42.

86 S. SPD-Fraktionssitzung, 28.6. 1950, in: Weber (Bearb.), Sitzungsprotokolle 1949-1957, 1. Teilbd., S. 136-138.

87 Vgl. Enders, Konflikt, S. 45 f. 


\section{Neue Hoffnung: Die Verkündung des Schuman-Plans}

Einen nicht unerheblichen Einfluß auf die Entscheidungen des Bundeskabinetts wie des Bundestages hatte die Veröffentlichung des Schuman-Plans am 9. 5. 1950 ausgeübt ${ }^{88}$. Das angelsächsische Entgegenkommen gegenüber den Deutschen in den Verhandlungen über die Revision des Besatzungsstatuts ${ }^{89}$ und die scharfe Auseinandersetzung zwischen Bonn und Paris in der Saarfrage ${ }^{90}$ hatten die französische Außenpolitik in den ersten Monaten des Jahres 1950 in eine lähmende „diplomatische Defensivposition“ gestürzt ${ }^{91}$. Wollte man sich auf der geplanten Außenministerkonferenz in London nicht von der anglo-amerikanischen Konzessionsbereitschaft überrollen lassen, so lautete die Devise im Quai d'Orsay, mußte Frankreich die Initiative an sich reißen und den Verbündeten ein überzeugendes Programm zur europäischen Integration der Bundesrepublik vorschlagen. Denn nur in diesem Rahmen schien es möglich, das eigene Sicherheitsbedürfnis mit der deutschen Forderung nach Gleichberechtigung und Aufhebung der besatzungsrechtlichen Fesseln in Einklang zu bringen.

Über die präzise Ausgestaltung eines solchen Konzeptes herrschte an der Seine indes Dissens. Der Unterabteilung Zentraleuropa schwebte als Plattform ein europäisches Parlament als erste Etappe für eine supranationale politische Organisation vor. Voraussetzung für diese Konstruktion schien die Stärkung der bereits bestehenden wirtschaftlichen Zusammenarbeit ${ }^{92}$. Doch gerade daran entzündete sich im Ministerium die Kritik. Einige Beamte trieb die Sorge um, daß die Bundesrepublik aufgrund ihres demographischen und ökonomischen Potentials schon jetzt „un danger sérieux “ für das wirtschaftliche Gleichgewicht seiner Nachbarn darstellte. Ohne die Beteiligung Großbritanniens würde sich die Balance in einer europäischen Wirtschaftsgemeinschaft noch mehr zuungunsten Frankreichs neigen. Da London aber kein Interesse an einer engeren Kooperation mit dem Kontinent zeigte und Paris nicht „la seule grande Puissance en face de l'Allemagne“ sein wollte, riet Alphand dazu, das Problem nicht auf der europäischen, sondern der globalen Ebene anzugehen ${ }^{93}$.

Unbemerkt von den Diplomaten im Außenministerium arbeitete auch eine kleine Gruppe um Jean Monnet, dem Commissaire général au Plan, an einem Projekt zur Bereinigung der deutsch-französischen Probleme. 1888 in Cognac, in der Charente geboren, agierte Monnet im Ersten Weltkrieg als eine der „Schlüsselfiguren " 94 bei der maritimen Logistik der Entente-Mächte. Von 1919 bis 1923 fun-

88 Aus der umfänglichen Literatur vgl, vor allem: Diebold, Schuman Plan; Kipping, Kartelle; Lappenküper, Schuman-Plan; Mittendorfer, Robert Schuman, S. 149-262; Poidevin, Robert Schuman, S. 244-296; Schwabe (Hg.), Anfänge; Spierenburg/Poidevin, Haute Autorité; Trausch, SchumanPlan.

89 Vgl. Kap. III.1.1.

so Vgl. Kap. III.3.1.

91 Küsters, Verhandlungen, S. 74.

92 S. AMAE, Europe 1944-1960, Généralités, Bd. 133, Bl. 78-83, Aufzeichnung der Abt. Europa im MAE, 7. 4. 1950 (Konzept FS); Aufzeichnung der Unterabt. Zentraleuropa im MAE, 18. 4. 1950, in: BDFD I, S. 219-224; Hitchcock, France Restored, S. 123 f.; Rouche, Le Quai d'Orsay, S. 39 f.

93 AMAE, PA-AP Papiers Massigli, Bd. 68, Bl. 239-241, Aufzeichnung, 19.4. 1950 (Konzept HA).

94 Schwarz, Adenauer, Bd. 1, S. 716. Zu Person und Politik Monnets s. Monnet, Erinnerungen; vgl. insbesondere: Duchêne, Jean Monnet; Fontaine, Jean Monnet; Roussel, Jean Monnet; s.a. Brin- 
gierte er als Stellvertretender Generalsekretär des Völkerbundes. Nach Jahren im internationalen Finanzgeschäft übernahm er 1939 den Vorsitz im französischenglischen Komitee für die Koordinierung des Transportwesens, der Versorgung und der Rüstung. 1943 wurde Monnet „Commissaire à l'Armement, l'Approvisionnement et à la Réconstruction “ im Comité Français de Libération Nationale. In den letzten Jahren des Zweiten Weltkriegs gelangte er zu der Ansicht, Westeuropa bedürfe einer wirtschaftlichen wie politischen Föderation ${ }^{95}$. Nach 1945 verdichtete sich diese Überzeugung. Als Commissaire général du Plan de Modernisation et d'Equipement widmete sich Monnet nun dem Wiederaufbau bzw. der Modernisierung der französischen Wirtschaft und trachtete danach, die Konkurrenzfähigkeit durch hohe Investitionsraten in den Basissektoren Kohle, Stahl, Elektrizität, Landmaschinen und Transport zu steigern. Dazu bedurfte es vor allem amerikanischen Kapitals, aber auch einer durch deutsche Kohlelieferungen wettbewerbsfähigen französischen Stahlindustrie ${ }^{96}$.

In den Augen seiner Kollegen aus dem Außenministerium wurden die deutschlandpolitischen Implikationen dieser Konzeption zunehmend fragwürdiger. Denn sie versuchte, einerseits mit Zwangsmaßnahmen den westdeutschen Wiederaufstieg hinauszuzögern, andererseits durch den Zeitgewinn einen industriellen Vorsprung zu erzielen, und widersprach damit dem Ziel der deutsch-französi-

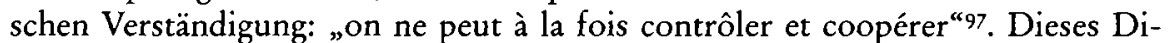
lemma sah auch Monnet. Da der Europarat die in ihn gesetzten Hoffnungen nicht zu erfüllen vermochte, er aber dennoch Churchills Zukunftsvision von den Vereinigten Staaten von Europa Gestalt verleihen und eine neue Etappe in den Beziehungen zum westlichen Nachbarn einleiten wollte, kam Monnet die Idee, eine supranationale Autorität im Montanbereich mit einer beschränkten Anzahl von Teilnehmern unter Einschluß der Bundesrepublik zu schaffen. Als überaus bedeutsam für die Entwicklung dieses Gedankens erwiesen sich das Scheitern der sogenannten „Finebel“-Verhandlungen im März ${ }^{98}$ sowie Monnets Fehlschlag, mit den Briten engere Wirtschaftsbeziehungen anzubahnen". Während Frankreich bisher die bilaterale Kooperation mit Großbritannien als wesentliche Bedingung für den Erfolg der europäischen Integration angesehen hatte, zog der Generalkommissar aus der Londoner Verweigerungshaltung den Schluß, nun einen Versuch mit Deutschland machen zu müssen: „Britain was no longer important. American support was all that counted." 100 Deshalb die historische Option des

kley/Hackett (Hg.), Jean Monnet; Küsters, Jean Monnet; Majone/Noël/Van den Bossche (Hg.), Jean Monnet; Schröder, Jean Monnet; Wilkens ( $\mathrm{Hg}$.$) , Interessen verbinden$

95 Vgl. Monnet, Erinnerungen, S. 282-287; Duchêne, Jean Monnet, S. 126-146; Gerbet, Genèse; Roussel, Jean Monnet, S. 368-399; Schwartz, Atlantik-Brücke, S. 142-149.

96 Vgl. Duchêne, Jean Monnet, S. 147-180; Mioche, Plan Monnet; Roussel, Jean Monnet, S. 429-459; Schwartz, Atlantik-Brücke, S. 149-153.

97 Aufzeichnung Valéry, Mai 1950, in: BDFD II, S. 594-596, hier S. 594; vgl. Trausch, Schuman-Plan, S. 115 f. mit Anm. 29.

$98 \mathrm{Zu}$ den Bemühungen um die Errichtung einer Frankreich, Italien und die BENELUX-Staaten umfassenden Freihandelszone vgl. Bossuat, La France, Bd. 2, S. 710-721; Griffiths/Lynch, L'échec; Poidevin, Robert Schuman, S. 234-239.

99 S. Monnet, Erinnerungen, S. 354-360; Bossuat, La France, Bd. 2, S. 615-647; Roussel, Jean Monnet, S. 492-511; Schwartz, Atlantik-Brücke, S. 142-155.

100 Lynch, Role, S. 124; s.a. AMAE, Europe 1944-1960, Généralités, Bd. 111, Bl. 152-156, Aufzeich- 
von ihm nun ausgearbeiteten und von Schuman übernommenen Plans vor allem im „Durchbruch zur Supranationalität ohne Großbritannien“" zu sehen"101, erscheint indes zweifelhaft. Sie lag doch wohl eher in der Hinwendung zum supranationalen Integrationskonzept unter Einbeziehung der Bundesrepublik ${ }^{102}$, wobei diese Hinwendung für Paris wie für Bonn gewiß auch „ein Stück ,nationalstaatlicher Politik" war ${ }^{103 .}$

Neben diesen genuin politischen Überlegungen bewirkten auch wirtschaftliche Faktoren das Umdenken an der Seine: Zum einen sah sich die französische Regierung der angelsächsischen Forderung einer Erhöhung der deutschen Stahlquote von 11,1 Millionen Tonnen gegenüber, die sie zum Verdruß der deutschen Stahlindustrie durch den Plan einer stärkeren Produktionsverlagerung nach Frankreich zu untergraben versuchte ${ }^{104}$. Zum anderen besaß Paris bei einer Koksimportquote von $70 \%$ seines Bedarfs keinen Einfluß auf die Erhöhung der Kohleproduktion an der Ruhr und befürchtete, Bonn könne den Abbau drosseln und Kohle importieren. Darüber hinaus begannen die Deutschen, schwedisches Eisenerz dem französischen vorzuziehen, so daß Frankreich sein Hauptzahlungsmittel für die deutsche Kohle zu verlieren drohte. Schließlich zog die Gefahr einer Überproduktionskrise in der europäischen Montanindustrie auf, die von der über die nötigen Kohlevorräte verfügenden Bundesrepublik ausgenutzt werden konnte. Ein weiteres trat hinzu. Monnet sorgte sich um die Wettbewerbsfähigkeit der französischen Industrie. Er beklagte deren Hang zu Protektionismus und Malthusianismus, wollte sie der deutschen Konkurrenz aussetzen und implizit zur Modernisierung zwingen. Dazu mußten freilich zwei Bedingungen erfüllt sein: gleicher Zugang zu den Rohstoffen und gleiche Transportbedingungen ${ }^{105}$. Jeder dieser ökonomischen Aspekte wog schon schwer. Überlagert wurden sie indes von der in Paris antizipierten Gefahr, der östliche Nachbar könne dank seiner in vielen Sparten besseren Produktionsbedingungen eines Tages Europa dominieren „by controlling the economic development of its clients"106. Bisher war es der "von vielfach übertriebener Konkurrenzangst" geprägten französischen Wirtschaft noch weitgehend gelungen, die Einfuhr deutscher Waren zu behindern ${ }^{107}$. Doch die Zeit arbeitete eindeutig für West-Deutschland, das die von Frankreich belieferten Märkte im Ausland bedrohte und sich gar anschickte, den französischen Markt zu „erobern".

Mit Sorge betrachtete Monnet indes nicht nur die ökonomische Situation im Hexagon, sondern auch die politische Lage d'outre Rhin. Sie wirkte auf ihn wie „un cancer dangereux pour la paix“108. Die Deutschen brauchten eine neue Per-

nung der Abt. Europa im MAE, 5. 6. 1950 (Konzept FS); FJM, AMG 24/4/2, Aufzeichnung Monnet, 28. 8. 1950.

101 So Loth im Widerspruch zu Monnet (Loth, Europäische Integration, S. 242).

$102 \mathrm{Vgl}$. Ziebura, Beziehungen, S. $85 \mathrm{f}$.

${ }_{103}$ Herbst, Option, S. 86.

$104 \mathrm{Vgl}$. Salewski an Henle, Aufzeichnung, 26.1. 1950, in: BDFD II, S. 108-112; Henle an Tewaag, 11. 3. 1950, nebst Aufzeichnung, in: ebd., S. 116-118.

105 Zu den ökonomischen Faktoren des Schuman-Plans vgl. Goschler/Buchheim/Bührer, Schumanplan; Kipping, Kartelle; Milward, Reconstruction, S. 362-420; Trausch, Schuman-Plan, S. $114 \mathrm{f}$.

106 Lynch, Role, S. 120.

${ }_{107}$ Reinhardt an Erhard, Vermerk V B 4a-20388/50, 11. 5. 1950, in: BDFD II, S. 153.

108 Monnet an Schuman, Aufzeichnung Nr. 1, 1.5. 1950, Secret, in: Beyer, Robert Schuman, S. 153- 
spektive, die er ihnen bezeichnenderweise nicht durch eine forcierte Wiedervereinigungspolitik aufzuzeigen gedachte. Denn abgesehen von der kaum erreichbaren Zustimmung der Sowjetunion hielt er die Wiedererrichtung eines deutschen $\mathrm{Na}$ tionalstaates für fatal, „because it would inevitably sooner or later be drawn into the Eastern orbit“. So blieb aus seiner Sicht als alternatives Terrain der Hoffnung für die Deutschen die Chance zur Zusammenarbeit mit den freien Völkern ${ }^{109}$. Auch die von den Amerikanern favorisierte Westintegration lehnte er ab, weil sie die Sowjetunion herausforderte und die Bundesrepublik dazu bringen konnte, die Teilung zu akzeptieren. Wenn die Gegebenheiten eine Lösung der „deutschen Frage" nicht erlaubten, so lautete daher seine pragmatische Devise, mußten sie geändert werden: „Il faut entreprendre une action dynamique qui transforme la situation allemande et l'esprit des Allemands“. Europa hieß die Zauberformel, und Frankreich war gefordert, die Initiative zu ergreifen ${ }^{110}$.

Am 15. 4. beauftragte der Generalkommissar den Rechtsberater des Quai d'Orsay und Professor der Rechte Paul Reuter mit der Erstellung eines Exposés über die Organisationsform eines europäischen Kohle- und Stahlmarktes ${ }^{111}$. Auf der Basis dieser Studie entwickelte er mit seinen Mitarbeitern Etienne Hirsch und Pierre Uri einen Plan, den sie in den nächsten zwei Wochen neunmal überarbeiteten ${ }^{12}$. Sein Grundkonzept der Zusammenlegung der europäischen Montanindustrie war keineswegs vom Himmel gefallen. Schon 1948 hatte der amerikanische Botschafter Douglas ähnliche Überlegungen angestellt. Paul Reynaud unterbreitete der Beratenden Versammlung des Europarates im Dezember 1949 den Plan einer gemeinsamen Behörde für den europäischen Stahl. André Philip und Edouard Bonnefous forderten ebenfalls die Internationalisierung der europäischen Schwerindustrie ${ }^{13}$. Im November präsentierte François-Poncet dem Quai d'Orsay eine deutschlandpolitische Ausarbeitung, in der er angesichts des von ihm erwarteten schnellen ökonomischen Wiederaufstiegs der Bundesrepublik für die wirtschaftliche Zusammenarbeit plädierte und zu raschem Handeln drängte, um die gegenwärtige Kooperationsbereitschaft Bonns zu nutzen ${ }^{114}$. Mitte Dezember hielt er die Formel deutsch-französischer „accords de concurrence“ für einen praktikablen Ansatzpunkt, die er wenige Wochen später durch die Idee einer europäischen Wirtschaftsintegration ergänzte ${ }^{115}$. Adenauer empfahl in seinen Interviews mit Kingsbury-Smith am 7. bzw. 21.3. ein „Verschmelzen der beiden Länder in bezug auf Zölle und Wirtschaft" ${ }^{116}$. Einen Tag später fügte er diesem Vor-

160, hier S. 154; s.a. ders. an dens., Aufzeichnung, 3. 5. 1950, in: Fondation Jean Monnet pour l'Europe (Hg.), L'Europe, S. 42-48.

109 In diesem Sinne äußerte sich Monnet gegenüber dem englischen Botschafter Harvey (Harvey an Bevin, Tel. 144, 1. 3. 1951, Priority, Confidential, in: DBPO, 2. Reihe, Bd. 1, S. 417 f.).

110 Monnet an Schuman, Aufzeichnung Nr. 1, 1. 5. 1950, Secret, in: Beyer, Robert Schuman, S. 155; zur Motivation Monnets vgl. insgesamt: Duchêne, Jean Monnet, S. 181-206.

111 S. Reuter, Communauté, S. 23-25; Monnet, Erinnerungen, S. $375 \mathrm{f}$.

$112 \mathrm{~S}$. die Versionen in: FJM, AMG $1 / 2 / 1$ bis AMG 1/2/9.

113 Vgl. Gerbet, Genèse, S. 528 f.; Monnet, Erinnerungen, S. 359; Willis, France, S. $81 \mathrm{f}$.

114 S. AMAE, Europe 1944-1960, Allemagne, Bd. 371, Bl. 138-147, François-Poncet an Schuman, Aufzeichnung, 6.11. 1949; Bock, Perzeption, S. 614 u. 619.

115 François-Poncet an Schuman, Nr. 1200/CM, 18. 12. 1949, in: François-Poncet, Rapports mensuels, Bd. 1, S. 219-222, hier S. 221. vgl. Kap. III.1.1; s.a. Unterredung zwischen Auriol und François-Poncet vom 28. 12. 1949, in: Auriol, Journal, Bd. 3, S. $461 \mathrm{f}$.

116 PA, Abt. 2, Bd. 581, Bl. 103-109, Interview Adenauers mit Kingsbury-Smith vom 21. 3. 1950, 
schlag gegenüber dem französischen Regierungschef Bidault die Anregung von Expertentreffen auf den Gebieten Stahl, Kohle und Chemieprodukte hinzu117.

Nachdem Monnet von Bernard Clappier, dem Kabinettschef Schumans, erfahren hatte, der Außenminister sei auf der Suche nach einem Konzept, das er seinen Kollegen am 10.5. in London präsentieren könne, legte er seine Gedanken am 28. 4. in einem Memorandum vor. Wie würde der Minister reagieren? Seit 1948 vertrat er die These, eine Lösung des Sicherheitsproblems gegenüber Deutschland könne nur im Rahmen der westlichen Allianz gefunden werden. „Problème allemand: ressources et énergies allemandes - se borner à les endiguer et freiner, par interdictions, par coalitions contraires, ou les mettre en valeur, les faire fructifier en commun au profit de toute l'Europe unifiée."118 Im Herbst 1949 sprach er sich gegenüber Vizekanzler Blücher für den Ausbau der Ruhrbehörde zu einem „Organ der europäischen wirtschaftlichen Arbeitsteilung “ aus ${ }^{119}$. Die Umsetzung dieser Erwägungen in konkrete Politik war dem Minister indes bis zum Frühjahr 1950 nicht gelungen. Im Gegenteil - seine Deutschlandpolitik stand vor dem „Bankrott"120, was bei ihm im April „eine regelrechte innere Krise“121 verursachte. Wie sollte er seinen angelsächsischen Kollegen gegenüber in London auftreten? Was konnte er ihnen anbieten, ohne den französischen Interessen zu schaden?

In dieser von Unsicherheit und Mißtrauen geprägten Lage ${ }^{122}$ bot Monnets Ausarbeitung den heiß ersehnten Ausweg, den Schumans eigene Beamte trotz aller gedanklicher Planungen nicht zu weisen imstande waren. Im Bewußtsein gewisser „origines américaines" 123 prüfte der Außenminister sie ein Wochenende lang in seinem Landhaus in Scy-Chazelles und erklärte dem Generalkommissar danach: "Ich mache mit"124. Bidault hingegen, der Président du Conseil, konnte sich nicht zu einer Zustimmung durchringen. Ja, er nahm sich nicht einmal die Zeit, das ihm von Monnet zugesandte Papier zu lesen ${ }^{125}$, zumal es seinen am 16.4. veröffentlichten Vorstellungen von einem atlantischen Hohen Rat zur Koordinierung der Verteidigungs- und Wirtschaftspolitik gänzlich zuwiderlief ${ }^{126}$.

PIB-Mitteilung Nr. 347/50; zur Bedeutung dieses Vorstoßes für Monnet und Schuman s. Monnet, Erinnerungen, S. 363-365; Poidevin, Robert Schuman, S. $272 \mathrm{f}$.

117 S. AN, 457 AP 59, Papiers Bidault, Koutzine an Bidault, 22.3. 1950; Soutou, Georges Bidault, S. 293.

118 ADM, 34 J 22, Papiers Schuman, Notiz Schumans, o.D.; vgl. Trausch, Schuman-Plan, S. $113 \mathrm{ff}$.

119 Vgl. Kabinettssitzung, 3. 11. 1949, in: Kabinettsprotokolle, Bd. 1, S. 170.

120 Ziebura, Beziehungen, S. 74.

121 Poidevin, Robert Schumans Deutschland- und Europapolitik, S. 18.

$122 \mathrm{Zu}$ dieser Einschätzung s. BA, NL Blankenhorn, Bd. 3, Bl. 251, Tb. 4. 5. 1950.

123 Mélandri, Etats-Unis, Bd. 2, S. 538-544; s.a. Schröder, Jean Monnet, S. 73-103; Schwabe, Staatskunst, S. 224.

124 Zitiert nach: Monnet, Erinnerungen, S. 381; s.a. Roussel, Jean Monnet, S. $522 \mathrm{f}$.

125 S. Monnet an Bidault, 28. 4. 1950, in: ebd., S. 520-522; Monnet, Erinnerungen, S. 381 f.; Bidault, Rebell, S. 216f.; Demory, Georges Bidault, S. 301-304; Soutou, Georges Bidault, S. 293-295. Soutous Vorwurf an Monnet, er habe mit Schuman und Bidault gespielt, indem er dem einen gegenüber mit dem Memorandum vom 28. 4. die Faktoren Europa und deutsch-französische Integration, dem anderen aber mit dem Memorandum vom 3. 5. die Kontrolle Deutschlands und die Entwicklung der französischen Industrie herausgekehrt habe, erscheint nicht stichhaltig, da Monnet sowohl Schuman als auch Bidault beide Dokumente zusandte.

126 S. Rede Bidaults in Lyon, 16. 4. 1950, im Auszug in: EA 1950, S. 3149. Bidaults Biograph erklärt die Nichtbeachtung des Memorandums von Monnet hingegen mit Belastungen durch "une époque agitée" (Dalloz, Georges Bidault, S. 306); s.a. Demory, Georges Bidault, S. 296 f. 
Monnets „Notes de réflexions“ vom 1. und 3.5. überzeugten Schuman endgültig ${ }^{127}$. Da er den allmählich Kontur gewinnenden Plan so geheim wie möglich halten wollte, setzte er lediglich zwei Kabinettskollegen, René Mayer und René Pleven, davon in Kenntnis. François-Poncet hingegen weihte er ebenso wenig ein wie die konsternierten Beamten im Quai d'Orsay ${ }^{128}$. Auch auf der internationalen Ebene informierte er zwei Politiker, den einen eher notgedrungen, den anderen hingegen absichtlich: Dean Acheson, der auf seiner Reise nach London am 7. 5. in Paris einen Zwischenstopp einlegte ${ }^{129}$, und Konrad Adenauer. $\mathrm{Da}$ Schuman insbesondere an einer umgehenden Kontaktaufnahme zum Kanzler gelegen war, schickte er seinen engen Mitarbeiter Robert Mischlich nach Bonn, um dort am späten Vormittag des 8. 5.130 über Blankenhorn zwei Briefe an Adenauer weiterzuleiten. Im offiziellen Schreiben, auf den 7.5. datiert, teilte er nach einleitenden Worten über den Zweck der Mission von Mischlich und der Bitte um strenge Diskretion den Wortlaut einer für den folgenden Tag geplanten Erklärung vor dem Conseil des Ministres mit und skizzierte dann „les lignes générales d'un système qui modifierait complètement les relations économiques entre nos deux pays ${ }^{{ }^{\prime \prime} 131}$.

Die seit dieser Zeit von interessierten Kreisen betriebene Mythenbildung um den Schuman-Plan und die Männer, die ihn ins Werk setzten, verliert natürlich ihren Glanz, wenn man erkennt, daß bei den Protagonisten vornehmlich die eigenen Interessen den Ausschlag dafür gaben, die Hand über den Rhein zu reichen. Beide Staatsmänner verfolgten mit dem Projekt „keineswegs ein primär europapolitisches" Interesse, sondern in erster Linie handfeste nationale Ziele132 - wirtschaftliche und vor allem politische ${ }^{133}$. Adenauer fühlte sich beim Studium der Überlegungen Schumans sofort an seinen Plan von 1924/25 über die „Kuppelung der Schwerindustrie beider Länder und eine entsprechende Vereinigung der Zollgebiete" erinnert ${ }^{134}$. Fünfundzwanzig Jahre später, im August 1949, hatte er - wie bereits erwähnt - vor dem Hintergrund der Debatte über die Internationalisierung der Thyssen-Hütte Schuman abermals einer „umfassende[n] internationa-

${ }_{127}$ S. Monnet an Schuman, Aufzeichnung Nr. 1, 1. 5. 1950, Secret, in: Beyer, Robert Schuman, S. 154; ders. an dens., Aufzeichnung, 3. 5. 1950, in: Fondation Jean Monnet pour l'Europe, (Hg.), L'Europe, S. 42-48.

128 S. Bérard, Ambassadeur, Bd. 2, S. 312 f., Tb. 9. 5. 1950; Chauvel, Commentaire, Bd. 2, S. 268; Dumaine, Quai d'Orsay, S. 502; Bock, Perzeption, S. 619 f; Bossuat, La France, Bd. 2, S. 753 f.

129 Zur anfänglich reservierten, dann aber dezidiert positiven Haltung Achesons zum Schuman-Plan s. Acheson an Webb, Tel. 211, 10. 5. 1950, Top secret, in: FRUS 1950, Bd. 3, S. $694 \mathrm{f}$.; Acheson, Creation, S. 382-389; Mélandri, Etats-Unis, Bd. 2, S. 545-550; Schwabe, Staatskunst, S. 223-228.

${ }_{130}$ S. Mischlich, Mission secrète, S. 59 f. Mischlich nennt irrtümlicherweise den 9. 5. als Datum seiner Reise. Blankenhorn spricht in seinem Tagebuch vom 8. 5., „vormittags 12 Uhr“ (BA, NL Blankenhorn, Bd. 3, Bl. 277, Tb. 8. 5. 1950; Blankenhorn, Verständnis, S. 100 f., Tb. 8. 5. 1950).

131 Schuman an Adenauer, 7. 5. 1950, in: Fondation Jean Monnet pour l'Europe (Hg.), L'Europe, S. 60 f., hier S. 61. Das von Adenauer in seinen Erinnerungen erwähnte handschriftliche Schreiben Schumans (Adenauer, Erinnerungen 1945-1953, S. 327) gilt seit Jahrzehnten als verschollen (Poppinga, Mut, S. 511 f.).

132 Köhler, Adenauer, S. 607.

133 Vgl. dagegen Kipping, Kartelle.

134 Unterredung zwischen Adenauer und Hans Schäffer vom 3. 6. 1950, im Auszug in: Schwabe ( $\mathrm{Hg}$.), Anfänge, S. 132-140, hier S. 137; s.a. Adenauer an Paul Silverberg, 11. 5. 1950, in: Adenauer, Briefe 1949-1951, S. 209. Köhler sieht in dieser Vordatierung Adenauers eine bewußte Irreführung, um von seinen Aktivitäten des Jahres 1923 abzulenken (Köhler, Adenauer, S. 604). 
le[n] Zusammenarbeit auf dem Gebiet von Kohle und Eisen" das Wort geredet ${ }^{135}$. Den Kanzler leitete die Überzeugung, das Gleichgewicht in Europa sei durch den Zweiten Weltkrieg zerstört und der Machtverlust des Alten Kontinents müsse durch einen Zusammenschluß aller europäischen Demokratien ausgeglichen werden. Zur Konsolidierung und außenpolitischen Stabilisierung bedurfte die junge Bundesrepublik des bewußt angestrebten Aufgehens in einem "integrierten“ Westeuropa. Eine herausragende Rolle spielte für ihn dabei die Beseitigung des französisch-deutschen Gegensatzes als notwendige Voraussetzung für jede europäische Einigung, die ihrerseits aber ebenfalls als „Mittel zum Zweck“ wirkte"136. Adenauer zögerte begreiflicherweise keinen Moment, Schumans Vorstoß zu unterstützen. Gewiß, das Angebot stand in einem auffälligen Kontrast zum „véto absolu“, das Staatspräsident Auriol zwei Tage zuvor einer deutschen Aufrüstung entgegengestellt hatte ${ }^{137}$. Von einer Verflechtung der Schwerindustrie, wie Adenauer sie stets proklamiert hatte, war außerdem nicht die Rede, da die Eigentumsverhältnisse nicht verändert und die Schwerindustrie lediglich unter die Kontrolle der Hohen Behörde gestellt werden sollten ${ }^{138}$. Dennoch identifizierte er sich so stark mit dem Schuman-Plan, daß er darin „son propre enfant“ glaubte erkennen zu können ${ }^{139}$. Nach kurzer Beratung mit Blankenhorn übergab er Mischlich daher am Abend des 8. 5. zwei Schreiben an Schuman, in denen er dessen Gedanken „als einen entscheidenden Schritt zu einer engen Verbindung Deutschlands mit Frankreich und damit zu einer neuen, auf der Grundlage friedlicher Zusammenarbeit aufgebauten Ordnung in Europa" würdigte und seine Bereitschaft zur Realisierung des Planes definitiv bestätigte ${ }^{140}$.

Vielfältige Motive zeichneten für diesen Entschluß verantwortlich. Zum einen bot das Projekt die Möglichkeit der gegenseitigen Kontrolle über Kohle und Stahl, also auch über den Rüstungssektor, und konnte somit zur Vertrauensbildung beitragen ${ }^{141}$. Außerdem glaubte der Kanzler, wie Schuman, an die Vorbildfunktion einer erfolgreichen Integration im Montanbereich für andere Wirtschaftsgebiete. Ja, er erwartete von dem projektierten ökonomischen Zusammenschluß auch ein politisches Zusammengehen, „vielleicht auch ein militärisches, obgleich er selbst Deutschland möglichst aus einer Aufrüstung heraushalten wolle“142. Darüber hinaus besaß der Plan für die Bundesrepublik den Vorteil, daß er mit Teilen des Besatzungsstatuts kollidierte und damit nicht nur den Weg zur vollen Entfaltung ihres industriellen Potentials, sondern auch zur politischen

135 Adenauer an Schuman, 25.8. 1949, Vertraulich, in: Adenauer, Briefe 1949-1951, S. 94-96, hier S. 95; vgl. Kap. III.1.1.

136 Trausch, Schuman-Plan, S. 117.

137 "Paris-presse/l'intransigeant", 11. 5. 1950, im Auszug auch in: BDFD III, S. 182 f., hier S. 182; s.a. AdG $1948 / 49$, S. 2370B.

138 Vgl. Köhler, Adenauer, S. 604.

${ }^{139}$ François-Poncet an Schuman, Nr. 609/CM, 21. 5. 1950, in: François-Poncet, Rapports mensuels, Bd. 1, S. 272-281, hier S. 276.

${ }_{140}$ Adenauer an Schuman, 8. 5. 1950, in: Adenauer, Briefe 1949-1951, S. 208; s.a. Mischlich, Mission, S. 60 u. 64; Legoll, Konrad Adenauer, S. 254.

$141 \mathrm{~S}$. Erklärung Hallsteins in der Sitzung des Bundestagsausschusses für Auswärtige Angelegenheiten vom 31. 10. 1950, in: Hölscher (Bearb.), Sitzungsprotokolle, S. 151.

142 Tb. Hans Schäffer, 3. 6. 1950, in: Schwabe (Hg.), Anfänge, S. 138. 
Souveränität ebnete ${ }^{143}$. Die Offerte bot seiner Meinung nach die große Chance, "gleichberechtigt an einer gemeinsamen Aufgabe“ zu wirken und den bilateralen Beziehungen „einen neuen Auftrieb zu konstruktiver Zusammenarbeit“ zu geben ${ }^{144}$. Sodann stellte er durch die Einbeziehung der Kohlegruben an der Saar auch die Bereinigung der Saarfrage in Aussicht. Schließlich spielten für Adenauer auch die Überzeugung der amerikanischen Unterstützung ${ }^{145}$ und eine gewisse Enttäuschung über England eine Rolle. Hatte er noch in seinem Interview mit Kingsbury-Smith London die Tür zur deutsch-französischen Union weit öffnen wollen, beklagte er sich nun, „daß Englands Außenpolitik sich von den alten Methoden nicht lösen könnte und auf das ,Teilen und Herrschen ' hinausginge" ${ }^{146}$.

Nach den zahlreichen Enttäuschungen der letzten Monate faßte der Bundeskanzler wieder Vertrauen zum französischen Außenminister. Schuman war es allem Anschein nach gelungen, sich von der im Quai d'Orsay mit Macht wirkenden Gruppe von Vertretern einer germanophoben Sicherheitspolitik um Parodi zu befreien. Der Inhalt des Planes, die Geheimmission Mischlichs und die Tatsache der offenbar völlig ausgeschalteten französischen Hohen Kommission ließen den Kanzler jedenfalls vom Triumph des Ministers über seine Mitarbeiter schwärmen ${ }^{147}$. Endlich bot sich die Gelegenheit, das Verhältnis beider Staaten auf der Basis wirtschaftlicher Realitäten und nicht von Ressentiments zu gestalten, wenngleich der Kanzler selbst zugab, daß ihm die Beziehungen zu Frankreich sehr wohl eine Herzensangelegenheit waren ${ }^{148}$. Alles in allem bot sich der Bundesrepublik eine einmalige Chance, die nicht ungenutzt verstreichen durfte, auch wenn es sich um „un saut dans l'inconnu“ handelte"149.

Nachdem beide Minister Einvernehmen über die Durchführung des Planes erzielt hatten, steuerten sie eine möglichst medienwirksame Veröffentlichung an. Mit der Zustimmung Adenauers und dem anschließend eingeholten Plazet des keineswegs begeisterten Ministerrates im Rücken ${ }^{150}$ berief Schuman am Abend des 9. 5. eine große Pressekonferenz in den Salon de l'Horloge des Quai d'Orsay. In der Erkenntnis der unabdingbar notwendigen Einheit der demokratischen Staaten des Kontinents und der Einsicht, „l'Europe ne se fera pas d'un coup“,

143 S. Schalfejew an Adenauer, I A-2122/50, 11.5. 1950, in: Küsters, Bonn und der Schumanplan, S. 83-85; Alphand, L'étonnement d'être, S. 217, Tb. 10. 5. 1950.

144 Adenauer an Schuman, 8. 5. 1950, in: Adenauer, Briefe 1949-1951, S. 208 u. 209.

145 Adenauer sah Acheson als „wahren Anstifter" der französischen Initiative (zitiert nach: Schwartz, Atlantik-Brücke, S. 158).

146 Tb. Hans Schäffer, 3. 6. 1950, in: Schwabe (Hg.), Anfänge, S. 133.

147 Entgegen besseren Wissens beglückwünschte Adenauer François-Poncet aus Gründen der Bonhomie zu seiner „maßgebend[en]“ Beteiligung am Zustandekommen des Plans (PA, Abt. 2, Bd. 744, Bl. 7, Adenauer an François-Poncet, 5135/4158/50, 12. 5. 1950), woraufhin François-Poncet in geschickter Umgehung der ihn brüskierenden Tatsachen antwortete: „C'est vous dire qu'en ce qui concerne ma modeste contribution, tout mon zèle est acquis à cette grande entreprise." (Ebd., Bl. 93, François-Poncet an Adenauer, 18. 5. 1950). Um die Stimmung des Kanzlers nicht zu verderben, hielt es auch Bérard für ratsam, Adenauer in seiner (vermeintlich) irrigen Auffassung nicht zu korrigieren (AMAE, Europe 1944-1960, Généralités, Bd. 111, Bl. 6f., Bérard an MAE, Tel. 2164/ 65, 11. 5. 1950, Priorité).

$148 \mathrm{Vgl}$. Gehler, Klein- und Großeuropäer, S. 588.

149 Steinert, Saut.

150 Bidault behauptet in seinen Memoiren, er habe dem Plan in der entscheidenden Ministerratssitzung zum Durchbruch verholfen (Bidault, Rebell, S. 218; Soutou, Georges Bidault, S. 294). 
wollte er Fakten schaffen, die die Alte Welt allmählich zusammenwachsen ließen und Frankreich die Chance böten, zumindest eine regionale Führung zu übernehmen. Aus der Besorgnis gegenüber einem amerikanischen Übergewicht in Europa sowie der Furcht vor einem wiedererstarkten Deutschland erklärte er daher die Bereitschaft seiner Regierung, "de placer l'ensemble de la production franco-allemande de charbon et d'acier, sous une Haute Autorité commune, dans une organisation ouverte à la participation des autres pays d'Europe " ${ }^{\text {"51. }}$. Zwei Stunden später bat Adenauer seinerseits die Presse zu sich, um die deutsche Teilnahme an der Realisierung des Projektes zu verkünden. „Au milieu d'une émotion et d'un enthousiasme incroyables" 152 begrüßte der Kanzler die französische Initiative, die ihm zugleich Genugtuung und Hoffnung bot, weil das vom Bundeskabinett wenige Stunden zuvor beschlossene Beitrittsgesuch für den Europarat und die von ihm in aller Deutlichkeit herausgestellte „Basis der Gleichberechtigung", auf der der Schuman-Plan ruhte, eindrucksvoll die Richtigkeit seiner Politik zu bestätigen schienen ${ }^{153}$. Mit einem Schlag hatte sich seine seit Wochen andauernde Verärgerung über Frankreich verwandelt: „le vinaigre du Chancelier fédéral s'est changé en miel“, kommentierte François-Poncet den abrupten Stimmungsumschwung ${ }^{154}$.

Die entscheidende Hürde hatte das Projekt genommen. Nun ging es Schuman um die Zerstreuung des Mißtrauens der nicht unmittelbar involvierten Staaten. Angesichts sofort aufkommender angelsächsischer Beschwerden hinsichtlich eines neuen Kohle- und Stahlkartells ${ }^{155}$ versuchte er während des Außenministertreffens in London seine beiden Kollegen davon zu überzeugen, daß seiner Regierung nichts ferner läge als eine derartige Firmenkonzentration. Wider besseren Wissens unterstrich er zugleich die Vereinbarkeit der geplanten Gemeinschaft mit dem deutschen Besatzungsregime. „No modification would be made to the statute and the functions of the Ruhr Authority and Military Security Board"..156 Während Bevin zu diesen Vorstellungen auf Distanz ging, legte Acheson seine Zweifel ab und wurde zu einem „enthusiastischen Befürworter" des SchumanPlans 157 .

Als Schuman danach trachtete, sein Projekt international abzusichern, bemühte sich Adenauer wie so häufig in entscheidenden politischen Momenten darum, die Fäden auf der nationalen Ebene in der eigenen Hand zu behalten ${ }^{158}$. Eine Koordinierung der deutschen Positionen schien durchaus geboten, denn die erste Reaktion der interessierten Ministerien ließ nicht unerhebliche Meinungsverschieden-

\footnotetext{
151 Regierungserklärung Schumans, 9. 5. 1950, in: BDFD I, S. 225-227, hier S. 225.

152 Bérard, Ambassadeur, Bd. 2, S. 312 f., Tb. 9. 5. 1950.

${ }_{153}$ Pressekonferenz Adenauers, 9.5. 1950, in: Adenauer, Reden, S. 175-181, hier S. 180; s.a. BA, NL Blankenhorn, Bd. 4, Bl. 2f., Tb. 9. 5. 1950; Blankenhorn, Verständnis, S. 102 f.; Artikel Holldacks, in: "Süddeutsche Zeitung", 11. 5. 1950, auch in: BDFD III, S. 180-182; Legoll, Konrad Adenauer, S. 255-261.

154 François-Poncet an Schuman, Nr. 609/CM, 21. 5. 1950, in: François-Poncet, Rapports mensuels, Bd. 1, S. 272.

155 Vgl. Mélandri, Etats-Unis, Bd. 2, S. 556-561.

156 Zusammenfassung von Schlußfolgerungen des Außenministertreffens in London, MIN/TRI/ $\mathrm{DEC} / 3$, 12. 5. 1950, Top Secret, im Auszug, in: DBPO, 2. Reihe, Bd. 1, S. 45-47, hier S. $46 \mathrm{f}$.

157 Schwartz, Atlantik-Brücke, S. 155; s.a. Schröder, Jean Monnet, S. 116-121.

${ }_{158}$ S. Kabinettssitzung, 16. 5. 1950, in: Kabinettsprotokolle, Bd. 2, S. 390.
} 
heiten erkennen. Peter Pfeiffer, Leiter der Diplomatenschule in Speyer, bekundete gegenüber französischen Kollegen sein Erstaunen über die ohne gründliche Prüfung des Schuman-Plans abgegebene Erklärung des Kanzlers ${ }^{159}$. Das Bundesministerium für den Marshallplan wertete das französische Vorhaben zwar als einen für Deutschland „ganz großen politischen Schritt nach vorne“, witterte aber eine beträchtliche Rechnung. Frankreich wolle offenbar die Führung auf dem Kohlegebiet an Deutschland abgeben und dafür die auf dem Stahlgebiet fordern. „Es scheint die Zeit der deutschen Stahlquote noch ausnutzen zu wollen, um auf vertraglichem Wege sich gegen eine zu starke deutsche Konkurrenz zu sichern." ${ }^{160}$ Dementsprechend warnte Minister Blücher in der Sitzung des FDP-Bundesvorstandes am 17. 7. eindringlich davor, den Schuman-Plan nur unter politischen Gesichtspunkten zu durchleuchten ${ }^{161}$. Geprägt von der ihnen nahestehenden Ruhrindustrie, trat diese Betonung des wirtschaftspolitischen Aspektes in der Willensbildung der Liberalen in den nächsten Monaten immer stärker in den Vordergrund ${ }^{162}$. Auch das Bundeswirtschaftsministerium verband nach einer internen Besprechung ${ }^{163}$ die grundsätzliche Billigung des Planes mit Bedenken und Forderungen. Eine Realisierung, so hieß es in einer ersten Stellungnahme, setze "gleichberechtigte Vertragspartner im vollen Besitz ihrer Souveränität" voraus und sei daher mit den besatzungsrechtlichen Fesseln der Bundesrepublik nicht in Einklang zu bringen ${ }^{164}$. Minister Erhard machte darüber hinaus keinen Hehl aus seiner Absicht, sein Konzept der liberalen Wirtschaftsordnung durch die supranationale Hohe Behörde nicht gefährden lassen zu wollen ${ }^{165}$.

Angesichts dieser geballten Ladung von Vorbehalten aus den Reihen der Politik war es nur zu verständlich, daß auch aus der deutschen Industrie Kritik kam. Trotz aller Opferbereitschaft zum Wohle der deutsch-französischen Beziehungen verlangte sie, die wirtschaftlichen Nachteile des Planes nicht außer acht zu lassen, und mahnte die Aufhebung der Produktionsbeschränkungen, den Abbau der alliierten Kontroll- und Aufsichtsgremien, eine strukturelle Neuordnung der Eisenund Stahlindustrie sowie die bevorzugte Behandlung westdeutscher Investitionsvorhaben an ${ }^{166}$.

Adenauer hatte also mit Widerständen zu rechnen, was auch Schuman sah. Zur Stabilisierung ihres Konsenses schickte er Mitte Mai Monnet zur ausführlichen Berichterstattung nach Bonn. Nur widerwillig erteilte die Hohe Kommission die Erlaubnis zum Gespräch mit dem Bundeskanzler, untergrub diese bilaterale Kon-

159 S. AMAE, Europe 1944-1960, Allemagne, Bd. 566, Bl. 141 f., Aufzeichnung der Unterabt. Zentraleuropa im MAE, 6. 7.1950 (Konzept CA).

160 PA, SFSP, Bd. 289, Bl. 3 f., Bundesministerium für den Marshallplan, Az. II/2c-4/31, 24. 6. 1950, Vertraulich.

161 S. Erklärung Blüchers in der Sitzung des FDP-Bundesvorstandes, 17. 7. 1950, in: Wengst (Bearb.), Sitzungsprotokolle 1949-1954, S. 91.

$162 \mathrm{Vgl}$. Jeutter, EWG, S. 95-97.

${ }^{163}$ S. Interne Besprechung im BMWi vom 10. 5. 1950, 11. 5. 1950, in: BDFD II, S. $581 \mathrm{f}$.

164 Schalfejew an Adenauer, I A-2122/50, 11. 5. 1950, in: Küsters, Bonn und der Schumanplan, S. 8385, hier S. 84

165 Vgl. Hentschel, Ludwig Erhard, S. 127-130; Küsters, Streit, S. 338; Roussel, Jean Monnet, S. 550 f.

166 Vgl. Aufzeichnung Sohl, 2. 6. 1950, in: BDFD II, S. 596-606; Henle an Adenauer, Aufzeichnung, 10. 6. 1950, in: ebd., S. 606-611; zur Einstellung der Wirtschaftsvereinigung Eisen- und Stahlindustrie vgl. Bührer, Ruhrstahl, S. 170 f. u. 205; zur Haltung der deutschen Industrie gegenüber der europäischen Integration insgesamt vgl. zusammenfassend: ders., Federation. 
sultation von Regierung zu Regierung doch implizit das Besatzungsstatut. Ihr war natürlich klar, daß der Schuman-Plan ihre Existenzgrundlage allmählich in Frage stellte, weil nur eine ,souveräne' Bundesrepublik an den zukünftigen Verhandlungen teilzunehmen vermochte ${ }^{167}$. Adenauer mußte diese Entwicklung natürlich recht sein. Dennoch sah er dem Treffen mit Skepsis entgegen. Auch Monnet wirkte nervös und unruhig168. Indes, die eineinhalbstündige Unterredung verlief „günstiger und konstruktiver" als erwartet ${ }^{169}$, begründete gar einen lange währenden „contact amical“ zwischen beiden Politikern ${ }^{170}$. Geschickt räumte Monnet letzte Vorbehalte aus, betonte den im wesentlichen politischen Grundgedanken des Schuman-Planes, dem er sogar eine moralische Komponente testierte. Die bisherigen Integrationsversuche krankten seiner Meinung nach daran, daß sie eine Föderation souveräner Staaten anvisierten. Notwendig sei aber ein supranationaler Ansatz, der vor allem im Bereich der deutsch-französischen Beziehungen, dem neuralgischen Punkt in Europa, zum Ziel führen könne. Frankreich wolle die Beziehungen zur Bundesrepublik auf eine gänzlich neue Basis stellen und das Trennende, insbesondere die Kriegsindustrien, zum gemeinsamen Nutzen wenden. Adenauer pflichtete dem bei, hob ebenfalls die moralische Seite des Unternehmens hervor und zugleich die europapolitische Dimension: „L'Allemagne [...] sait que son sort est lié au sort de l'Europe occidentale“171.

Allerdings traten in dem einen oder anderen Gesprächspunkt auch gewisse Meinungsverschiedenheiten zu Tage. So favorisierte Adenauer im Gegensatz zu Monnet einen bilateralen Alleingang und erst in einer zweiten Stufe den Beitritt dritter Länder, was Frankreich aber aus Rücksicht auf seine europäischen Partner ablehnte ${ }^{172}$. Der prinzipiellen Idee Monnets eines Pools der Kohle- und Stahlkapazität stimmte der Kanzler hingegen ebenso uneingeschränkt zu wie dem Ziel einer bindende Beschlüsse verabschiedenden Hohen Behörde. Zugleich einigten sie sich darauf, bis zur grundsätzlichen politischen Einigung jede Einmischung der Ministerien abzuwehren und die kommenden Regierungsverhandlungen ausschließlich von „Leute[n] mit allgemeinem politischem und wirtschaftlichem Überblick" führen zu lassen ${ }^{173}$. Adenauer dachte dabei deutscherseits an Her-

167 S. McCloy an Acheson, Tel. 268, 23. 5. 1950, Confidential, in: FRUS 1950, Bd. 3, S. 705-709; Robertson an Bevin, Tel. 803, 24. 5. 1950, Immediate, Restricted, in: DBPO, 2. Reihe, Bd. 1, S. 83-86.

168 S. Bérard, Ambassadeur, Bd. 2, S. 318, Tb. 23. 5. 1950.

169 Interview Adenauers mit dem „Daily Telegraph“, in: BA, NL Blankenhorn, Bd. 4, Bl. 82-85, o.D.; im Auszug in: AdG 1950, S. 2405H; s.a. Schwarz, Adenauer, Bd. 1, S. 720.

170 AMAE, Europe 1944-1960, Généralités, Bd. 111, Bl. 54f., François-Poncet an MAE, Tel. 2405/06, 24. 5. 1950, Urgent, Réservé. Zu dem nicht spannungsfreien Verhältnis zwischen Adenauer und Monnet s.a. Wilkens, Jean Monnet.

171 Unterredung zwischen Adenauer und Monnet vom 23. 5. 1950, in: Fondation Jean Monnet pour l'Europe (Hg.), Naissance, S. 197-203, im Auszug in: BDFD I, S. 227-230, hier S. 229; vgl. Adenauer, Erinnerungen 1945-1953, S. 336f.; Aufzeichnung Blankenhorn, 24.5. 1950, in: AAPD 1949/50, S. 154-159; Blankenhorn, Verständnis, S. 104f., Tb. 23. 5. 1950; Monnet, Erinnerungen, S. 393-395; Legoll, Konrad Adenauer, S. 262-267; Roussel, Jean Monnet, S. 537-539; Schwarz, Adenauer, Bd. 1, S. 720-725.

172 S. Tb. Hans Schäffer, 3. 6. 1950, in: Schwabe (Hg.), Anfänge, S. 135. Während Erhard wie Adenauer die deutsch-französischen Gespräche im Anfangsstadium nicht durch Einbeziehung Dritter komplizieren wollte (Schneider an Erhard, Aufzeichnung, 22.5. 1950, in: BDFD II, S. 583-587), hielt Blücher eine derartige „deutsch-französische Ausschließlichkeit" für problematisch (PA, SFSP, Bd. 67, Bl. 19, Blücher an Adenauer, 22. 5. 1950).

173 Tb. Hans Schäffer, 3.6. 1950, in: Schwabe (Hg.), Anfänge, S. 135; s.a. ebd., S. 136; PA, Abt. 2, 
mann Josef Abs und den früheren Staatssekretär im Reichsfinanzministerium, Hans Schäffer, den er noch am selben Tag zu einer dringenden Unterredung nach Bonn bat ${ }^{174}$. Monnet sprach sich gegen Abs aus, nicht weil er in ihm einen überlegenen Verhandlungsführer fürchtete ${ }^{175}$, sondern weil Abs „während der Besatzungszeit für deutsche Stellen in Frankreich aufgetreten sei“176. Da auch Schäffer abwinkte, berief Adenauer Walter Hallstein, Hans Boden, Walter Bauer, Herbert Blankenhorn, Hans vom Hoff und Franz Grosse in die deutsche Delegation ${ }^{177}$. Mit dieser Zusammensetzung aus Männern seines Vertrauens konnte er sich dann leichter der Anregung der um ihren Einfluß fürchtenden Kabinettskollegen anschließen, einen Ministerausschuß unter dem Vorsitz des Kanzlers mit Blücher, Erhard, Schäffer und Storch einzusetzen ${ }^{178}$. Im gemeinsamen Pressekommuniqué, mit dem Adenauer Monnet „eine wirksame diplomatische Waffe“ 179 in den Auseinandersetzungen um die englische Teilnahme in die Hand gab, bekundeten sie „völlige Übereinstimmung“ der Auffassungen und ein großes Interesse „an einer schnellen Verwirklichung des Vorschlages“180. Sollte der Besuch zu einem „Meilenstein auf dem Weg zur Einigung und Einheit“" werden, fragten sich die Gazetten, oder aber würde die Geschichte ihn „als ein letztes Alarmläuten vor Toresschluß" verzeichnen ${ }^{181}$ ?

In den Regierungen in Paris und Bonn neigte man voll Optimismus zur ersten Einschätzung. Die vom Abschluß der Saarkonventionen Anfang März eingeläutete „période des oppositions et des chicanes“ sei vorbei, notierte Bérard in seinem Tagebuch. Sicher, so fuhr er fort, die Ablehnung des Projektes durch Schumacher sei ebenso gewiß wie Adenauersche Manöver voraussehbar, doch könne weder das eine noch das andere Frankreich von seinem Weg abbringen ${ }^{182}$. Und FrançoisPoncet kam nicht umhin festzustellen, daß der Kanzler jenen, die ihn nach den Interviews mit Kingsbury-Smith belächelt hatten, nun die Stirn bieten könne. Denn der Schuman-Plan liefere ihm „une revanche éclatante“ gegenüber seinen Gegnern, „une consécration“ in den Augen seiner Anhänger ${ }^{183}$. Auch in der französischen Presse errang Adenauer einen klaren Sieg über Schumacher, weil seine Politik die einzige zu sein schien, „qui soit positive"184.

Tatsächlich, so faßte eine die Reaktionen im Ausland vergleichende Aufzeichnung des Quai d'Orsay zusammen, erfuhr der Schuman-Plan in der Bundesrepu-

Bd. 744, Bl. 70f., Schäffer an Adenauer, 24. 5. 1950; Kabinettssitzungen, 12. u. 16. 6. 1950, in: Kabinettsprotokolle, Bd. 2, S. 453 u. $462-464$.

174 S. Tb. Hans Schäffer, 3. 6. 1950, in: Schwabe (Hg.), Anfänge, S. 136. Zur Biographie Schäffers ausführlich: Wandel, Hans Schäffer.

175 In diesem Sinne: Köhler, Adenauer, S. 608.

$176 \mathrm{~Tb}$. Hans Schäffer, 3. 6. 1950, in: Schwabe (Hg.), Anfänge, S. 136.

177 S. Adenauer an Monnet, 16.6. 1950, Entwurf, in: Adenauer, Briefe 1949-1951, S. 231f.; Bührer, Ruhrstahl, S. 180 f.

178 S. Kabinettssitzungen, 12. u. 16. 6. 1950, in: Kabinettsprotokolle, Bd. 2, S. 453 u. $462-464$.

179 Schwarz, Adenauer, Bd. 1, S. 725.

180 PA, Abt. 2, Bd. 744, Bl. 25, PIB-Mitteilung, Nr. 507/50, 23. 5. 1950.

181 Artikel Grüssens, in: „Mannheimer Morgen“, 24. 5. 1950, auch in: BDFD III, S. 187-189, hier S. 187.

182 Bérard, Ambassadeur, Bd. 2, S. 315, Tb. 14. 5. 1950.

${ }^{183}$ François-Poncet an Schuman, Nr. 609/CM, 21. 5. 1950, in: François-Poncet, Rapports mensuels, Bd. 1, S. 277.

184 „Le Monde“, 17. 6. 1950, im Auszug auch in: BDFD III, S. 194 f., hier S. 195. 
blik die lebhafteste Zustimmung. Motive und Ziele dieser Haltung blieben dem französischen Außenministerium freilich nicht verborgen:

- der Wunsch nach einer Fusion der deutschen und französischen Kohle- und Stahlproduktion als Basis einer europäischen Integration;

- die Absicht, als gleichberechtigtes Mitglied in die Gemeinschaft der europäischen Demokratien aufgenommen zu werden;

- die Möglichkeit zur Produktionssteigerung im Stahlbereich;

- die Tendenz, mit dem Schuman-Plan das Saarproblem zu lösen;

- die Perspektive neuer Absatzmärkte für die deutsche Industrie, etwa in Afrika ${ }^{185}$.

Eine Ausnahme von dieser im großen und ganzen positiven Reaktion in den politischen Kreisen der Bundesrepublik bildete wie schon bei der Frage des Beitritts zum Europarat die Sozialdemokratie 186. Sie begrüßte das Projekt zunächst im Prinzip, drängte aber zugleich auf die Aufhebung des Ruhrstatuts und warnte vor der Errichtung eines internationalen Kartells ${ }^{187}$. Unterstützung erfuhr die SPD von Teilen ihrer französischen Schwesterpartei, namentlich von Guy Mollet, Generalsekretär der SFIO, seit dem Tod Léon Blums im März im Besitz der „direction effective, morale et intellectuelle" der Partei ${ }^{188}$ und seit Juli Ministre d'Etat chargé du Conseil de l'Europe. Geboren am 2.1. 1906 in Flers im Departement Orne, hatte die Gasvergiftung seines Vaters im Ersten Weltkrieg ihn schon früh zu politischem Engagement geführt. 1921 trat er in die Sozialistische Jugend von Le Havre, zwei Jahre später in die SFIO ein und betätigte sich neben seinem Lehramtsstudium seit 1927 auch auf gewerkschaftlicher Ebene. Im Zweiten Weltkrieg konnte er nach kurzer Gefangenschaft aus Deutschland fliehen, arbeitete als Englischlehrer und schloß sich dem Widerstand an. Im Oktober 1944 übernahm Mollet die Departementsleitung der Résistancegruppe „Organisation civile et militaire" in Arras. Nach der Befreiung wählte ihn die Stadt 1945 zu ihrem Bürgermeister; im selben Jahr wurde er Parlamentsabgeordneter des Pas-de-Calais, Ämter die er bis zu seinem Tode 1975 nicht wieder aufgeben sollte. Zum jahrelang „unentbehrlichsten Politiker der IV. Republik“ 189 erhob ihn die überraschende Wahl 1946 zum Generalsekretär seiner Partei. Mollet machte sich als Wortführer jener Stimmen einen Namen, die die SFIO nach links öffneten und mehr Gemeinsamkeiten mit den Kommunisten suchten, ohne die ideologische Distanz außer acht zu lassen. Zehn Jahre später erhielt Mollet, der 1946/47 und 1950 bis 1952 Staatsminister für die Beziehungen zum Europarat war, die Chance, als Chef einer Mitte-Links-Minderheitenregierung eigene politische Ziele zu realisieren. Mit sechzehn Monaten sollte sie nicht nur das höchste Lebensalter aller Kabinette der

${ }_{185}$ S. AMAE, Europe 1944-1960, Généralités, Bd. 111, Bl. 115-137, Aufzeichnung der Abt. Europa im MAE, 1.6. 1950 (Konzept PP); s.a. ebd., Bl. 225-228, Aufzeichnung des MAE, 15.6. 1950. Lacroix-Riz bezeichnet die Direction d'Europe als Verfasser des Dokuments (Lacroix-Riz, Paris et Washington, S. 243). Zu den ersten Auslandsreaktionen s.a. Bossuat, La France, Bd. 2, S. 749 f.

186 Vgl. grundsätzlich: Hrbek, SPD, S. 102-126; Klotzbach, Sozialdemokratie; Paterson, SPD, S. 4969.

${ }_{187}$ S. Grundsatzreferat Schumachers auf dem Parteitag in Hamburg, 22. 5. 1950, in: Schumacher, Reden, S. 762-767; Bundestagsrede Schumachers, 13.6. 1950, in: BT, Sten. Ber., Bd. 4, S. 2474-2477; Merseburger, Kurt Schumacher, S. 468-471.

188 Lefebvre, Guy Mollet, S. 133.

189 Weisenfeld, Geschichte Frankreichs, S. 51. 
IV. Republik erreichen, sondern auch eine Reihe wichtiger politischer Leistungen vollbringen: den Beitritt zur EWG, den Abschluß des Saarabkommens, die Schaffung der praktischen Voraussetzungen für den schnellen Aufbau der französischen Atommacht, die Vorbereitung eines Rahmengesetzes, das den schwarzafrikanischen Kolonien eine Halbautonomie einräumte, schließlich den Beginn der Entkolonialisierung in Nordafrika. Wie einflußreich er auch in den folgenden Jahren blieb, zeigt nicht zuletzt die Mai-Krise 1958, in der er nach Staatspräsident Coty wohl die zweitwichtigste Rolle spielte und maßgeblich zu ihrer legalen und friedfertigen Beendigung beitrug. Als entschiedener Anhänger eines freien und unabhängigen Europa der dritten Kraft trat Mollet für einen supranational geeinten Kontinent ein, der das wiedervereinigte Deutschland umschloß und dessen Neutralisierung verhinderte ${ }^{190}$.

Dennoch wetterte Mollet gegen den Schuman-Plan als „l'expression de la politique vaticane" ${ }^{191}$, setzte sich aber mit seiner Sichtweise in der SFIO nicht durch. Die Mehrheit hörte auf die Argumente von André Philip oder Salomon Grumbach, die die Initiative der Regierung befürworteten und der deutschen Schwesterpartei nationalistisches Denken vorwarfen ${ }^{192}$. Auf Kritik stieß das Vorgehen Schumans hingegen bei den Gaullisten, weil sie zunächst eine praktische Übereinkunft mit den Deutschen und auf deren Basis eine „fédération européenne encadrant l'Allemagne" verlangten ${ }^{193}$. Kompromißlose Gegner besaß das Vorhaben auf der parlamentarisch äßßrsten Linken und Rechten ${ }^{194}$. In Opposition zu ihm stand aber auch die französische Stahl- und die Chemieindustrie, die um ihre Wettbewerbsfähigkeit fürchteten ${ }^{195}$.

Trotz aller Genugtuung über die weithin positiven Signale aus der Bundesrepublik blieb die französische Diplomatie angesichts der damit verbundenen weitreichenden Erwartungen vorsichtig. Sicher, die Frankophilie im deutschen Volk war nun allenthalben sichtbar, doch diesen „désir ancien et profond d'accord avec la France" hatte François-Poncet auch schon bei den Nazis gespürt. Selbst Hitler, so erinnerte er seinen Minister in diesen Tagen, hatte ihm gegenüber den offenbar ehrlichen Wunsch geäußert, ,,que l'on m'élevât un jour une statue comme à l'homme qui aurait réconcilié l'Allemagne et la France““196. Im Quai d'Orsay nahm man diese Warnungen sehr ernst. Würde sich der deutsche Wunsch nach Verständigung nicht sofort in sein Gegenteil umkehren, wenn sich die Hoff-

190 Zu Person und Politik Mollets vgl. Bossuat, Guy Mollet; Lefebvre, Guy Mollet; eine kurze biographische Skizze in: Yvert (Hg.), Dictionnaire, S. $823 \mathrm{f}$.

191 Erklärung Mollets in der Sitzung des SFIO-Parteivorstands, 10. 5. 1950, im Auszug in: BDFD III, S. 174-178, hier S. 174.

192 Vgl. Rede Grumbachs auf dem Parteitag der SFIO vom 26. 5.-29. 5. 1950, im Auszug in: ebd., S. 191-194; Resolution des SFIO-Parteivorstands, 10.5. 1950, in: ebd., S. 178 f.; Artikel von Philips in "Allemagne", Juni/Juli 1951, im Auszug in: ebd., S. 196-198; zur Haltung der SFIO insgesamt vgl. Latte, Europapolitik, S. 27-32; Loth, Sozialismus, S. 265-270; Schaeffer, Recherche, S. $117-120$.

193 Interview de Gaulles, 10. 7. 1950, in: Jouve, Le Général de Gaulle et la construction de l'Europe, Bd. 2, S. 168; s.a. Bjøl, L'Europe, S. 219.

194 Vgl. ebd., S. 234-236; Manin, RPF, S. 83-86; Latte, Europapolitik, S. 23-39.

195 Vgl. Mioche, Patronat; Willis, France, S. 94-98.

196 Zitiert nach: François-Poncet an Schuman, Nr. 609/CM, 21. 5. 1950, in: François-Poncet, Rapports mensuel, Bd. 1, S. 277; s.a. AMAE, Europe 1944-1960, Généralités, Bd. 111, Bl. 14-16, Trutie de Varreux an François-Poncet, Nr. 288/HC/OBS/ S-H-LMM, 16. 5. 1950. 
nungen nicht erfüllten? Hing die Hochstimmung in der Bundesrepublik über den Schuman-Plan nicht auch damit zusammen, daß die Deutschen in ihm einen Beitrag zum Aufbau einer „Dritten Kraft“ zwischen den Weltmächten und zum Neutralismus sahen ${ }^{197}$ - ein Konzept, von dem sich der Schuman-Plan mit seiner impliziten Funktion der westlichen Stabilisierung doch subkutan distanzierte $^{198}$ ?

Ungeachtet derartiger Überlegungen und mancherlei Befürchtungen hielt der französische Außenminister an ,seinem" Plan fest. Auch die englische Verweigerungshaltung konnte Schuman nicht beirren, wiewohl er in einem längeren Noten- und Memorandenwechsel - vergeblich oder vorgeblich - versuchte, London umzustimmen. Als die angesprochenen fünf Staaten mit Frankreich am 3.6. in einem Kommuniqué den Willen zum Eintritt in konkrete Verhandlungen erklärten, blieb Großbritannien abseits stehen ${ }^{199}$ - eine tiefe Zäsur in den französisch-englischen Beziehungen, die im Quai d'Orsay zumal vor dem Hintergrund ihrer deutschlandpolitischen Implikationen keineswegs uneingeschränkt begrüßt wurde. Zwar galt die Gefahr eines deutschen Übergewichts in Europa als nicht akut und die Kooperation mit den Deutschen für den Aufbau Europas erforderlich, zumal Frankreich weiterhin über wirksame Kontrollmittel verfügte. Dennoch schien es sinnvoll, sich stets „leur penchant naturel“ vor Augen zu führen und im Kopf zu halten, daß die englische Teilnahme an der europäischen Integration doch eines Tages notwendig werden könnte. „Et nous ne pourrons jamais être sûrs de l'appui de Washington si les Britanniques sont résolus à contrecarrer nos projets“. Doch gerade auf die Haltung der Amerikaner kam es an, wenn man den Erfolg wollte200.

\section{Deutsche und Franzosen „Seite an Seite“}

Gleichwohl - die Marschrichtung lag fest. Am 20. 6. eröffnete Schuman in Anwesenheit der sechs Regierungsdelegationen die Konferenz über die Verhandlungen zur Europäischen Gemeinschaft für Kohle und Stahl. In einer recht pathetischen Rede im Uhrensaal des Quai d'Orsay stellte er abermals die Bedeutung der Stunde für die deutsch-französischen Beziehungen in den Mittelpunkt seiner Ausführungen: Es gehe darum, beide Nationen in einem Werk des Friedens miteinander zu verbinden, um der europäischen Gemeinschaft die latente Ursache von Mißtrauen

197 S. ebd., Bl. 152-156, Aufzeichnung der Abt. Europa im MAE, 5. 6. 1950 (Konzept FS), im Auszug in: BDFD I, S. 230-232, hier S. 231.

198 Vgl. Loth, Europäische Integration, S. 242 f.; ders., Abschied, S. 183; Mélandri, Etats-Unis, Bd. 2, S. 561-563.

199 S. Sechs-Mächte-Kommuniqué, 3.6. 1950, in: EA 1950, S. 3173; der französisch-englische Entscheidungsprozeß wird dokumentiert in: DBPO, 2. Reihe, Bd. 1, S. 1-155; EA 1950, S. 3167-3174; Massigli, Comédie, S. 196-207; vgl. grundlegend: Dell, Schuman Plan; s.a. Bell, France, S. 105-122; Bullen, British Government; zur englischen Europapolitik der ersten Nachkriegsjahre ausführlich: Schmidt (Hg.), Großbritannien; Wurm, Großbritannien; Young, Britain; ein erhellender historischer Vergleich der britischen Europapolitik nach den beiden Weltkriegen bei: Wirsching, Europapolitik.

200 AMAE, Europe 1944-1960, Généralités, Bd. 111, Bl. 152-156, Aufzeichnung der Abt. Europa im MAE, 5. 6. 1950, im Auszug in: BDFD I, S. 230-232, hier S. 232; vgl. Lacroix-Riz, Paris et Washington, S. 247, mit falschem Datum 9.6. 1950; zu den Bedenken innerhalb des Quai d'Orsay über den antienglischen Kurs Monnets und Schumans s.a. Bérard, Ambassadeur, Bd. 2, S. 324-326, Tb. 12.6. 1950. 
und Angst zu entreißen. Auf der Basis dieser friedfertigen Zusammenarbeit sei dann ein solides Gebäude zu errichten, das allen europäischen Staaten guten Willens offen stünde ${ }^{201}$. Am Tage nach der feierlichen Begrüßung präzisierte Monnet in ersten Treffen der Delegationschefs und in den Besprechungen mit den einzelnen Vertretungen ${ }^{202}$ die französischen Vorstellungen ${ }^{203}$. Vom Originalkonzept, wie es am 9. 5. dargelegt worden war, sollte nach den monatelangen Verhandlungen nicht allzuviel übrig bleiben. Nachdem er schon zu Beginn des Monats ersten Bedenken der BENELUX-Staaten vor einer „Diktatur“ der Hohen Behörde mit dem Gedanken der politischen Verantwortung dieses Gremiums gegenüber einer aus den nationalen Volksvertretungen gewählten parlamentarischen Körperschaft und der Möglichkeit eines Mißtrauensvotums entgegengetreten war ${ }^{204}$, charakterisierte Monnet dieses Organ nun als Gremium neutraler Persönlichkeiten, die von den Regierungen ernannt werden sollten. Ohne auf Details einzugehen, signalisierte er der deutschen Abordnung, daß man mit Blick auf das gemeinsame Verhältnis „intern zu einer Verständigung über die Beteiligung der beiden Länder an den Sitzen kommen werde“205. Als neuen Aspekt entwickelte er am 21. 6. den Gedanken, der Hohen Behörde durch „Entnahme aus den Kohle- und Stahlproduktionen“ eigene Ressourcen zukommen zu lassen und sie so von den Regierungen unabhängig zu machen ${ }^{206}$.

Drei Tage später legte der französische Delegationschef dann in einer Art „Überrumpelungstaktik“207 ein aus 40 Artikeln bestehendes „Document du travail“ vor, das fortan die Grundlage für die multilateralen Verhandlungen abgab. Es visierte die Schaffung einer Hohen Behörde zur Sicherstellung der Versorgung mit Kohle und Stahl zu gleichen Bedingungen, Beseitigung aller künstlichen Behinderungen normaler Wettbewerbsverhältnisse und die Angleichung der Arbeits- und Lebensbedingungen der Arbeiter auf höherem Niveau an. Durch die Preispolitik sollte sie die Erzeuger vor unlauteren Praktiken schützen und Lohnkürzungen als Mittel des Wettbewerbs verhindern. Die Vorlage sah außerdem die Aufgabe sämtlicher Zölle im Montanbereich sowie quantitativer Beschränkungen und für die Übergangszeit einen Ausgleichsfonds vor, um Produktionsverlagerungen schrittweise vornehmen zu können208.

Beim deutschen Delegationschef Walter Hallstein ${ }^{209}$ stieß das Papier auf entschiedene Vorbehalte. Vor allem kritisierte er die Vielzahl technischer Einzelhei-

201 S. Rede Schumans, 20.6. 1950, in: L'Année politique 1950, S. 312-314.

202 Die Zusammensetzung der sechs Delegationen bei: Dichgans, Montanunion, S. 58-60.

${ }^{203}$ S. Sitzung vom 21. 6. 1950, in: BDFD II, S. 617-621; Sitzung vom 22. 6. 1950, in: AAPD 1949/50, S. 194-202; PA, SFSP, Bd. 53, Bd. 62, Bl. 19-25, Sitzung vom 23. 6. 1950, Mo/P/2.

${ }_{204}$ S. AN, 363 AP 17, Papiers Mayer, Aufzeichnung an das Comité interministeriel, 12. 6. 1950; zur Haltung der BENELUX-Staaten vgl. grundlegend: Griffiths, Benelux-Staaten; Dumoulin, La Belgique; Kersten, Surprise; Roussel, Jean Monnet, S. 555-561.

205 Unterredung zwischen Monnet und der deutschen Delegation vom 22.6. 1950, Mo/P/1, in: AAPD 1949/50, S. 190-194, hier S. $193 \mathrm{f}$.

206 Monnet, Erinnerungen, S. 410.

207 Küsters, Bonn und der Schumanplan, S. 85.

${ }_{208}$ S. PA, SFSP, Bd. 93, Bl. 3-56, Document du travail, 25.6. 1950, in deutscher Übersetzung ebd. Bl. 57-97; am 27.6. 1950 stellte Monnet das Dokument der Presse in einer Kurzfassung vor (BDFD II, S. 612-624); eine leicht gekürzte deutsche Übersetzung in: EA 1950, S. 3409-3411.

${ }^{209}$ Zum Verhältnis zwischen Hallstein und Monnet s. Monnet, Erinnerungen, S. 405; Blankenhorn, Verständnis, S. 109, Tb. 16.6. 1950. 
ten und Planungselemente, wodurch seiner Meinung nach die Gefahr bestand, daß die Verfechter der liberalen Wirtschaftsordnung in der Bundesrepublik , in dem Plan irre gemacht“ würden, obwohl es sich bei ihnen um seine „überzeugtesten Anhänger" handelte210. Ungeachtet derartiger Kritikpunkte waren die Deutschen aber aufgrund der politischen Tragweite des gesamten Projektes prinzipiell entschlossen, „à appuyer jusqu'au bout les vues de la France" ${ }^{211}$. Nachdem man sich in der ersten Verhandlungsrunde darauf verständigt hatte, eine Hohe Behörde mit ausgedehnten Kompetenzen zu schaffen und durch eine Art Parlament kontrollieren zu lassen, kehrten die Bonner Vertreter Ende Juni zufrieden und mit der Genugtuung an den Rhein zurück, daß Deutsche und Franzosen seit langer Zeit wieder "Seite an Seite" marschierten ${ }^{212}$.

Vor dem Hintergrund der Widerstände aus den BENELUX-Staaten gegen den vorgesehenen institutionellen Rahmen hielt Schuman es für ratsam, sich in der Verhandlungspause mit gleichlautenden Mitteilungen erneut an die fünf Regierungen zu wenden, um noch einmal den zentralen Gedanken seines Planes herauszukehren. Frankreich beabsichtige, so hieß es dort, mit der Errichtung der Hohen Behörde ein erstes Element zur europäischen Einigung zu schaffen und damit einen Beitrag zur deutsch-französischen Versöhnung wie zur Aufrechterhaltung des Friedens zu leisten. Alle Partner seien daher aufgerufen, ihre nationalen Interessen zugunsten des Gemeinwohls zurückzustellen ${ }^{213}$. Zweifellos sprach er Adenauer mit diesen Worten voll aus dem Herzen. Auch der Kanzler hielt die Errichtung einer lebensfähigen Gemeinschaft der westeuropäischen Völker für unabdingbar und mahnte daher in seinem Antwortschreiben an, „egoistische wirtschaftliche Interessen der großen Aufgabe, der Schaffung einer echten Föderation, unter[zu]ordnen" 214 .

Kurz bevor er es abschickte, hatte Hallstein der Bundesregierung über den Gang der Dinge berichtet und vom weisungsbefugten Kabinettsausschuß die Ermächtigung erhalten, auf der Basis des französischen Arbeitsplans weiter zu verhandeln ${ }^{215}$. Ehe Hallstein seine Direktiven in der nächsten Sitzung der Delegationen darlegte, informierte er als Zeichen der neuen deutsch-französischen Harmonie am 2. 7. Monnet vorab und verlangte dabei als notwendigen weiteren Arbeitsschritt - in einer gewissen Anlehnung an die Vorbehalte der BENELUX-Staaten die Festlegung allgemeiner Grundsätze für die Tätigkeit der Hohen Behörde. Der deutsche Delegationschef definierte sie als „Zentrum für gegenseitige Informatio-

210 PA, SFSP, Bd. 83, Bl. 27 f., Deutscher Verhandlungsausschuß für den Schuman-Plan, Tb. 25. 6. 1950, Geheim. Zu Hallsteins Europapolitik vgl. zusammenfassend: Bärenbrinker, Hallsteins Europakonzeption.

211 AMAE, Europe 1944-1960, Généralités, Bd. 112, Bl. 37, François-Poncet an MAE, Tel. 3087/88, 27. 6. 1950, Réservé; s.a. Bérard, Ambassadeur, Bd. 2, S. 333, Tb. 29. 6. 1950; McCloy an Acheson, Nr. 5595, 29. 6. 1950, Secret, Priority, in: FRUS 1950, Bd. 3, S. 739. Daß die politische Motivation bei der Entstehung des Schuman-Plans und den Regierungsverhandlungen 1950/51 im Vordergrund standen, betonen auch: Diebold, Schuman Plan, bes. S. 8-16; Milward, Reconstruction, S. 407; Poidevin, Robert Schuman, S. 244 f.; Willis, France, S. 80.

212 PA, Abt. 3, AZ 221-09, Bd. 1, von Kessel an Kordt, 4. 7. 1950.

213 S. ebd., Abt. 2, Bd. 744, Bl. 293-295, François-Poncet an Adenauer, 28. 6. 1950.

214 Adenauer an Schuman, 30. 6. 1950, in: Beyer, Schuman, S. 109.

215 S. Aufzeichnung Kab/1/19, Vertraulich, o.D., in: BDFD II, S. 624-627; Kabinettssitzung vom 29.6. 1950, in: Kabinettsprotokolle, Bd. 2, S. 492 f; Unterredung zwischen Adenauer und der AHK vom 29.6. 1950, in: AAPD, Adenauer und die Hohen Kommissare 1949-1951, S. 218. 
nen und dauernde Kooperation", das keineswegs völlig seinem eigenen Ermessen überlassen werden dürfe. Der Sinn des Schuman-Plans müsse darin liegen, „die natürliche Auslese im Produktionsprozeß“ mittels eines einheitlichen Marktes im Gesamtgebiet der vertragschließenden Staaten sicherzustellen, in dem sämtliche Subventionen bzw. die "künstlichen und politischen Differenzierungen" gestrichen würden. Dem durch Krieg und Nachkriegsverhältnisse bedingten unterschiedlichen Stand des technischen Produktionsapparates sei dabei Rechnung zu tragen. Monnet erklärte sich mit dieser Grundlinie durchaus einverstanden. Auch die von Hallstein geforderte Einbeziehung der Überseegebiete in den einheitlichen Markt begrüßte er. Demgegenüber stieß dessen Forderung nach Einrichtung eines permanenten Schiedsgerichtes als „Hüter der Objektivität der Hohen Behörde" bei ihm auf Skepsis ${ }^{216}$, weil er befürchtete, eine derartige Instanz könne sich mit der Zeit zum „Träger der eigentlichen Autorität“ etablieren²1. Ohne Einigung blieb schließlich auch die Frage der Einflußnahme der Hohen Behörde auf die Preisgestaltung: Während Monnet durch sie Minimum- und Maximumpreise festsetzen lassen wollte, lehnte Adenauer Rationierungen, Kontingentierung und Preisfixierungen $a b^{218}$, so daß Hallstein der Hohen Behörde nur die Festlegung der Prinzipien der Preisbildung zugestehen konnte 219.

Als die Delegationen am 3.7. ihre Unterredungen fortsetzten, stimmten die Leiter, die stets in der abgeschlossenen Atmosphäre der Rue de Martignac tagten, dem französischen Konzept grundsätzlich zu, machten aber zahlreiche Änderungswünsche geltend. In einer eng an die Regierungslinie gehaltenen Erklärung hob Hallstein abermals die vornehmlich politische Bedeutung des Projektes hervor. Wenngleich er die vom Kabinett festgelegten Grundsätze trotz der von Monnet geäußerten Vorbehalte nicht relativierte, ließ er keinen Zweifel darüber aufkommen, wie sehr die Bundesregierung die durch den Plan aufgeworfenen wirtschaftlichen Probleme zu lösen gewillt war ${ }^{220}$. Um Einvernehmen über die organisatorische Grundstruktur zu erzielen, wurden auf Vorschlag Monnets fünf Ausschüsse gebildet, von denen die von ihm selbst geleitete institutionelle Arbeitsgruppe sich als die wichtigste erwies 221.

Zwei Grundsatzfragen bestimmten in der Folge die Diskussionen: Woher bekommt die Hohe Behörde die Autorität für ihr Handeln? Und wie kann sie kontrolliert werden? Die Franzosen beharrten auf der Ansicht, sie bezöge ihre Macht aus einem von den Parlamenten zu ratifizierenden Vertrag, während die Nieder-

216 Rede Hallsteins während der Sitzung der Delegationen vom 3.7. 1950, Mo/P/3, in: AAPD 1949/ 50, S. 224-229, hier S. 227 u. 228.

217 Unterredung zwischen der deutschen und der französischen Delegation vom 2. 7. 1950, in: BDFD II, S. 627-632, hier S. 627.

218 S. AMAE, DE-CE, Bd. 516, Bl. 1, Leroy-Beaulieu an Monnet, 27.6. 1950, Secret.

${ }^{219}$ S. Unterredung zwischen der deutschen und der französischen Delegation vom 2.7. 1950, in: BDFD II, S. 627-632; zum Problem der Preisgestaltung s.a. Goschler/Buchheim/Bührer, Schumanplan, S. 196-202; Griffiths, Schuman Plan Negotiations, S. 47-51.

220 S. Rede Hallsteins während der Sitzung der Delegationen vom 3. 7. 1950, Mo/P/3, in: AAPD 1949/50, S. 224-229; Vollsitzung der Delegationen vom 3. 7. 1950, Mo/P/5, in: ebd., S. 230-233; Roussel, Jean Monnet, S. 562-565.

$221 \mathrm{Zu}$ den übrigen zählten die Arbeitsgruppe für Produktion, Investitionen und Preise unter Etienne Hirsch, für Handelspolitik unter Charpentier, für soziale Fragen unter Uri und für Definition von Kohle und Stahl unter Desrousseaux (PA, SFSP, Bd. 62, Bl. 92, Vollsitzung der Delegationen, 4. 7. 1950, Mo/P/6). 
länder - bestärkt von Belgiern und Luxemburgern - die Regierungen als Rechtsquelle verstanden und deshalb dem Ministerrat ein gewisses Weisungsrecht zubilligen wollten ${ }^{222}$. Demgegenüber standen die italienische und die anfangs sehr behutsam auftretende deutsche Delegation eher auf der französischen Seite. So bezeichnete Hallstein nicht nur Kompetenz und Unabhängigkeit der Hohen Behörde als „Stützpfeiler für Europa"“223, sondern begrüßte auch den Gedanken ihrer Verantwortlichkeit gegenüber der parlamentarischen Versammlung, die einem europäischen Parlament den Weg bereite224.

In diesem Sinne argumentierte die deutsche Delegation vornehmlich föderalistisch, weil sie zunächst wohl eine echte Chance sah, dem Schuman-Plan eine bundesstaatliche Struktur zu geben ${ }^{225}$. Außerdem bestand für sie angesichts des die deutsche Souveränität beschneidenden Besatzungsstatuts kein Grund, einem Ministerrat Kontrollbefugnisse über die Hohe Behörde zu übertragen, konnte sie in diesem Gremium doch autark agieren. Die Bundesregierung dachte daran, den Ministerrat mit der Gemeinsamen Versammlung zu einem „Montan-Kongreß“ nach amerikanischem Vorbild dualistisch mit Zweikammersystem oder monistisch mit Einkammersystem zusammenzufassen ${ }^{226}$. Monnet aber lehnte die dualistische deutsche Lösung strikt ab und durchkreuzte auch die Bestrebungen der BENELUX-Staaten, die Schaffung einer mit echten Kompetenzen ausgestatteten supranationalen Behörde in das „Fahrwasser intergouvernementaler Zusammenarbeit" zu lenken 227. Am 20.7. erklärten sich daraufhin der holländische und der belgische Delegierte prinzipiell bereit, der Errichtung eines supranationalen Organisationssystems zuzustimmen. Da sie aber nunmehr versuchten, den Ministerrat gegenüber der Hohen Behörde zu stärken ${ }^{228}$, plädierte Monnet angesichts des prinzipiell erreichten Konsenses für eine größere Rolle der gemeinsamen parlamentarischen Versammlung, die zukünftig „unmittelbar von den europäischen Völkern" gewählt werden sollte229.

Vor dem Hintergrund der durch den Korea-Krieg und der Lancierung des Macmillan-Planes ${ }^{230}$ veränderten internationalen Situation drängte der Generalkommissar Anfang August auf ein rasches Ende der Beratungen. Den Delegationen riet er, sich auf einen Katalog konkreter Anweisungen für die Tätigkeit der Hohen Behörde im ersten Jahr zu beschränken. Angesichts der noch bestehenden vielfäl-

222 S. Sitzung des Institutionellen Ausschusses, 12. 7. 1950, Inst/P/1, in: AAPD 1949/50, S. 250-253; Griffiths, Benelux-Staaten, S. 265-267.

223 Zitiert nach: Monnet, Erinnerungen, S. 420.

${ }^{224}$ S. Rede Hallsteins während der Sitzung der Delegationen vom 3. 7. 1950, Mo/P/3, in: AAPD 1949, S. 224-229; PA, Abt. 3, AZ 221-09, Bd. 1, Pressekonferenz dess., 14. 7. 1950.

${ }^{225}$ S. ebd., Sitzung des Juristischen Sachverständigen-Ausschusses für den Schuman-Plan vom 17. 8. 1950, 19. 8. 1950; s.a. die Darstellung des deutschen Mitgliedes des juristischen Ausschusses Hermann Mosler (Mosłer, Entstehung).

226 Küsters, Verhandlungen, S. 84.

${ }_{227}$ Ebd., S. 86; s.a. Unterredung mit Monnet vom 27. 7. 1950, Mo/P/9, in: AAPD 1949/50, S. 283 f.

228 S. Sitzung des Organisations-Ausschusses vom 20. 7. 1950, Inst/P/2, Vertraulich, in: ebd., S. 269271; Sitzung dess. vom 21.7. 1950, in: ebd., S. 272 f.

${ }^{229}$ Hallstein an Blankenhorn, Tel. 2, Cito, 12. 7. 1950, in: ebd., S. 243-246, hier S. 246.

230 Zum Plan Macmillans eines Kohle- und Stahlpools unter dem Dach des Europarates vom 8. 8. 1950 s. Macmillan, Tides of Fortune, S. 201-209; zur Reaktion Monnets und Hallsteins s. Monnet, Erinnerungen, S. 424; PA, SFSP, Bd. 63, Bl. 33, Sitzung der Deutschen Europarat-Vertreter mit der Deutschen Delegation für den Schuman-Plan vom 13.8. 1950, Geheim, Teil 1. 
tigen Differenzen waren die Verhandlungsführer dafür jedoch nicht zu gewinnen. Hallstein ließ ihn unverblümt wissen, daß Adenauer mit einem baldigen Konferenzabschluß nicht einverstanden sei ${ }^{231}$. Dennoch faßten die Mitarbeiter Monnets die Beratungsergebnisse am 5. 8. in einem „Memorandum sur les institutions“ zusammen, das von den Delegationsleitern aber nur zum Teil akzeptiert wurde ${ }^{232}$. Zwar bestand im wesentlichen Einvernehmen darüber, mit der Hohen Behörde, dem Ministerrat, der Gemeinsamen Versammlung und dem Gerichtshof vier Organe mit supranationalem Charakter zu bilden ${ }^{233}$, doch zeigte sich bei der Diskussion der noch strittigen Punkte rasch der Kompromißcharakter dieses Übereinkunft. Hallstein bemängelte die geringe Berücksichtigung der am 2. 8. übergebenen deutschen Vorschläge und die bescheiden-supranationalistisch ausgefallenen französischen Vorstellungen hinsichtlich der Rolle des Parlamentes ${ }^{234}$. Auch die Rolle des Ministerrates galt aus seiner Sicht keineswegs als geklärt, hatte die deutsche Delegation diesem Gremium bisher überhaupt noch nicht zugestimmt, wohl aber erklärt, darüber diskutieren zu wollen. Hallstein akzeptierte weder den holländischen Plan, die Vollmachten des Ministerrates auch auf den Verteidigungssektor auszudehnen, noch den französisch-holländischen Vorschlag des Majoritätsprinzips bei Weisungen des Ministerrats. Vielmehr sollten dessen Befugnisse seiner Ansicht nach „klein gehalten“ bleiben und die Direktiven „einstimmig erfolgen“235.

Gegensätze gab es zwischen Bonn und Paris aber nicht nur in diesen institutionellen Fragen, sondern auch in bezug auf den einheitlichen Markt. In einem Memorandum über die Tätigkeit der Hohen Behörde während der Anlaufphase hatte Monnet für eine Übergangszeit die Forderung sowohl der Aufhebung der Zölle und Kontingente als auch der Schaffung gleicher Preise sowie der Etablierung von Ausgleichskassen aufgestellt ${ }^{236}$. Im Einklang mit sonstigen protektionistischen Maßnahmen gegen eine Ausweitung des deutsch-französischen Handelsvolumens ${ }^{237}$ verfolgte Paris offenbar das Ziel, den drohenden Einbruch der Ruhrindustrie in den französischen Markt solange zu verhindern, bis die Vorteile der Konkurrenten aufgehoben waren ${ }^{238}$. Insbesondere der geplante Mechanismus der

231 S. Unterredung zwischen Hallstein und Monnet vom 2. 8. 1950, Mo/P/10, in: AAPD 1949/50, S. $294 \mathrm{f}$.

232 S. PA, SFSP, Bd. 93, B1. 113-121, Memorandum, 5. 8. 1950; Sitzung des Institutionellen Ausschusses vom 4./5. 8. 1950, Inst/P/5, Vertraulich, in: AAPD 1949/50, S. 296-300.

${ }^{233}$ S. PA, SFSP, Bd. 56, B1. 20-79, Bericht über die Arbeit der Delegationen vom 20.6.-10. 8. 1950, in deutscher Übersetzung ebd., Bl. 89-147.

${ }^{234}$ S. ebd., Bd. 103, Bl. 74-76, Unterredung zwischen Hubert und Ophüls vom 2. u. 3. 8. 1950, Jur/P/ 9; ebd., Bl. 50-69, Institutionen des Schuman-Plans, Stand vom 10.8., Inst/P/6; ebd., Bd. 56, B1. 80-86, Bemerkungen der deutschen Delegation zu den französischen Berichten über die Verhandlungen vom 20. 6.-10. 8. 1950, Sonst/P/2a, 24. 8. 1950, Vertraulich.

${ }^{235}$ Ebd., Bd. 63, Bl. 29, Sitzung der deutschen Europarat-Vertreter mit der deutschen Delegation für den Schuman-Plan vom 13.8. 1950, Geheim, Teil 1; s.a. ebd., Bd. 67, Bl. 25-28, Aufzeichnung, 26. 7.1950 .

${ }_{236}$ S. ebd., Bd. 93, Bl. 157-161, Memorandum, 9. 8. 1950 (Übersetzung); vgl. Griffiths, Schuman Plan Negotiations, S. 54-61.

${ }_{237}$ Vgl. Seeliger an BMWi, FS V B 4a-39407/50, 9. 9. 1950, Durchschrift, in: BDFD II, S. 154f.; zu den am 20. 10. 1950 mit der Paraphierung eines neuen Abkommens beendeten schwierigen Handelsvertragsverhandlungen s. Vermerk der Abt. Außenwirtschaft im BMWi, V B 4a-45550/50, 21.11. 1950, in: ebd., S. 155-158; Lefèvre, Relations, S. 326-329.

$238 \mathrm{Vgl}$. Goschler/Buchheim/Bührer, Schumanplan, S. $198 \mathrm{f}$. 
Ausgleichskassen und der Preissenkung stieß in der Bundesregierung auf erhebliches Mißfallen ${ }^{239}$. Zwar war man sich in Bonn bewußt, für die Verwirklichung des einheitlichen Marktes Opfer in Form einer Anhebung der niedrigen deutschen Preise erbringen zu müssen. Man wollte aber eine nur allmähliche Angleichung vornehmen lassen und dadurch auch die erforderlichen Ausgleichszahlungen mildern. Paris beabsichtigte demgegenüber „das genaue Gegenteil, nämlich schnelle Herstellung des einheitlichen Marktes und hohe deutsche Zahlungen" in den Pool240. Im Sinne eines Kabinettsbeschlusses vom 23. 8.241 wirkten die deutschen Vertreter in ihren Besprechungen mit den französischen Kollegen deshalb am 29. und 31. 8. darauf hin, preissteigernde Maßnahmen möglichst zu verhindern und Lösungsmöglichkeiten in sogenannten technischen Mitteln zu finden. Monnet mußte schließlich seine ursprünglichen Vorstellungen zurückschrauben, konnte aber durchsetzen, daß gezieltes Lohndumping bzw. diskriminierende Preise verboten wurden und die Hohe Behörde die Fixierung von Höchst- und (im Krisenfall) Mindestpreisen vornehmen konnte ${ }^{242}$.

Derweil begann die zweite Verhandlungsphase über die materiellen Bestimmungen des abzuschließenden Vertragswerkes ${ }^{243}$. Anfang Oktober hatten sich die Abordnungen über die Zuständigkeiten der Organe weitgehend geeinigt und dabei insbesondere die Befugnisse der Hohen Behörde durch „ein fein gesponnenes Netz von Entscheidungs-, Zustimmungs- und Anhörungsrechten “ beschnitten ${ }^{244}$. Mitte des Monats berieten die Delegationschefs einen französischerseits am 10. 10. präsentierten Vertragsentwurf, der in einer ersten Redaktion schließlich am 9. 11. genehmigt wurde 245 . Vier Wochen später lag der Vertrag in groben Zügen vor $^{246}$. Bis zu seiner Unterzeichnung sollten indes noch vier lange Monate vergehen, Monate, in denen das Erreichte mehr als einmal äußerst gefährdet schien, weil sich in der Zwischenzeit die Geschäftsgrundlage für die Hauptprotagonisten grundlegend veränderte.

\section{Der Schuman-Plan vor dem Aus?}

Nach der Hausse des Sommers geriet das Verhältnis zwischen Bonn und Paris im Herbst 1950 in große Turbulenzen. Verantwortlich dafür zeichneten einerseits der Gewichtszuwachs der Bundesrepublik durch die nach dem Ausbruch des Koreakrieges im Zuge der amerikanischen Forderung nach einer deutschen Wiederbe-

${ }^{239}$ S. PA, SFSP, Bd. 63, Bl. $27 \mathrm{f}$, Sitzung der deutschen Europarat-Vertreter mit der deutschen Delegation für den Schuman-Plan vom 13.8. 1950, Geheim, Teil 1.

240 Ebd., Abt. 2, Bd. 745, Bl. 78-87, Gemeinsame Sitzung des Interministeriellen Ausschusses mit der Delegation für den Schuman-Plan vom 24. 8. 1950, Min/1, Vertraulich; s.a. Goschler/Buchheim/ Bührer, Schumanplan, S. 197.

${ }^{241}$ S. Kabinettssitzung, 23. 8. 1950, in: Kabinettsprotokolle, Bd. 2, S. 629-632.

${ }^{242}$ S. Unterredung zwischen Hallstein und Monnet vom 29.8. 1950, in: BDFD II, S. 634-637; vgl. Goschler/Buchheim/Bührer, Schumanplan, S. 200-202; Griffiths, Schuman Plan Negotiations, S. $50 \mathrm{f}$.

${ }^{243}$ Vgl. Schneider an Erhard, Vermerk, 26. 9. 1950, in: BDFD II, S. 637-642.

244 Küsters, Verhandlungen, S. 91.

${ }^{245}$ S. FJM, AMG 8/3/2, Projet d'organisation du traité, Oktober 1950; AN, 457 AP 30, Papiers Bidault, Première rédaction du projet de traité, 9.11.1950.

$246 \mathrm{Vgl}$. Monnet an Schuman, Memorandum, 30.11. 1950, in: Monnet/Schuman, Correspondance, S. 71-73; ders. an dens., Memorandum nebst Note générale, 4. 12. 1950, in: ebd., S. 74-89. 
waffnung gestärkte deutsche Verhandlungsposition, andererseits die nicht nur aus Bonner Sicht vorhandenen Widersprüche in der Pariser Deutschlandpolitik: Zwar betrachteten die Franzosen ihre Nachbarn im Rahmen des Schuman-Plans als gleichgestellt, trachteten aber ansonsten nach Kräften danach, diese Gleichberechtigung gerade zu verhindern ${ }^{247}$. Irritiert über die tatsächlichen Ziele der französischen Politik, fragten kritische Stimmen mit wachsendem Selbstbewußtsein in Deutschland zunehmend lauter nach der Notwendigkeit der Montanunion. Wirtschaftskreise, in denen die anfängliche positive Einstellung ohnehin mittlerweile einer „distanziert-skeptischen Beurteilung“ gewichen war ${ }^{248}$, meldeten in Anbetracht des sich abzeichnenden Stahlbooms immer größere Zweifel an ${ }^{249}$. Geradezu eine „Schockwirkung“250 löste an der Seine eine scharfe antifranzösische Attacke aus, die Robert Lehr wenige Tage vor seiner Ernennung zum Innenminister am 1. 10. in München öffentlich ritt ${ }^{251}$. Die Bestürzung fiel um so größer aus, als Schuman und Monnet die Gegner ihres Plans in Politik und Wirtschaft nur mit Mühe hatten umstimmen können252. Adenauer sah sich genötigt, zur Philippika Lehrs auf Distanz zu gehen. Am 5. 10. beteuerte Blankenhorn gegenüber Bérard das Festhalten der Bundesregierung an der Montanunion. Zur Begründung wies er aber nicht auf ihre politische Bedeutung für den Aufbau Europas oder die deutsche Außenpolitik, sondern lediglich auf den von einem Fehlschlag zu erwartenden herben Prestigeverlust für den Kanzler ${ }^{253}$.

Dessen Ukas ließ die Kritiker nicht verstummen. „Ein neuer Wind wehte, der Deutschland desorientierte“, so sah es Monnet ${ }^{254}$. Mit Unbehagen registrierte er, wie sich die stärker gewordene deutsche Stellung nicht nur in der juristischen Kleinarbeit in Paris, sondern auch in Bonn hinsichtlich der prinzipiellen Einschätzung des Projektes bemerkbar machte. Hatten die Deutschen bisher die Auffassung vertreten, der Schuman-Plan biete die einzige Möglichkeit zu einem effektiven eigenen Beitrag zur westlichen Verteidigung, sahen sie nun - in französischer Perspektive - plötzlich eine Chance zu einer Aufrüstung auf nationaler Ebene $^{255}$. Alarmiert von dieser anscheinenden oder scheinbaren deutschen Kehrtwende forderte Monnet Schuman in zwei Memoranden am 9. und 16. 9. zur Fortsetzung des seit Mai eingeschlagenen Weges sowie zur Akzeptierung eines deutschen Wehrbeitrags auf, „dans le cadre européen supranational d'un Plan Schuman élargi“256. Denn nur in einer solchen Perspektive sei es möglich, die nationale

\footnotetext{
247 S. Harvey an Bevin, Tel. 145, 1. 3. 1951, Priority, Confidential, in: DBPO, 2. Reihe, Bd. 1, S. 418420.

248 Bührer, Ruhrstahl, S. 176.

249 Vgl. ebd., S. 185.

250 PA, Abt. 3, AZ 221-09, Bd. 1, Aufzeichnung von Kessel, 23. 10. 1950.

251 Vgl. AdG 1950, S. 2634B; Schneider an Schalfejew, Vermerk, 25. 10. 1950, in: BDFD II, S. 642-645; Bührer, Ruhrstahl, S. $186 \mathrm{f}$.

252 S. PA, Abt. 3, AZ 221-09, Bd. 1, Aufzeichnung von Kessel, 23. 10. 1950.

${ }^{253}$ S. AMAE, Europe 1944-1960, Allemagne, Bd. 186, Bl. 187-189, François-Poncet an MAE, Tel. 5120/24, 5. 10. 1950, Secret, Réservé; s.a. die Äußerungen von Brentanos gegenüber der französischen Hohen Kommission (ebd., Généralités, Bd. 121, Bl.176f., de Guiringaud an MAE, Tel. 5655/57, 25. 10. 1950, Réservé); Bührer, Ruhrstahl, S. 187; Poidevin, Rôle, S. 107.

254 Monnet, Erinnerungen, S. 435.

255 S. Monnet an Schuman, Tel. , 14. 9. 1950, Urgent, Réservé, in: Monnet/Schuman, Correspondance, S. 56.

256 Ders. an dens., Memorandum, 16. 9. 1950, in: ebd., S. 58f., hier S. 59.
} 
Wiederbewaffnung der Bundesrepublik zu verhindern, Europa zu schaffen und Frankreich die im Frühsommer gewonnene "position de leader sur le continent" zu erhalten ${ }^{257}$.

$\mathrm{Zu}$ den zunehmend heftigeren deutsch-französischen Dissonanzen im Herbst 1950 sorgte jedoch nicht nur das Problem der Wiederbewaffnung, sondern zum wiederholten Male auch die Saarfrage ${ }^{258}$. Zu erheblichen Turbulenzen kam es außerdem im Hinblick auf die Internationale Ruhrbehörde (IRB). „Il s'agit avant tout", so hatte der Quai d'Orsay seine Position zur Ruhrfrage Ende 1949 definiert, "d'amorcer ainsi l'internationalisation, en vue de la paix, des industries lourdes occidentales et de faciliter notre action en faveur d'une fédération euro-

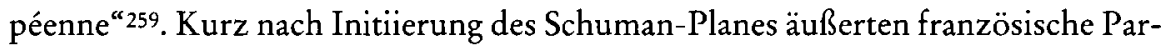
lamentarier die Sorge, das Projekt bereite der Ruhrkontrolle ein rasches Ende. Schuman beeilte sich daraufhin, ihnen Ende Mai in einer Rede vor der Außenpolitischen Kommission der Assemblée Nationale mit dem Argument entgegenzutreten, Deutschland bleibe den bestehenden Restriktionen unterworfen. Wenn die Mitglieder der Ruhrbehörde der neuen Organisation beiträten, könne freilich eine Fusion beider Institutionen ins Auge gefaßt werden ${ }^{260}$.

Weder diese Erklärung noch Blankenhorns kategorische Versicherung vom Juni, die deutsche Delegation habe nicht den Auftrag, das Problem der Stahlproduktionsquote oder das der Kompatibilität beider Behörden aufzuwerfen ${ }^{261}$, führten an der Seine zu einer Beruhigung. Zu Recht, denn im Herbst schnitt die deutsche Delegation die Frage doch offiziös an und schlug die Verbindung des Montanvertrages mit einem Protokoll vor, in dem die sechs Mitglieder die allmähliche Übertragung der IRB-Kompetenzen auf die Hohe Behörde anerkennen sollten 262 .

Im Conseil des Ministres gelangte man jetzt zu der Erkenntnis, daß das Fortbestehen der Ruhrbehörde nach dem Inkrafttreten des Montanvertrages tatsächlich weder nötig noch möglich sei. Die Regierung hielt diese Ansicht indes noch zurück und signalisierte lediglich die Bereitschaft zu einem Briefwechsel anläßlich der Vertragsunterzeichnung, in dem sie ihre Haltung zur Ruhrbehörde mitteilen wollte ${ }^{263}$. Wenngleich die Minister davon überzeugt waren, bisherige Positionen räumen zu müssen, mochten einige unter ihnen das Feld nicht kampflos preisgeben. So empfahl René Mayer im Januar 1951, die Abschaffung der IRB der Verkündigung eines Gesetzes über den Besitz der Ruhrminen durch die Bundesregierung zu unterwerfen 264 . Schuman hielt ihm daraufhin Anfang Februar entgegen, man könne die Auflösung dieser Institution nicht mit der Frage nach den zukünf-

${ }^{257}$ Ders. an dens., Memorandum, 9. 9. 1950, in: ebd., S. 53-55, hier S. 54; s.a. Kap. III.4.2.

${ }^{258} \mathrm{Vgl}$. Kap. III.3.1.

259 Aufzeichnung des MAE, Nr. 2, 30. 12. 1949, in: BDFD II, S. 103-105, hier S. 105; s.a. Leroy-Beaulieu an François-Poncet, Aufzeichnung Nr. 2925, 19. 1. 1950, in: ebd., S. 105-108.

260 Vgl. Poidevin, Rôle, S. 111; ders., Frankreich und die Ruhrfrage, S. 330.

261 S. AMAE, Europe 1944-1960, Généralités, Bd. 112, Bl. 50, François-Poncet an MAE, Tel. 3155/ 56, 30. 6. 1950, Réservé.

262 S. ebd., Bl. 184, ders. an dass., Tel. 6124/25, 11.11. 1950, Réservé; Bérard, Ambassadeur, Bd. 2 , S. 358, Tb. 7. 11. 1950.

${ }^{263}$ S. Kabinettssitzung, 12. 12. 1950, in: Kabinettsprotokolle, Bd. 2, S. 880-883.

264 S. AN, 363 AP 17, Papiers Mayer, Mayer an Schuman, 15. 1. 1951; Mayer, Etudes, S. 163-166; Poidevin, René Mayer, S. 81-83. 
tigen Eigentumsrechten in der Ruhrindustrie verbinden: „Nous mettrions à la conclusion du Plan [Schuman] une condition entièrement nouvelle que ni nos alliés ni le gouvernement fédéral n'accepteraient" ${ }^{\prime 265}$. In diesem Sinne willigte er darin ein, nach der Paraphierung des Montanvertrages in einem Brief an die Bundesregierung festzuhalten, „daß der Fortbestand der Ruhrbehörde sich mit den Prinzipien des Schuman-Plans nicht vereinbaren lasse" und das Ruhrabkommen entsprechend geändert werden müsse ${ }^{266}$. Adenauer schien diese Zusage jedoch zu vage, und er verlangte, die Abschaffung der Ruhrbehörde nicht - wie die Franzosen es beabsichtigten - erst mit Inkrafttreten, sondern mit Unterzeichnung des Vertrages durchzusetzen ${ }^{267}$. Abermals wich Schuman dem deutschen Druck und akzeptierte auf Anregung von Monnet folgenden Kompromißvorschlag: Aufhebung der theoretischen Beschränkung des Stahlproduktionsniveaus mit dem Inkrafttreten des Vertrags; Übertragung der Verteilungsbefugnisse auf die Hohe Behörde ab der Ratifikation ${ }^{268}$.

Gravierende Dissonanzen zwischen Bonn und Paris verursachte auch Gesetz Nr. 27 vom 16. 5. 1950 über die Entflechtung der westdeutschen Montanindustrie, das insbesondere die großen deutschen Stahlfirmen, die Verbundwirtschaft und den als zentrale Verkaufsstelle der Ruhrkohle fungierenden „Deutschen Kohleverein" (DKV) betraf. Es umfaßte im wesentlichen drei Aspekte: die Anzahl von Einheiten, in die die Ruhrindustrie geteilt werden sollte, die Menge von Stahlkonzernen, die eigene Minen besitzen durften, und schließlich das Schicksal des DKV 269. Bezüglich dieses Vereins hatten sich die Deutschen mit den Franzosen und Amerikanern zunächst gegen die Auflösung ausgesprochen ${ }^{270}$. Unter dem Eindruck der New Yorker Vereinbarungen über die deutsche Wiederbewaffnung änderte Frankreich indes im September seine Haltung und forderte unter Berufung auf die Durchführungsverordnung der Alliierten Hohen Kommission zum Gesetz Nr. 27 vom 14. 9. 1950 die Liquidation großer Stahlfirmen mit dem Ziel des Verbots vertikaler Konzentrationen, letztlich der Entmachtung der Ruhrschwerindustrie ${ }^{271}$.

Adenauer drohte den Hohen Kommissaren daraufhin mit dem sofortigen Abzug der Schuman-Plan-Delegation ${ }^{272}$. Zugleich schickte er Erhard in einer persönlichen Mission zu Monnet, um sich bei ihm darüber zu beschweren, daß die West-

265 AN, 363 AP 17, Papiers Mayer, Schuman an Mayer, 2. 2. 1951.

266 Adenauer, Teegespräche 1950-1954, S. 35, Tee-Empfang, 8. 2. 1951; s.a. ebd., S. 40, Tee-Empfang, 15. 2. 1951; AN, 363 AP 17, Papiers Mayer, Monnet an Mayer, 15. 1. 1951; ebd., Schuman an Mayer, 2. 2. 1951; Poidevin, Rôle, S. 111-113; ders., Frankreich und die Ruhrfrage, S. 330 f.

267 S. AN, 81 AJ, Carton 148, Monnet an Hirsch, 8. 1. 1951; Griffiths, Negotiations, S. 68.

268 S. Monnet an Schuman, 10. 3. 1951, in: Monnet/Schuman, Correspondance, S. 107.

${ }^{269} \mathrm{~S}$. Text des Gesetzes in: Amtsblatt der Alliierten Hohen Kommission für Deutschland, 1950, Nr. 20, S. 298-316; zur französischen Position s. AN, 81 AJ, Carton 137, Monnet an Schuman, Projet d'instructions, 22. 12. 1950. Ausführlich zum Problem der Entflechtung: Bossuat, La France, Bd. 2, S. 767-776; Gillingham, Coal, S. 266-283; ders., Ruhrpolitik; ders., Ruhr Problem; Griffiths, Schuman Plan Negotiations, S. 61-66; Lüders, Ruhrkontrollsystem, S. 307-329.

270 Vgl. Schwabe, Staatskunst, S. 233; Kabinettsprotokolle, Bd. 2, S. 724; Griffiths, Schuman Plan Negotiations, S. 64.

271 Vgl. Gillingham, Ruhrpolitik, S. 20; Schwabe, Staatskunst, S. 234.

272 S. Unterredung zwischen Adenauer und der AHK vom 23. 9. 1950, in: Kabinettsprotokolle, Bd. 3, S. 132-141; s.a. Unterredung zwischen Erhard und der Amerikanischen Hohen Kommission vom 10. 10. 1950 , in: ebd., S. $199-203$. 
mächte die deutsche Montanindustrie ohne jede Rücksprache mit ihm reorganisierten, während Bonner Regierungsvertreter gleichberechtigt am Tisch der Verhandlungen in Paris säßen. Der Generalkommissar sah die deutsche Kritik sehr wohl als berechtigt an. Träte der Montanvertrag erst einmal in Kraft, beruhigte er den Wirtschaftsminister, würde eine Reihe von Widersprüchen in der alliierten Deutschlandpolitik umgehend beseitigt ${ }^{273}$. Auch François-Poncet mochte sich der Argumentation Adenauers nicht verschließen. Ansonsten aber wirkte die Haltung der Deutschen auf ihn anmaßend: Im Moment der Aufnahme in die europäische Familie hielten sie es für legitim, der Vergangenheit den Rücken zu kehren. Unfähig seien sie zu verstehen, wieso die Franzosen ihnen mit Blick auf die sowjetische Aggression die europäische Integration anböten, ohne ihr Mißtrauen gegenüber einem Nachbarn abzubauen, „dont nul ne saurait, à l'heure actuelle, prédire ce qu'il sera demain. Le temps, seul, pourrait accorder en nous le sentiment avec la raison." Doch die Deutschen könnten nicht warten, und die Alliierten übten Druck auf Frankreich aus, um die Bundesrepublik möglichst rasch in die westliche Staatenwelt zu integrieren ${ }^{274}$. Gleichwohl äußerte der Hohe Kommissar in Übereinstimmung mit seinen beiden westlichen Kollegen die Bereitschaft, Empfehlungen der Bundesregierung zur Durchführung des Gesetzes Nr. 27 anzunehmen, wenngleich man darauf beharrte, die Verantwortung über die Entflechtung in den eigenen Händen zu behalten ${ }^{275}$.

Mit diesen punktuellen Konzessionen gab sich Adenauer nicht mehr zufrieden. Am 13. 10. ließ er die Gesamtheit der besatzungsrechtlichen Bestimmungen in einem umfangreichen Memorandum an Monnet frontal attackieren. Während das Besatzungsstatut Deutschland als möglichen „Gegner" behandle, betrachte der Schuman-Plan es als Partner und ebne ihm den Weg in die europäische Gemeinschaft; während das Statut die Souveränität Deutschlands verneine, setze der Plan sie als unerläßlich voraus. Auch die besatzungsrechtlichen Restriktionen in der Wirtschaft stünden mit ihm nicht im Einklang, weil er gleiche Marktbedingungen aller Teilnehmerstaaten verlange. Die Inkompatibilität der einschlägigen Bestimmungen beider Dokumente müsse das Funktionieren der Montanunion von vornherein beeinträchtigen ${ }^{276}$.

Für Monnet kam dieser Vorstoß keineswegs überraschend, empfand er es doch als ganz natürlich, wenn Adenauer jedes Mittel nutzte, um die deutsche Position zu verbessern. Das nahm dem Angriff aber nichts von seiner Gefährlichkeit. Bonn zog angesichts der französischen Widerstände gegenüber einer deutschen Wiederbewaffnung den Pariser Willen zur Kooperation insgesamt in Zweifel und gefährdete damit den Schuman-Plan. Daher drängte Monnet seine Regierung am 14. 10. zu einer Erklärung, in der sie sich für die Einbeziehung deutscher Truppen in eine

${ }^{273}$ S. Monnet an Schuman, Aufzeichnung, 28.9. 1950, in: Monnet/Schuman, Correspondance, S. 60f.; AMAE, Europe 1944-1960, Allemagne, Bd. 375, Bl. 53, Abt. für wirtschaftliche Angelegenheiten im MAE an Französische Hohe Kommission Bonn, Tel. 2758/59, 30. 9. 1950.

274 Ebd., Bd. 375, Bl. 59f., François-Poncet an MAE, Tel. 5073/76, 3. 10. 1950.

275 S. Aufzeichnung Blankenhorn, 13. 10. 1950, in: Kabinettsprotokolle, Bd. 3, S. 218 f.; Unterredung zwischen Erhard und der Amerikanischen Hohen Kommission vom 10. 10. 1950, in: ebd., S. 199203.

276 Hallstein an Monnet, Memorandum, 13. 10. 1950, in: BDFD I, S. 237-242, hier S. 237. 
europäische Armee aussprechen sollte 277 . Zwar entsprach der Président du Conseil René Pleven dieser Bitte zehn Tage später ${ }^{278}$, doch waren damit die deutschfranzösischen Dissonanzen keineswegs ausgeräumt - im Gegenteil! Mit gewachsenem Selbstbewußtsein formulierte die Bundesregierung Anfang November ein (inoffizielles) Junktim, indem sie die Unterzeichnung des Montanvertrages von einer Klarstellung der Struktur der Ruhrindustrie abhängig machte. Nachdem das Kabinett am 2. 11. beschlossen hatte, das Dokument nicht zu paraphieren, „bevor nicht die letzten wesentlichen Punkte geklärt und festgelegt sind" 279 , betonte Adenauer gegenüber François-Poncet wenige Tage darauf, daß er den Abschluß der Verhandlungen zwar baldmöglichst wünsche und daher das Abkommen zu paraphieren gedenke, ohne eine Lösung des IRB-Problems abzuwarten. Er behalte sich aber die „réserve formelle“ vor, den Vertrag nicht eher dem Bundestag zuzuleiten, bis diese Frage geregelt sei280. In diesem Sinne konstatierte ein Vermerk des Auswärtigen Amtes noch einmal im Dezember in aller Entschiedenheit, es sei „unerläßlich, daß vor Unterzeichnung des Schuman-Plans eine grundsätzliche Übereinstimmung zwischen den Alliierten und der Bundesregierung über die Neuordnung der deutschen Montanindustrie berbeigeführt wird"281. Gleichzeitig drängte das Bundeswirtschaftsministerium im Kanzleramt auf die Klärung noch offener wirtschaftspolitischer Probleme ${ }^{282}$. Adenauer veränderte daraufhin seine Taktik, setzte darauf, die Verhandlungen zu verschleppen und erst einmal das Ergebnis der geplanten Viermächtekonferenz ${ }^{283}$ sowie die weitere Haltung Frankreichs gegenüber der deutschen Wiederbewaffnung abzuwarten ${ }^{284}$. Demgegenüber regte Hallstein zwecks baldigen Abschlusses der Pariser Beratungen an, bei der Hohen Kommission auf eine schnelle Bereinigung des Entflechtungskomplexes hinzuwirken 285 . Eine solche Problemlösung ließ indes auf sich warten, stellte die Frage der Dekonzentration doch sowohl für Frankreich aus politischen wie ökonomischen Gründen eine wichtige Vorbedingung zur Schaffung der Montanunion dar. Aus der Sicht Monnets und Schumans war es zwingend erforderlich, die Dominierung der deutschen Politik durch die Ruhrmagnaten zu verhindern, der französischen Industrie gleiche Wettbewerbschancen $z u$ bieten und die angelsächsischen Ängste vor einem gigantischen Kartell zu zerstreuen ${ }^{286}$. Monnet arrangierte daher seit Oktober eine Reihe von Treffen mit amerikanischen Regierungsvertretern, um das DKV-Problem zu bereinigen. Mitte Dezember einigten

277 S. Monnet an Schuman, 14. 10. 1950, in: Monnet/Schuman, Correspondance, S. 61-63.

$278 \mathrm{Vgl.} \mathrm{Kap.} \mathrm{III.4.2.}$

279 Kabinettssondersitzung, 2. 11. 1950, in: Kabinettsprotokolle, Bd. 2, S. 793.

280 S. AMAE, Europe 1944-1960, Généralités, Bd. 112, Bl. 184, François-Poncet an MAE, Tel. 6124/ 25, 11. 11. 1950, Réservé.

281 PA, SFSP, Bd. 54, Bl. 207 f., Vermerk, 8. 12. 1950.

282 S. Erhard an Adenauer, I A 3, 11. 12. 1950, in: BDFD II, S. 647-650; vgl. auch Wirtschaftsvereinigung Eisen- und Stahlindustrie an Adenauer, 11. 12. 1950, in: ebd., S. 650-652.

$283 \mathrm{Vgl}$. Kap. III.1.2.

${ }_{284}$ S. Kabinettssitzung, 12. 12. 1950, in: Kabinettsprotokolle, Bd. 2, S. 880-883.

${ }^{285}$ S. PA, SFSP, Bd. 54, Bl. 202 f., Hallstein an Adenauer, 11. 12. 1950; Ansprache dess. in der Sitzung des Auswärtigen Ausschusses vom 12. 12. 1950, in: Hölscher (Bearb.), Sitzungsprotokolle 19491953 , S. $170-181$.

286 S. Monnet an Schuman, 22. 12. 1950, in: Monnet/Schuman, Correspondance, S. $90 f$. Zur französischen Furcht vor deutscher Konkurrenz s.a. Vertreter der französischen Stahlindustrie an Schuman, 20. 2. 1951, in: BDFD II, S. 662-666. 
sie sich auf die Auflösung der Organisation und eine Einschränkung des Verbundes zwischen Kohle und Stahl287. Bonn weigerte sich aber, dieses Übereinkommen zu akzeptieren, zumal die westdeutsche Wirtschaft Adenauer eindringlich aufforderte, die Verbundwirtschaft zu erhalten und „keine Beschränkung der deutschen Kohleverkaufsorganisation" hinzunehmen ${ }^{288}$. In Übereinstimmung mit den Amerikanern unterbreiteten die Franzosen daraufhin den Kompromiß, den DKV durch maximal zwölf Verkaufsorganisationen zu ersetzen ${ }^{289}$. Doch auch dies galt an Rhein und Ruhr als inakzeptabel, wenngleich Paris offiziös mit dem Verzicht auf den Schuman-Plan drohte, falls es auf dem Gebiet der Entflechtung nicht zu einem Mindestmaß an deutschen Zugeständnissen käme ${ }^{290}$. Nicht einmal die Warnung des deutschen Generalkonsuls in Paris vor einem Sturz Schumans ${ }^{291}$ oder der Hinweis des von Monnet Mitte Februar nach Bonn geschickten Etienne Hirsch, in Paris spreche man „von nichts anderem als der deutschen Vorherrschaft in Europa“292, ließen Adenauer einlenken.

Der Erfolg des Schuman-Plans hing nun ausschließlich von den im Januar 1951 einsetzenden deutsch-amerikanischen Gesprächen über die Ruhrindustrie $a b^{293}$. Abermals erwies sich der Faktor DKV als das größte Problem, zumal hier eine geschlossene Front von SPD, Gewerkschaften und betroffenen Unternehmern existierte ${ }^{294}$. Lobend nahm Adenauer dabei zur Kenntnis, daß Schuman keinen Zeitdruck ausübte, obwohl die Verhandlungen über die Montanunion wochenlang ruhten ${ }^{295}$. Selbst ihn erfüllte der Schuman-Plan Anfang März mit „Mißtrauen“. Dennoch mußte man seiner Meinung nach daran festhalten ${ }^{296}$ und alsbald zur Paraphierung gelangen ${ }^{297}$. Einen Fehlschlag konnte sich die Bundesrepublik kaum leisten, drohte dann doch ein Rückfall der französischen Deutschlandpolitik hinter den 9. Mai 1950298. Mit Blick auf die nahende Konferenz der Außenministerstellvertreter im Palais Marbre Rose ${ }^{299}$ war ihm daran gelegen, daß „sich Deutschland und Frankreich wenigstens auf einem Gebiet, nämlich dem wirt-

287 S. Monnet an Schuman, 22. 12. 1950, in: Monnet/Schuman, Correspondance, S. 90 f.; AN, 363 AP 17, Papiers Mayer, Memorandum Monnets, 9. 3. 1951; Schröder, Jean Monnet, S. 123-129 u. $189 \mathrm{f}$.

288 Pferdmenges an Adenauer, 27.12. 1950, nebst Aufzeichnung vom 23.12. 1950, in: BDFD II, S. 652-654, hier S. 654 .

${ }^{289}$ S. Monnet an Schuman, 22. 1. 1951, in: Monnet/Schuman, Correspondance, S. 97-100; Schröder, Jean Monnet, S. $191 \mathrm{f}$.

290 S. PA, Abt. 3, AZ 221-09, Bd. 1, Feihl an Kordt, Aufzeichnung 221-08-IIIb, 29. 1. 1951.

291 S. ebd., AZ 205-00/22, Bd. 1, Hausenstein an AA, 205 Nr. 297, 24. 1. 1951.

292 Lenz, Tagebuch, S. 39, Tb. 21. 2. 1951; s.a. ebd., S. 39 f., Tb. 22. 2. 1951; zum Hirsch-Besuch vgl. Bruce an Acheson, Tel. 4932, 21. 2. 1951, Secret, in: FRUS 1951, Bd. 4, S. 93-96.

293 Vgl. ausführlich: Schröder, Jean Monnet, S. 192-198; Schwartz, Atlantik-Brücke, S. 272-284.

294 S. Kost an Adenauer, 5. 1. 1951, in: BDFD II, S. 655 f.; Lenz, Tagebuch, S. 34f., Tb. 16. u. 17. 2. 1951; Briefing paper der Amerikanischen Hohen Kommission, 2. 2. 1951, Secret, in: FRUS 1951, Bd. 4, S. 86-90; zum Verhältnis der Gewerkschaften zum Schuman-Plan ausführlich: Volkmann, DGB.

295 S. PA, SFSP, Bd. 67, Bl. 104f., François-Poncet an Adenauer, 13. 1.1951 (Übersetzung); Adenauer, Teegespräche 1950-1954, S. 49-51, Tee-Empfang, 9. 3. 1951.

296 PA, Abt. 2, Bd. 1299, Unterredung zwischen Adenauer und McCloy vom 2.3. 1951, 5. 3. 1951, Geheim; s.a. Lenz, Tagebuch, S. 51, Tb. 2. 3. 1951.

297 S. Kabinettssitzung, 2.3. 1951, in: Kabinettsprotokolle, Bd. 4, S. 203; McCloy an Acheson, Tel. 7132, 3. 3. 1951, Secret, Priority, in: FRUS 1951, Bd. 4, S. 97 f.

${ }^{298}$ S. ders. an dens., Tel. 6850, 19. 2. 1951, Secret, Priority, in: ebd., S. 91-93; Schwabe, Staatskunst, S. 237.

299 Vgl. Kap. III.1.2. 
schaftlichen, träfen" 300 . Das hatten auch die Industriellen an der Ruhr einzusehen. Unter dem Druck der Verhältnisse und wohl auch amerikanischer Pressionen akzeptierten sie die Konzessionen der Bundesregierung 301.

Aus Angst vor den unkalkulierbaren politischen Konsequenzen eines Scheiterns willigte Adenauer am 14.3. in einen natürlich als „vernünftig “302 verkauften Kompromiß ein: Neuorganisation der deutschen Stahlindustrie unter Berücksichtigung der Bewahrung wettbewerbsfähiger Unternehmen; partieller Erhalt der Verbundwirtschaft, indem Stahlwerke Kohlegruben bis zu einer Bedarfsdekkung von $75 \%$ besitzen durften; Liquidation des DKV bis 1952. Darüber hinaus verpflichtete sich die Bundesrepublik zum Eintritt in die Montanunion und zu einem Kartellverbot ${ }^{303}$. Nach dieser den Schuman-Plan rettenden ${ }^{304}$ Einigung konnte nun auch die Paraphierung des Vertragswerkes erfolgen, wenngleich noch nicht alle offenen Fragen geklärt waren. Schuman drängte gar darauf, noch vor seiner für den 20. 3. geplanten Abreise in die USA die Unterzeichnung des Dokuments vorzunehmen. Sein Ziel war es dabei, die Ratifizierung vor den anstehenden Parlamentswahlen durchzusetzen, da er sich vor einem Rechtsruck und einer Stärkung de Gaulles fürchtete. Denn der General - so formulierte es der Generalsekretär der Schuman-Plan-Konferenz, Valéry, in einer vertraulichen Mitteilung gegenüber der deutschen Delegation - habe sich zwar der Einigung Europas und der deutsch-französischen Versöhnung verschrieben. Er verstehe darunter aber etwas anderes als Schuman. De Gaulle denke offenbar an eine „unter seinem Oberbefehl stehende europäische Armee, die im wesentlichen aus Franzosen und Deutschen bestehe und die er in einem Kreuzzug gegen die Barbaren des Ostens kommandieren werde. "305 Obwohl der Wunsch des französischen Außenministers von amerikanischer Seite lebhaft unterstützt wurde ${ }^{306}$, lehnte der Bundeskanzler ihn als „Husarenattacke“307 ab. Allerdings akzeptierte er die von Hallstein am 19. 3. vollzogene Paraphierung ${ }^{308}$, deren Termin ihm vor allem deshalb

300 Adenauer, Teegespräche 1950-1954, S. 45, Tee-Empfang, 22. 2. 1951; s.a. François-Poncet an Schuman, Nr. 435/CM, 28. 2. 1951, in: François-Poncet, Rapports mensuel, Bd. 1, S. 412-414. Zur Numerierung s. AMAE, Europe 1944-1960, Allemagne, Bd. 125, Bl. 238.

301 Bérard wußte nach der Unterzeichnung des Vertrages über die Montanunion aus guter Quelle zu berichten, die „l'entourage“ von McCloy habe zur Uberwindung der Widerstände in industriellen Bereichen nicht davor zurückgeschreckt, „à recourir à la menace de faire éventuellement couper les fonds Marshall" (ebd., Bd. 376, Bl. 261, Bérard an MAE, Tel. 2442/50, 21. 4. 1951, Réservé, Priorité; Bérard, Ambassadeur, Bd. 2, Tb. 21. 4. 1951).

302 Adenauer, Teegespräche 1950-1954, S. 55, Tee-Empfang, 15. 3. 1951.

303 S. Adenauer an AHK, BK 487/51, 14. 3. 1951, in: Neuordnung der Eisen- und Stahlindustrie, S. 455-457; AN, 457 AP 31, Papiers Bidault, Monnet an Bidault, 16. 3. 1951; ebd., 363 AP 17, Papiers Mayer, ders. an Mayer, 16. 3. 1951; ebd., Memorandum dess., 9. 3. 1951; PA, Abt. 3, AZ 22109, Bd. 1, Pressekonferenz Hallsteins, 14.3. 1951. Am 8.3. 1951 hatten sich Adenauer und McCloy darauf verständigt, daß der DKV nicht vor dem 1.10. 1952 liquidiert werde (Adenauer, Teegespräche 1950-1954, S. 49-51, Tee-Empfang, 9. 3. 1951; Kabinettssitzung, 9. 3. 1951, in: Kabinettsprotokolle, Bd. 4, S. 221); s.a. Monnet an Schuman, 1.7. 1952, in: Monnet/Schuman, Correspondance, S. 145-147.

$304 \mathrm{Vgl}$. Schwabe, Staatskunst, S. 238.

${ }^{305}$ PA, Abt. 3, AZ 221-09, Bd. 2, von Marchtaler an Blankenhorn, Aufzeichnung, 29. 3. 1951.

306 S. ebd., Abt. 2, Bd. 747, Bl. 234, Aufzeichnung Dittmann, 17.3. 1951; McCloy an Acheson, Tel. 7411, 15. 3. 1951, in: FRUS 1951, Bd. 4, S. $102 \mathrm{f}$.

307 Aufzeichnung Seebohm, zitiert nach: Kabinettsprotokolle, Bd. 4, S. 230, Anm. 56; s.a. Adenauer an McCloy, 18. 3. 1951, in: Adenauer, Briefe 1951-1953, S. $25 \mathrm{f}$.

308 S. PA, BStS, Bd. 122, Ansprache Hallsteins, 19. 3. 1951 (PIB-Mitteilung Nr. 210/51); ebd., SFSP, 
nützlich schien, weil er Schuman die Möglichkeit gab, den Amerikanern das Dokument als Beweis für die Bereitschaft der Europäer zum Zusammenschluß vorzulegen ${ }^{309}$.

In Paris herrschte nun unverkennbare Erleichterung, war man doch allem Anschein nach erst jetzt „überzeugt", daß es Bonn mit der Politik der europäischen Integration "wirklich ernst" sei ${ }^{310}$. Anders als Schumacher, meinte François-Poncet mit einer gewissen Einäugigkeit, sähe Adenauer die deutschen Interessen nicht im Aushandeln kleinlicher Vorteile, sondern in der westlichen Gemeinschaft gewahrt, „en prenant hardiment parti, afin de surmonter, le plus rapidement possible, les conséquences funestes pour l'Allemagne de l'effondrement nazi “" ${ }^{111}$. Mit der Paraphierung des Montanvertrages waren die Sechs-Mächte-Verhandlungen im Kern abgeschlossen. Zur feierlichen Unterzeichnung sollten die Außenminister der Mitgliedstaaten Mitte April nach Paris kommen.

Adenauer maß der bevorstehenden Reise eine ganz besondere Bedeutung zu, handelte es sich dabei doch - abgesehen vom Aufenthalt Hitlers - um den ersten Besuch eines deutschen Regierungschefs in der französischen Hauptstadt seit den Tagen des Reichskanzlers Brüning ${ }^{312}$. Ihn galt es nicht nur sorgfältig vorzubereiten, sondern auch maximal zu nutzen. Adenauer ließ dazu eine umfangreiche Wunschliste ausarbeiten, die Hallstein und Blankenhorn in mehreren Gesprächen mit französischen Diplomaten in Bonn vorab präsentierten. So gab er der Hoffnung auf Freilassung einiger Kriegsgefangener ebenso Ausdruck wie dem Wunsch nach Einrichtung einer deutsch-französischen Kommission, die den Ministerien Lösungen für anstehende Probleme vorlegen sollte. Des weiteren regte der Kanzler die Errichtung eines Instituts für europäische Studien in Paris an und schlug eine beiderseitige Erklärung über den Willen zur gemeinsamen Politik auf der europäischen Ebene wie zur Koordinierung des Kulturaustausches vor. Außerdem sprach er sich für Erleichterungen im deutsch-französischen Handelsverkehr und eine ausgewogene Handelsbilanz aus. Angesichts derart weitgespannter Pläne war es nicht verwunderlich, daß François-Poncet argwöhnte, es gehe ihm in erster Linie darum, aus der Unterzeichnung des Montanvertrages politisches Kapital zu schlagen. Gleichwohl ließ er keinen Zweifel zu, wie sehr es im französischen Sinne sei, diese Anregungen nicht zurückzuweisen ${ }^{313}$.

Tief bewegt, setzte der Kanzler am 11.4. seinen Fuß auf den Pariser Boden. Denn mit der Gründung der Montanunion begann seiner Meinung nach nicht nur

Bd. 55, Bl. 28-30, Rede Monnets, 19. 3. 1951; AMAE, Europe 1944-1960, Généralités, Bd. 112, Bl. 243-244, François-Poncet an MAE, Tel. 1786, 19. 3. 1951; Adenauer an Monnet, Tel. , 19. 3. 1951, in: Monnet/Schuman, Correspondance, S. 108.

${ }^{309}$ S. Adenauer, Teegespräche 1950-1954, S. 55, Tee-Empfang, 15. 3. 1951.

310 PA, Abt. 3, AZ 221-09, Bd. 2, von Marchtaler an Blankenhorn, Aufzeichnung, 29. 3. 1951.

311 François-Poncet an Schuman, Nr. 774/CM, 30. 3. 1951, in: François-Poncet, Rapports mensuel, Bd. 1, S. 423-441, hier S. 438. Zur Numerierung s. AMAE, Europe 1944-1960, Allemagne, Bd. 125, Bl. 269.

${ }_{312}$ Zum Besuch Adenauers vgl. Schwarz, Begegnungen, S. 68-71; ders., Adenauer, Bd. 1, S. 858-866; Blankenhorn, Verständnis, S. 119-121, Tb. 11.-19. 4. 1951.

${ }^{313}$ S. AMAE, Europe 1944-1960, Généralités, Bd. 113, Bl. 9-11, François-Poncet an MAE, Tel. 2153/ 57, 6. 4. 1951, Réservé, Urgent; s.a. ebd., Allemagne, Bd. 376, Bl. 189f., Unterredung mit Blankenhorn vom 6. 4. 1951; François-Poncet an MAE, Tel. 2141/45, 6. 4. 1951, in: BDFD II, S. 165 f.; Becker an Hallstein, Aufzeichnung 304-06-IV-157/51, 6. 4. 1951, in: ebd., S. $167 \mathrm{f}$. 
„ein neuer Abschnitt der europäischen Geschichte“, sondern auch ein neues Kapitel im deutsch-französischen Verhältnis. Da die Zusammenfassung der Kohleund Stahlproduktion Kriege zwischen den Nachbarn „nicht nur undenkbar, sondern materiell unmöglich" machte, sah er mit dem Abschluß des Vertrages über die Europäische Gemeinschaft für Kohle und Stahl (EGKS) „den feierlichen und unwiderruflichen Schlußstrich“ unter eine Vergangenheit, in der beide Völker sich „aus Mißtrauen, Konkurrenzsucht und Egoismus immer wieder mit den Waffen in der Hand“" gegenübergetreten seien ${ }^{314}$. Diesen Kontext zwischen deutsch-französischer Versöhnung und europäischer Integration betonte Adenauer auch in einer kurzen Erklärung nach der Ankunft in Paris: Bewußt habe ihn die erste offizielle Auslandsreise nach dem Zweiten Weltkrieg an die Seine geführt: „Ich will damit dokumentieren, daß ich das deutsch-französische Verhältnis für die Kernfrage jeder europäischen Lösung halte. Wir müssen neue Wege beschreiten lernen. Nur wenn uns dies gelingt, kann ein neues Europa entstehen, in dem die Kleinstaaterei und der nationale Egoismus überwunden werden“"315.

Dazu bedurfte es freilich zunächst einmal einiger Anstrengungen der sechs Außenminister. Denn noch harrten heikle Fragen einer Lösung: die Wahl des Sitzortes, die Anzahl und Bestimmung der Mitglieder der Hohen Behörde oder die Gewichtung der Stimmen im Ministerrat ${ }^{316}$. In evidenter Analogie zur Vorlage des „Document du travail“ vom Juni 1950 hatte Frankreich den Partnerländern bereits am 24.3. ein Memorandum präsentiert, um die Gespräche in eine ihm genehme Richtung zu lenken ${ }^{317}$. Obwohl Monnet sich mit Adenauer am 4. 4. über das Prinzip der Gleichheit zwischen Frankreich und Deutschland in allen Organen verständigt hatte ${ }^{318}$, stimmte das Auswärtige Amt mit den französischen Vorschlägen keineswegs völlig überein ${ }^{319}$. Dennoch zogen Deutsche und Franzosen während der mehrtägigen Beratungen an der Seine meist an einem Strang, konnten sich aber gegen den Widerstand der BENELUX-Staaten kaum durchsetzen ${ }^{320}$. Ohne schließlich das Sitzproblem gelöst zu haben, unterzeichneten die sechs $\mathrm{Mi}$ nister am 18. 4. den EGKS-Vertrag, nicht zuletzt, weil alle „so sehr unter amerikanischem Druck standen, daß keiner es auf sich nehmen konnte, die Verhandlungen scheitern zu lassen" 321 . Gleichzeitig einigten sich Frankreich und Deutschland auf die Modalitäten zur Beteiligung der Saar an der Montanunion. Mit dem Brief zur Saarfrage 322 überreichte Schuman Adenauer ein weiteres Schreiben, in dem er die Auffassung seiner Regierung bekräftigte, daß die Funktionen der Ruhrbehörde in dem Maße erlöschen müßten, in dem die Hohe Behörde die Befugnisse

314 PA, BStS, Bd. 124, Rede Adenauers vor dem Club der ausländischen. Presse in Paris, 13. 4. 1951. 315 Ebd., Erklärung dess. bei seiner Ankunft in Paris, 11. 4. 1951.

316 S. Aufzeichnung Ophüls, 10. 4. 1951, in: BDFD I, S. 246-249.

317 S. PA, SFSP, Bd. 105, Bl. 51-53, Suggestions françaises, 24. 3. 1951; ebd., Bd. 286, Bl. 10-16, Memorandum, 13.4. 1951.

$318 \mathrm{Vgl}$. Monnet an Schuman, Memorandum, 8. 5. 1951, in: Monnet/Schuman, Correspondance, S. 113; Monnet, Erinnerungen, S. $447 \mathrm{f}$.

319 S. ebd., S. 446; PA, SFSP, Bd. 105, Bl. 60 f., Ergebnis der Besprechung vom 29. 3. 1951; ebd., Bl. 4750, Entwurf einer Instruktion für die politischen Fragen des Schumanplans, 5. 4. 1951.

$320 \mathrm{Vgl.} \mathrm{Küsters,} \mathrm{Verhandlungen,} \mathrm{S.} \mathrm{95-101;} \mathrm{Griffiths,} \mathrm{Benelux-Staaten,} \mathrm{S.} 268$.

${ }^{321}$ Lenz, Tagebuch, S. 71, Tb. 17. 4. 1951; s. den Vertrag nebst Anlagen in: BGBl 1952, Teil II, S. 448504.

$322 \mathrm{Vgl.} \mathrm{Kap.} \mathrm{III.3.1.}$ 
zur Ausübung ihrer Zuständigkeit gemäß der Konvention über die Übergangsbestimmungen erhielte, spätestens aber mit der Errichtung des Gemeinsamen Marktes für Kohle ${ }^{323}$. Darüber hinaus verständigten sich beide Politiker in Anlehnung an die Verhandlungen Monnets mit Adenauer zu Beginn des Monats abermals in einem Aide-mémoire darauf, zwischen beiden Staaten in den europäischen Institutionen das Prinzip der Gleichberechtigung herrschen zu lassen ${ }^{324}$.

Insgesamt lag damit nun ein vertraglicher Rahmen vor, der die außenpolitische Situation der Bundesrepublik erheblich aufwertete. Mit dem Beitritt zur EGKS und dem wenige Tage später erfolgenden Beschluß des Europarates, die Bundesrepublik als vollberechtigtes Mitglied aufzunehmen ${ }^{325}$, waren entscheidende Schritte auf dem Weg zur Eingliederung in die Gemeinschaft der westlichen Demokratien zurückgelegt. Den Kanzler verleiteten sie dazu, vollmundig zu verkünden, daß „von nun an keine europäische Entscheidung ohne Deutschland mehr getroffen werden kann“326. Für ihn besaß die Gründung der Montanunion eine ökonomische wie politische Dimension. Wie er in einer Pressekonferenz am 20. 4. unumwunden zugab, lagen die für die Bundesrepublik und die übrigen Mitglieder handfesten wirtschaftlichen Vorteile neben der erwarteten Verbilligung und Verbesserung der Stahlproduktion nicht zuletzt darin, die zur Wiederherstellung und zum Ausbau der beteiligten Wirtschaften notwendigen amerikanischen Kredite sehr viel leichter zu erhalten. Noch wichtiger war für ihn freilich der politische Gedanke, „eine wahrhafte Gemeinschaft der europäischen Länder zu schaffen auf dem Fuße völliger Gleichberechtigung“, die zweifellos auch auf andere europäische Staaten ihre Ausstrahlungskraft ausübte ${ }^{327}$. Letztlich bedeutete die Verwirklichung des Schuman-Plans für ihn nicht weniger als „den entscheidenden Wendepunkt in der Geschichte Europas“, Ansatz zu einer „dauernden wirtschaftlichen, politischen und ideologischen Gemeinschaft" und eine „völlig neue Grundlage“ für die Beziehungen zwischen der Bundesrepublik und Frankreich ${ }^{328}$. Energisch wehrte er sich gegen die wieder auflebenden Vorwürfe der SPD-Opposition, der Plan sei nichts anderes als eine „Verewigung des französischen Besatzungsstatuts“329. Vielmehr zeigte er sich fest davon überzeugt, die Montanunion werde

323 S. Schuman an Adenauer, 18. 4. 1951, in: BDFD II, S. 123 f.; Adenauer, Teegespräche 1950-1954, S. 65-68, Tee-Empfang, 20. 4. 1951. Das Ruhrstatut erlosch am 21.12. 1951.

324 S. Monnet an Schuman, Memorandum, 8. 5. 1951, in: Monnet/Schuman, Correspondance, S. 113. In einem Schreiben vom 18. 4. an Adenauer wies Schuman außerdem darauf hin, daß die französische Regierung hinsichtlich der von der deutschen Delegation aufgeworfenen Probleme, die möglicherweise auf dem deutschen Kohlemarkt vor der Amtsübernahme der Hohen Behörde auftreten könnten, der AHK die Bildung eines Ausschusses vorzuschlagen gedächte, der beauftragt werden sollte, „im Einvernehmen mit der Bundesregierung und allen Beteiligten [...] die für die Lösung der gegebenenfalls auftretenden Probleme geeigneten Verfahren und Organismen zu prüfen" (PA, Ref. 200, Bd. 20, Schuman an Adenauer, 18. 4. 1951 (Übersetzung)).

325 S. ebd., Abt. 2, Bd. 583, Bl. 121, Paris an dens., 2. 5. 1951; ebd., Bl. 122, Adenauer an Heuss, Tel. , 2. 5. 1951.

326 Ebd., Abt. 3, AZ 221-02, Rundfunkansprache Adenauers, 4. 5. 1951 (PIB-Mitteilung Nr. 357/51, 4. 5. 1951).

327 Ebd., BStS, Bd. 362, Ansprache dess. auf der Pressekonferenz, 20. 4. 1951, NfD.

328 Adenauer an Schuman, 19. 4. 1951, in: Beyer, Schuman, S. 117.

329 PA, BStS, Bd. 362, Ansprache Adenauers auf der Presse-Konferenz, 20.4. 1951, NfD; s.a. Adenauer, Teegespräche 1950-1954, S. 74f., Tee-Empfang, 20. 4. 1951; zu den Widerständen der SPD gegen den EGKS-Vertrag s. die Fraktionssitzung vom 8. 5. 1951, in: Weber (Bearb.), Sitzungsprotokolle 1949-1957, 1. Teilbd., S. 267 f. 
beide Nationen im Rahmen der europäischen Gemeinschaft „in aufrichtiger Freundschaft und in enger Zusammenarbeit für den Frieden und für die Ideale der freien Völker des Westens zusammenführen“330.

\section{Parlamentarische Hürden}

Zur Aussöhnung war es freilich noch ein langer Weg. So sah der kluge Beobachter Albrecht von Kessel das Klima in Paris gegenüber Deutschland zwar als „wesentlich verbessert“ an. Er warnte jedoch davor, dies als wirklichen Stimmungsumschwung mißzuverstehen. „Zurückhaltung und Reserve sind nun einmal Wesenszüge des französischen Volkes, Eigenschaften, die im Verhältnis zu uns auch in Zukunft bestimmend bleiben werden." 331 Der deutsche Diplomat stimmte damit weitgehend mit dem französischen Außenminister überein, der die Vertragsunterzeichnung ebenfalls „als einen Markstein der politischen Entwicklung Westeuropas und insbesondere der Beziehungen unserer beiden Länder“ begrüßte, ohne "die noch bevorstehenden Schwierigkeiten“ verkennen zu wollen ${ }^{332}$. In diesem Sinne hielt es die französische Hohe Kommission bereits wenige Tage nach der Zeremonie für geraten, die Bundesregierung darauf aufmerksam zu machen, daß die Notwendigkeit der Ratifizierung des Vertragswerkes von ihr Rücksicht auf die innenpolitische Situation in Paris verlange. Wenn sie schon keinen Einfluß auf Schumacher und dessen Agitation gegen den Schuman-Plan ausüben könne, solle sie doch zumindest die saarländischen Parteien und Politiker wie Jakob Kaiser zur Zurückhaltung auffordern ${ }^{333}$.

Adenauer nahm sich die Mahnungen durchaus zu Herzen. In der ersten Lesung des Vertragswerkes am 12.7. hob er eindringlich den Kompromißcharakter der Vertragstexte hervor und sprach sich kategorisch gegen das Einbringen jeglicher Abänderungsanträge aus. Bedenken gegen einzelne Bestimmungen seien aufgrund der immensen wirtschaftlichen, vor allem aber der politischen Bedeutung zurückzustellen, biete die Montanunion doch die einmalige Chance, dem Nationalismus, dem „Krebsschaden Europas, einen tödlichen Stoß“ zu versetzen ${ }^{334}$. In der SPD mochte dieser Argumentation niemand folgen. Seit April war sie zum Verdruß der französischen Schwesterpartei ${ }^{335}$, aber auch deutscher Gewerkschafter ${ }^{336}$ zu einer „totalen Ablehnung “337 übergegangen. Gesellschaftspolitisch attackierte die Sozialdemokratie die Montanunion als konservativ-klerikal-kapitalistisch-kartellistischen Pakt. Außenpolitisch verstand sie sie als Ausgeburt französischen Hegemoniestrebens. Deutschlandpolitisch sah sie in ihr mit den parallelen Schritten zur

330 Adenauer an Schuman, 19. 4. 1951, in: Beyer, Schuman, S. 117.

331 PA, NL Kessel, Ordner [1], von Kessel an Blankenhorn, 23. 4. 1951, Vertraulich.

332 Schuman an Adenauer, 21. 4. 1951, in: Adenauer, Briefe 1951-1953, S. 48.

333 S. AMAE, Europe 1944-1960, Allemagne, Bd. 376, Bl. 258-261, Bérard an MAE, Tel. 2442/50, 21. 4. 1951, Réservé, Priorité; Bérard, Ambassadeur, S. 370, Bd. 2, Tb. 21. 4. 1951.

334 Bundestagsrede Adenauers, 12.7. 1951, in: BT, Sten. Ber., Bd. 8, S. 6499-6502, hier S. 6501; s.a. AMAE, Europe 1944-1960, Généralités, Bd. 113, Bl. 126-128, François-Poncet an MAE, Tel. 4444, 12.7. 1951.

335 Vgl. Artikel von Philip, in: „Allemagne“, Juni/Juli 1951, S. 1 f., im Auszug auch in: BDFD III, S. 196-198.

336 Vgl. Heine an Mühlbach, 6.9. 1951, im Auszug in: ebd., S. 199-201.

337 Klotzbach, Sozialdemokratie, S. 337; vgl. Hrbek, SPD, S. 104-126; Paterson, SPD, S. 56-58. 
Westbindung ein Hemmnis für die Wiedervereinigung338. Dementsprechend lehnte Carlo Schmid das von der Regierung vorgelegte Ratifizierungsgesetz im Plenum mit der Begründung ab, der EGKS-Vertrag sei eine Karikatur des Schuman-Planes. In Anlehnung an Forderungen des Bundesrates ${ }^{339}$ stellte die Opposition den Antrag, eine zweite Lesung von einer Reihe von Voraussetzungen abhängig zu machen, wie verbindlicher Zusagen der Westmächte über die Abschaffung besatzungsrechtlicher Bestimmungen, einer Neuregelung der Verbundwirtschaft und des DKV sowie einer Klarstellung der Position des Saargebietes zur Montanunion $^{340}$.

Mochte der Kanzler auch gegenüber der französischen Hohen Kommission beteuern, er beabsichtige nicht, die Einrichtung der Montanunion hinauszuzögern ${ }^{341}$, so war an eine Beendigung des Ratifikationsverfahrens aus innenpolitischen Gründen vorläufig nicht zu denken. Im September erhoben sich in der FDP Stimmen, die eine parlamentarische Billigung der EGKS von der Beseitigung der Ruhrbehörde und diskriminierender Bestimmungen abhängig machten ${ }^{342}$. In einer demoskopischen Untersuchung vom Oktober 1951 sprachen sich nur 20\% der Befragten für die Annahme durch den Bundestag aus, 19\% dagegen, und 61\% hatten keine Meinung ${ }^{343}$. Vor dem Hintergrund der in der Z wischenzeit aufgetretenen Schwierigkeiten in den Verhandlungen über die Ablösung des Besatzungsstatuts und die deutsche Wiederbewaffnung ${ }^{344}$ begann Adenauer wenig später, mit dem Gedanken zu spielen, das EGKS-Abkommen erst im Zusammenhang mit dem Deutschland- und EVG-Vertrag zu ratifizieren ${ }^{345}$.

Auch in Frankreich drohte die Stimmung im Herbst vor allem durch eine „véritable fronde“ der Stahlindustrie ${ }^{346}$, die sich allerdings innerhalb der französischen Unternehmerschaft isolierte ${ }^{347}$, und durch innenpolitische oder taktischparlamentarische Ranküne gegen den Schuman-Plan umzuschlagen ${ }^{348}$. Die für die Idee der europäischen Integration günstige öffentliche Meinung hatte ihren Höhepunkt mittlerweile überschritten, der bereits "tot" geglaubte Neutralismus erwachte wieder zum Leben, und der Regierung drohte „der Boden unter den Füßen weg[zu]bröckeln“. Dabei sei sich „jeder“ darüber im klaren, so alarmierte

338 S. Presserklärung der SPD, 20. 4. 1951, Schumachers Artikel im „Hamburger Echo“, 21. 4. 1951, sowie seine Rede auf der Konferenz der Sozialen Arbeitsgemeinschaften der SPD, 24. 5. 1951, in: Schumacher, Reden, S. 805-818.

$339 \mathrm{Vgl}$. AdG 1951, S. 3003A.

${ }_{340}$ S. Bundestagsrede Schmids, 12.7. 1951, in: BT, Sten. Ber., Bd. 8, S. 6510-652i; AdG 1951, S. 3022C; Weber, Carlo Schmid, S. $435 \mathrm{f}$.

${ }^{341}$ S. AMAE, Europe 1944-1960, Généralités, Bd.113, Bl. 138f., Bérard an MAE, Tel. 8152/55, 20.11. 1951 .

${ }^{342}$ S. Resolution des FDP-Parteitages vom September 1951, in: Wengst (Bearb.), Sitzungsprotokolle 1949-1954, S. LXXXV; Jeutter, EWG, S. 97.

343 Vgl. Jahn, An Adenauers Seite, S. 131.

344 Vgl. Kap. III.1.1 u. III.4.1.

345 S. Adenauer, Teegespräche 1950-1954, S. 160, Pressetee, 15. 11. 1951.

346 Poidevin, Robert Schuman, S. 289. Zum massiven Widerstand der französischen Stahlindustrie vgl. Vertreter der französischen Stahlindustrie an Schuman, 20. 2. 1951, in: BDFD II, S. 662-666; Präsident der „Chambre Syndicale de la Sidérurgie Française“ Aubrun an Schuman, 3. u. 5.4. 1951, in: ebd., S. 666-669; Duclos an Vorstandsmitglieder des „Comité Central d'Entreprise de l'Union Sidérurgique du Nord de la France“, 4. 12. 1951, im Auszug in: BDFD III, S. 201-203.

$347 \mathrm{Vgl}$. Mioche, Patronat, S. 308-312.

348 Vgl. Poidevin, Robert Schuman, S. 289-295; Willis, France, S. 98-103. 
Gebhardt von Walther am 30. 11. das Auswärtige Amt, daß bei einer Ablehnung des Vertrages „eine rein negative Konzeption, beinahe ein Vakuum, der ,Neutralismus' zum Leitmotiv der französischen Politik werden muß“. Ohne einem Defätismus erliegen zu wollen, riet der zweite Mann an der Pariser Vertretung dazu, „schon jetzt ein Konzept zurecht[zu]legen, mit dem man einen Mißerfolg auffangen kann"349.

Angesichts derartiger, seine bisherige Zuversicht ${ }^{350}$ in Frage stellender Hiobsbotschaften beeilte sich Adenauer, den Ratifizierungsprozeß in Bonn zu forcieren. Über die neu gegründete „Arbeitsgemeinschaft Demokratischer Kreise“351 ließ er jetzt die öffentlichkeitswirksame Propagierung der Montanunion durchführen ${ }^{352}$. Am 30. 11. betonte er gegenüber den Spitzen der Koalition, die Verabschiedung des EGKS-Vertrages sei noch im Dezember „dringend wünschenswert“. Die französische Regierung würde es als „eine sehr große Hilfe“ betrachten, „wenn die Angelegenheit bei uns möglichst bald erledigt wird“353. In einem Brief an Vizekanzler Blücher unterstrich Adenauer Anfang Dezember vor dem Hintergrund einer sich mittlerweile klarer abzeichnenden Billigung durch die Assemblée Nationale, wie wichtig eine baldige deutsche Ratifikation sei. Das Ausland verstehe sie als Zeichen der Bereitschaft zur europäischen Integration. Zugleich bereite sie die "psychologischen Voraussetzungen" für den schnellen Abschluß des EVGVertrages ${ }^{354}$. Am Tag darauf beschloß das Bundeskabinett eine Sondersitzung zur Verabschiedung von Maßnahmen, um „die Annahme des Schumanplans noch vor Weihnachten sicherzustellen“ ${ }^{355}$.

Verpflichtend und erlösend in einem wirkte dann Mitte Dezember die Nachricht, das französische Parlament habe den Vertrag am Ende einer fünftägigen, bisweilen dramatischen Aussprache mit einem eindeutigen Votum passieren lassen. Das Ergebnis galt als um so beachtlicher, als sich die Debatte zu einer Erörterung des deutsch-französischen Verhältnisses entwickelt und dabei durch ihren "Ernst" und ihre „Ethik" bemerkenswert von früheren Wortgefechten abgehoben hatte ${ }^{356}$. Immer wieder stellten die Parlamentarier die bange Frage, ob Deutschland überhaupt zu einer echten Partnerschaft fähig oder ob der Ruf nach Gleichberechtigung nicht nur ein Vorwand für das eigene Machtstreben sei. General Aumeran, der beim Scheitern der EVG drei Jahre später traurige Berühmtheit erreichen sollte ${ }^{357}$, trieb diese Zweifel gegenüber dem östlichen Nachbarn auf die Spitze, als er gegen die Ratifizierung des Montanvertrags im Namen der

349 PA, BStS, Bd. 267, von Walther an Blankenhorn, 221-19, 30. 11. 1951.

350 Im Juli 1951 meinte Adenauer auf eine Journalisten-Frage hinsichtlich der innerfranzösischen W1derstände gegen die Ratifizierung des Schuman-Plans, die Verhandlungen in Paris hätten das Ansehen Frankreichs in der Welt so gesteigert, der amerikanische Druck sei so groß, daß die Franzosen sich einen solchen Prestigeverlust gar nicht leisten könnten (Adenauer, Teegespräche 19501954, S. 101, Tee-Empfang, 13. 7. 1951).

351 Zur Gründung s. Jahn, An Adenauers Seite, S. 101-104.

$352 \mathrm{Vgl}$. ebd., S. 131-133.

353 StBKAH, NL Adenauer, III 38, Adenauer an von Brentano, 30. 11. 1951, Persönlich.

354 Ebd., III 21, ders. an Blücher, Tel. , 6. 12. 1951, Geheim, Citissime, im Auszug in: Kabinettsprotokolle, Bd. 4, S. 826, Anm. 40.

355 Kabinettssitzung, 7. 12. 1951, in: ebd., S. 800.

356 PA, Abt. 3, AZ 221-09, Bd. 3, Hausenstein an AA, 221-09 Nr. 4720, 19. 12. 1951.

357 Vgl. Kap. III.4.3. 
Toten protestierte, die in drei Kriegen gegen Deutschland gefallen seien ${ }^{358}$. Das eisige Schweigen der meisten Parlamentarier ließ jedoch erkennen, daß ihre Bedenken nicht rückwärtsgewandt waren. Bedrohlicher für Schuman wurden die Reden des unabhängigen Abgeordneten Pierre André und des Progressisten Pierre Cot. Ihre mit wirtschaftspolitischen Argumenten unterfütterten Warnungen vor den katastrophalen Folgen des Schuman-Plans für die französische Industrie ${ }^{359}$ zwangen die Regierung, ihre Strategie, den Vertrag vor allem mit politischen Argumenten zu verteidigen, elastischer zu gestalten ${ }^{360}$. Zwar seien sich die Abgeordneten - so resümierte der genaue Beobachter der Diskussionen, Paul Frank - mit ihren Landsleuten wohl bewußt, „daß Europa weder auf den wirtschaftlichen noch auf den militärischen Beitrag Deutschlands verzichten kann“; gleichzeitig aber seien sie von einem „psychologischen Komplex“ befallen. In der Endabstimmung setzte sich schließlich der Wille zur Verständigung durch. Mit 377 gegen 235 Stimmen, vor allem jene der Kommunisten und der Gaullisten, sprachen sich die Parlamentarier am 13. 12. für die Billigung des Gesetzes über den EGKS-Vertrag aus ${ }^{361 .}$

Adenauer beeilte sich, Schuman zu diesem Erfolg zu beglückwünschen. Das französische Volk hatte damit den Willen zur europäischen Gemeinschaft bewiesen, von dem seines Erachtens allein der Frieden der Welt abhing ${ }^{362}$. Der Bundestag schien diese Entschlußkraft nur bedingt zu besitzen. Am Tage der französischen Ratifikation bereitete der Ältestenrat dem Kanzler die „blâmage“, die zweite Lesung gegen seinen Willen auf den 9./10. 1. 1952 zu verschieben ${ }^{363}$. Adenauer redete den Parlamentariern daher im Auswärtigen Ausschuß eindringlich ins Gewissen und warnte davor zu vergessen, daß „wir eben unterjocht sind“ 364 . Nach einer scharfen parlamentarischen Auseinandersetzung mit Ollenhauer, der den erkrankten Parteichef Schumacher vertrat, ließ der Bundestag das Gesetz zur Montanunion dann am 11.1. mit 232 gegen 143 Stimmen passieren ${ }^{365}$, „une date capitale“ für die Geschichte der noch jungen Republik ${ }^{366}$.

358 S. Rede Aumerans in der Assemblée Nationale, 6. 12. 1951, in: JO, Ass. Nat., Déb. parl. 1951, Bd. 9, S. 8876-8891.

359 S. Reden Andrés und Cots in der Assemblée Nationale, 7. 12. 1951, in: ebd., S. 8950-8956 u. 89588965.

360 S. Rede Plevens in der Assemblée Nationale, 11. 12. 1951, in: ebd., S. 9012-9015.

361 PA, Abt. 3, AZ 221-09, Bd. 3, Aufzeichnung Frank, o.D., Anlage zu Hausenstein an AA, 221-09 Nr. 4720, 19. 12. 1951; s. Debatte in der Assemblée Nationale, 7., 11. u. 13. 12. 1951, in: JO, Ass. Nat., Déb. parl. 1951, Bd. 9, S. 8854-9120; Artikel Ronsacs, in: „Franc-Tireur“, 10. 12. 1951, im Auszug auch in: BDFD III, S. $205 \mathrm{f}$.

362 S. Adenauer an Schuman, Tel. 0008 Bonn TW 03957 1110/98, 13. 12. 1951, in: Beyer, Schuman, S. 119; zur deutschen Reaktion auf die französische Ratifikation s.a. AMAE, Europe 1944-1960, Généralités, Bd. 113, Bl. 155 f., François-Poncet an MAE, Tel. 8806/08, 13. 12. 1951, Priorité.

${ }^{363}$ Ebd., Bl. 160, ders. an dass. an MAE, Tel. 8822/23, 14. 12. 1951, Réservé; s.a. ebd., Bl. 157-159, ders. an dass., Tel. 8815/19, 14. 12. 1951, Priorité, Urgent; Lenz, Tagebuch, S. 195, Tb. 13. 12. 1951.

364 Sitzung des Auswärtigen Ausschusses des Deutschen Bundestages vom 17. 12. 1951, in: Hölscher (Bearb.), Sitzungsprotokolle 1949-1953, S. 435-473, hier S. 462.

${ }_{365}$ Zum Verlauf der Debatte vom 9.-11. 1. 1952 s. BT, Sten. Ber., Bd. 10, S. 7482-7836.

366 AMAE, Europe 1944-1960, Généralités, Bd. 114, Bl. 40-43, François-Poncet an MAE, Tel. 311/ 315, 11. 1. 1952; s.a. ebd., Bl. 55-62, Unterabt. Zentraleuropa im MAE, Aufzeichnung, 15. 1. 1952; François-Poncet an Schuman, Nr. 260/CM, 1. 2. 1952, in: François-Poncet, Rapports mensuel, Bd. 1, S. 615-621. Zur Numerierung s. AMAE, Europe 1944-1960, Allemagne, Bd. 126, Bl. 287; Adenauer an Schuman, Tel. 48 S Bonn TW 3643 64/63 15 1110/ETAT, 15. 1. 1952, in: Beyer, Schuman, S. 123. 
Nach Hinterlegung sämtlicher Ratifikationsurkunden in Paris trat der Vertrag am 25. 7. in Kraft ${ }^{36}$.

Sechs Wochen später gereichte es dem Kanzler zur Ehre, die erste Sitzung des EGKS-Ministerrats aufgrund der alphabetischen Ordnung als Präsident eröffnen zu dürfen ${ }^{368}$. Entrüstet mußte er aber hinnehmen, daß nicht sein Parteifreund Heinrich von Brentano, sondern der belgische Sozialist Paul-Henri Spaak zum ersten Präsidenten der Gemeinsamen Versammlung gewählt wurde, wofür die christdemokratischen Abgeordneten vor allem ihre Kollegen von der SPD bzw. dem MRP verantwortlich machten ${ }^{369}$. Gewiß stellte diese Wahl kein Votum gegen Adenauer dar. Trotz aller Differenzen zwischen Bonn und Paris hatten die Verhandlungen über den Schuman-Plan vielmehr in aller Deutlichkeit unter Beweis gestellt, wie wichtig der Bundeskanzler für Frankreich war, während der Oppositionsführer nach seinen heftigen antifranzösischen Attacken der letzten Monate als ein Politiker galt, der die Unabhängigkeit seines Landes auf Kosten der europäischen Integration bewahren wolle. In dem Maße, wie das negative Bild Schumachers sich verfestigte, nahm das positive Adenauers konkretere Gestalt an. Mit Genugtuung registrierte der französische Hohe Kommissar, daß der Kanzler nach der Paris-Reise im April 1951 „plus francophile“ geworden sei. Schon vorher habe er seinen Wunsch nach einer deutsch-französischen Versöhnung nicht verborgen, sei aber von Frankreich oft enttäuscht worden. Danach habe er offenbar „une notion plus juste" von den französischen Stärken und Schwächen gewonnen. Adenauer nahm damit in den Augen François-Poncets eine gewisse Ausnahmestellung in der westdeutschen classe politique ein. Zwar seien nicht wenige seiner Landsleute von der Notwendigkeit einer deutsch-französischen Annäherung überzeugt, doch „plus rares encore sont ceux qui ne gardent pas la nostalgie, d'ailleurs souvent inconsciente, d'une Europe à direction allemande “370.

Die am 25. 7. 1952 in Kraft tretende Europäische Gemeinschaft für Kohle und Stahl leistete trotz mancher nicht erfüllter Erwartung eine doppelte Revolution: eine wirtschaftliche und eine im Vordergrund stehende politische ${ }^{371}$. Durch die Gründung des einheitlichen Marktes und die mit ihm einhergehende Rationalisierung, Leistungssteigerung und allgemeine Wirtschaftsexpansion trug die Montanunion zu einem verbesserten Lebensstandard in den angeschlossenen Volkswirtschaften bei. Über diese wirtschaftspolitische Wirkung hinaus setzte sie einen ersten wesentlichen Schritt in Richtung auf eine supranationale Gemeinschaft. Dem politischen Ziel der Verhinderung "politischen Mißbrauchs wirtschaftlicher

${ }^{367}$ S. Kommuniqué der Außenministerkonferenz der EGKS-Staaten, 25.7. 1952, in: Bulletin 1952, S. 967.

${ }^{368}$ S. Eröffnungsrede Adenauers, 8. 9. 1952 in: Bulletin 1952, S. 1211; Antwortrede Monnets, 8. 9. 1952, in: Notes et études documentaires, Nr. 1671, S. 11.

${ }^{369}$ S. AMAE, Europe 1944-1960, Généralités, Bd. 114, Bl. 233, François-Poncet an MAE, Tel. 7972/ 73, 11. 9. 1952; ebd., Bl. 237 f., ders. an dass., Tel. 7985/89, 12. 9. 1952; ebd., Bl. 246, ders. an dass., Tel. 8146, 19. 9. 1952.

370 Ders. an Schuman, Nr. 1064/CM, 1. 5. 1951, in: François-Poncet, Rapports mensuel, Bd. 1, S. 442462, hier S. 444 u. 447. Zur Numerierung s. AMAE, Allemagne 1944-1960, Bd. 125, Bl. 297. Zur positiven Entwicklung des Adenauer-Bildes s.a. Schwartz, Atlantik-Brücke, S. 286.

371 S. PA, SFSP, Bd. 98, B1. 1-170, Bericht der französischen Delegation über die Verhandlungen zum Schuman-Plan, Oktober 1951, bes. B1. 162-164 (Übersetzung). 
Macht ${ }^{\text {“ } 372}$ verhaftet, verminderte die EGKS die Angst, die deutsche Montanindustrie bedrohe die französische Sicherheit, und trug so zur Entspannung im beiderseitigen Verhältnis bei. Aus diesem zunächst negativen entwickelte der SchumanPlan ein positives Ziel, nämlich die Heranbildung eines Gemeinschaftsgefühls zwischen mehreren Partnerländern durch Fusionierung staatlicher Souveränität. Diesen engen Konnex zwischen der Entwicklung der europäischen Idee und der Normalisierung des deutsch-französischen Verhältnisses kleidete Wilhelm Hausenstein prägnant in die Worte: „In dem Maße, wie sich das Bewußtsein von der Notwendigkeit der europäischen Einigung im französischen Volk verbreitet hat, war für die ,Erbfeindschaft' mit Deutschland kein Platz mehr. " ${ }^{373}$

372 Ebd., Bd. 289, Bl. 48-55, Aufzeichnung des Bundesministeriums für den Marshallplan, o.D.; das Dokument wurde Hallstein am 22. 8. 1950 überreicht.

373 BA, NL Blankenhorn, Bd. 45b, Bl. 228-239, Hausenstein an AA, 210-00geh. 69/55, 20. 4. 1955, Geheim. 